\title{
Investigation into material resistance factors and properties of young, engineered Eucalyptus grandis timber
}

\author{
By: Calvin Pagel
}

Thesis presented in fulfilment of the requirements for the degree of Master of Engineering in Civil Engineering in the Faculty of Engineering at Stellenbosch University

Supervisor: Dr R Lenner

Co-supervisor: Dr CB Wessels

April 2019 


\section{Decleration}

By submitting this thesis electronically, I declare that the entirety of the work contained therein is my own, original work, that I am the sole author thereof (save to the extent explicitly otherwise stated), that reproduction and publication thereof by Stellenbosch University will not infringe any third party rights and that I have not previously in its entirety or in part submitted it for obtaining any qualification.

April 2019

Copyright (C) 2019 Stellenbosch University

All rights reserved 


\section{Abstract}

Only $1 \%$ of South Africa's total land area is used for forestry with $51 \%$ of that being used for Pinus and $40 \%$ for Eucalyptus species. A country wide shortage of adequate structural timber has been forecast for the near future where SA pine is the predominant structural timber species. Recent research has looked into Eucalyptus grandis to be used as a structural timber resource due to its fast growth rate and large plantation area. This hardwood has not traditionally been used structurally due to the physical defects commonly present in sawn, dried Eucalyptus grandis timber. The development of engineered timber products has been investigated as one way to mitigate some of these defects. Young Eucalyptus grandis which has been finger-jointed in the green state was recently introduced into the South African market. Tests completed by Crafford (2013) on the material showed promising mechanical strength results with low variability when compared to similar SA pine. This lead to the consideration of determining a specific material resistance reduction factor for use with the young Eucalyptus grandis as the current factor prescribed in the code is deemed to be overly conservative as it was calibrated for softwood timber. The finger-jointed timber had still experienced many physical defects, such as twist and checking. Face lamination of the material was thus proposed with the aim of reducing defects and to further decrease the mechanical strength variation. In this study two sets of samples were tested, a group of 100 standard green finger-jointed Eucalyptus grandis and a set of 100 finger-jointed and face laminated samples. This allowed for comparisons to be made to determine if the face lamination is a worthwhile inclusion and to produce material strength results to be used for partial factor determination. The face lamination was completed using a one-component polyurethane adhesive with timber in the wet, unseasoned state. Both sets were dried to equilibrium moisture content to assess physical defects, which are usually aggravated during drying. Four point bending tests were completed to determine the flexural characteristics, modulus of elasticity (MOE) and modulus of rupture (MOR), of the samples. Only flexural strength tests were completed due to the limited material available and as they are the indicator properties listed by the JCSS along with being the most important properties for roof truss design which is the predominant end use of structural timber in South Africa. Both sets performed well in terms of warp deformation with no cases above rejection limits for bow and cup. A total of $1 \%$ of laminates had excessive twist compared to the $9 \%$ of the 
standard boards. The standard set had significantly more check (20\%) and split (15\%) defect rejections compared to the $4 \%$ for check a $0 \%$ for split achieved by the laminated set. Structural grade S7 requirements were achieved for MOE and MOR of both sets. Only a small difference in coefficient of variation (COV) of approximately $1 \%$ was recorded between the sets but a $12 \%$ lower COV was achieved for the MOR of the sets compared to equivalent SA pine. The material resistance reduction factor calculated for MOR was found to be governing, with essentially equivalent factors for the laminates and standard boards of 0.776 and 0.769 respectively. It is thus proposed that a reduction factor of 0.77 be implemented in the code for the Eucalyptus grandis to be used instead of the current 0.68 which was originally devised for softwood timber. Although the lamination process did not reduce the variation in strength results to a significant extent, significantly lower defects were recorded for the laminated set. This would result in a higher yield of material with a better visual appeal which could allow for it to be a more valuable product. For both sets, the 0.09 gain in reduction factor may not seem to be a large advantage, but when coupled with the higher structural grade being achieved and the shorter rotation age than SA pine, the young, finger-jointed and face laminated Eucalyptus grandis is a promising option for structural timber use in a country as timber scarce as South Africa. 


\section{Opsomming}

Slegs $1 \%$ van Suid-Afrika se totale grondoppervlakte word vir bosbou gebruik en daarvan word $51 \%$ vir die Pinus spesie en $40 \%$ vir die Eucalyptus spesie gebruik. 'n Landswye tekort aan voldoende struktuurhout is voorspel vir die nabye toekoms waar Suid-Afrikaanse denne die oorheersende strukturele houtsoort is. Onlangse navorsing het Eucalyptus grandis as ' $\mathrm{n}$ strukturele houtbron ondersoek as gevolg van dié spesie se vinnige groeikoers en die groot plantasie oppervlakte wat huidiglik beskikbaar is. Hierdie loofhoutspesie word nie tradisioneel vir strukturele doeleindes gebruik nie as gevolg van die fisiese afwykings wat algemeen voorkom in gesaagde en gedroogte Eucalyptus grandis hout. Die ontwikkeling van verwerkte houtprodukte is ondersoek as 'n manier om sommige van hierdie afwykings te verminder. Jong Eucalyptus grandis wat in die nat en onbehandelde toestand gevingerlas is, is onlangs aan die Suid-Afrkaanse mark bekendgestel. Toetse wat Crafford (2013) op die materiaal voltooi het, het belowende meganiese sterkte-eienskappe getoon met lae veranderlikheid in vergelyking met soortgelyke SA dennehout. Dit het gelei tot die oorweging om 'n spesifieke materiaal weerstand gedeeltelike-faktor te bepaal wat gebruik kan word vir jong Eucalyptus grandis aangesien die huidige faktor wat in die kode voorgeskryf word gekalibreer was vir naaldhout en dus te konserwatief is. Die gevingerlasde Eucalyptus grandis het steeds verskeie fisiese afwykings getoon, soos vervorming en oppervlakbarse. Platkant-laminering van die materiaal was dus voorgestel om fisiese afwykings te verminder en om meganiese sterkte variasie verder te verminder. In hierdie studie is twee stelle monsters getoets: 'n groep van 100 standaard nat en onbehandelde Eucalyptus grandis monsters en 'n groep van 100 gevingerlasde en platkantgelamineerde monsters. Dit het toegelaat dat vergelykings gemaak kon word om te bepaal of platkant-laminering ' $n$ waardevolle insluiting is en om materiaalsterkte resultate te lewer wat gebruik kon word om die gedeeltelike-faktor te bepaal. 'n Eenkomponent poliuretaan gom is gebruik om hout in die nat en onbehandelde toestand te lamineer. Beide stelle is gedroog tot veselversadigingspunt om fisiese afwykings te evalueer, wat gewoonlik tydens die droog proses vererger word. Vierpunt buig toetse is voltooi om die buigkarakteristieke, modulus van elastisiteit (MOE) en breukmodulus (MOR) van die monsters te bepaal. Slegs buigsaamheidstoetse is voltooi as gevolg van die beperkte materiaal wat beskikbaar was en aangesien dit die aanwyser-eienskappe is wat deur die JCSS gelys word, asook die belangrikste 
eienskappe vir dakkappontwerp is - wat die oorheersende eindgebruik van strukturele hout in Suid-Afrika is. Beide stelle het goed presteer in terme van buigvervorming, met geen gevalle bo verwerpingsgrense vir boog en koppie vervorming nie. Slegs $1 \%$ van die gelamineerde borde het oormatige vlakke van draai ervaar in vergelyking met die $9 \%$ van die standaardborde. Die standaard stel het aansienlik meer oppervlakbarse (20\%) en spleting (15\%) afwykings gehad wat bo verwerpingsgrense geval het in vergelyking met die $4 \%$ vir oppervlakbarse en 0 $\%$ vir spleting wat deur die gelamineerde stel bereik is. Strukturele graad S7 vereistes is behaal vir die MOE en MOR van beide stelle. Die koëffisiënt van veranderlikheid (KVV) van die twee stelle het met slegs $1 \%$ verskil, maar die MOR van die stelle het 'n KVV van $12 \%$ laer as ekwivalente SA dennehout verwerf. Daar is gevind dat die materiaal weerstand gedeeltelikefaktor vir die MOR beherend is, met byna ekwivalente waardes vir die gelamineerde- en standaardborde van onderskeidelik 0.776 en 0.769. Daar word dus voorgestel dat 'n gedeeltelike-faktor van 0.77 geïmplementeer word in die kode wat vir die Eucalyptus grandis gebruik word, in plaas van die huidige 0.68 wat oorspronklik vir naaldhout bepaal is. Alhoewel die lamineringsproses nie die variasie in sterkte tot 'n aansienlike mate verminder het nie, is aansienlik minder afwykings waargeneem by die gelamineerde stel. Dit lei tot 'n hoër opbrengs van materiaal, asook 'n materiaal wat visueel meer aantreklik is. Die gevolg is 'n produk wat pontensieel meer waardevol is. Dit mag dalk voorkom dat die 0.09 toename in die gedeeltelikefaktor van beide stelle nie 'n groot voordeel is nie, maar gepaard met die hoër strukturele graad wat bereik is en die korter rotasie ouderdom van die Eucalyptus grandis in vergelyking met SA dennehout, is die jong, gevingerlasde en platkant-gelamineerde Eucalyptus grandis 'n belowende opsie vir strukturele houtgebruik in 'n land wat so houtskaars is soos Suid-Afrika. 


\section{Plagiarism declaration}

I know that plagiarism is wrong.

Plagiarism is to use another's work (even if it is summarised, translated or rephrased) and pretend that it is one's own.

This assignment is my own work.

Each contribution to and quotation (e.g. "cut and paste") in this assignment from the work(s) of other people has been explicitly attributed, and has been cited and referenced. In addition to being explicitly attributed, all quotations are enclosed in inverted commas, and long quotations are additionally in indented paragraphs.

I have not allowed, and will not allow, anyone to use my work (in paper, graphics, electronic, verbal or any other format) with the intention of passing it off as his/her own work.

I know that a mark of zero may be awarded to assignments with plagiarism and also that no opportunity be given to submit an improved assignment.

I know that students involved in plagiarism will be reported to the Registrar and/or the Central Disciplinary Committee.

Name:

Student no:

Signature:

Date: 


\section{Acknowledgements}

I would like to extend my sincere thanks and appreciation to the following persons and institutions:

- Dr. Roman Lenner as the supervisor of my studies along with my co-supervisor Dr. Brand Wessels for your continual support and guidance through my thesis and for all the valuable lessons you have shared and the knowledge you have provided.

- The Hans Merensky Foundation for sponsoring my studies, without which this goal would not have been realised.

- To those of the Department of Forest and Wood Science for welcoming me as one of your own and especially to Mr. Wilmour Hendrikse for all of the assistance with my testing and navigating a new department.

- To Andrew Way, Alex Green and Janeke Volkman, my office-mates for the countless hours of entertainment and support. The daily coffee breaks and idea sharing were an instrumental aspect in the completion of this thesis.

- My house-mates Thomas Rickelton, Arshad Vawda and Frikkie Viviers for the banter and upliftment.

- To my family for all of your love and support throughout my life and especially my studies, I would not be in this position if it were not for all of you. For the holidays, visits and calls that helped to refresh and re-calibrate in order to get it done.

- My loving girlfriend Megan for your constant love and support every step of the way. You have kept me sane, calm and collected through it all with your love and continuing encouragement to get everything done while still keeping a smile on my face. I truly am lucky to have you by my side. 


\section{Table of contents}

Abstract

Opsomming. .iii

Plagiarism declaration $\mathbf{v}$

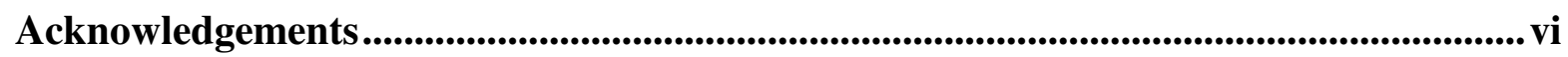

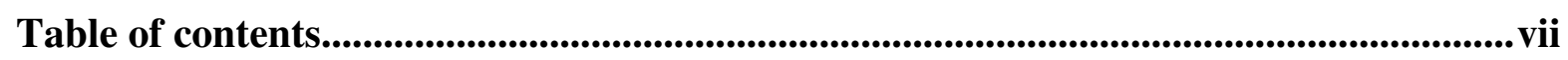

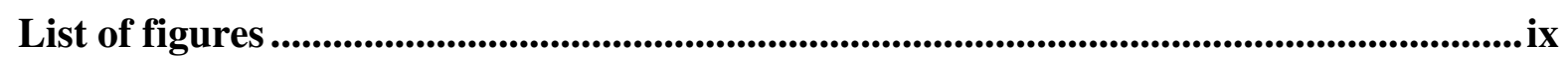

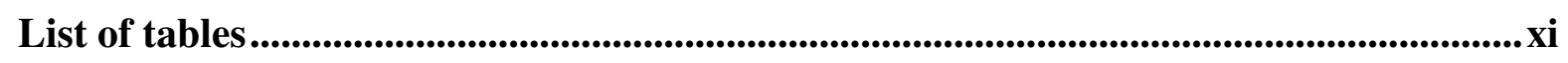

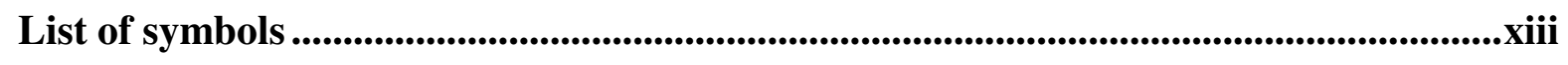

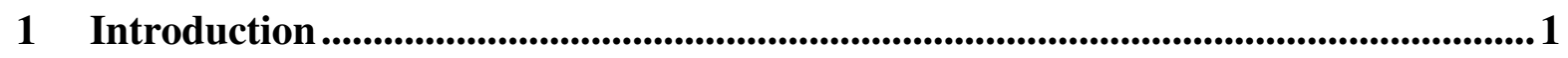

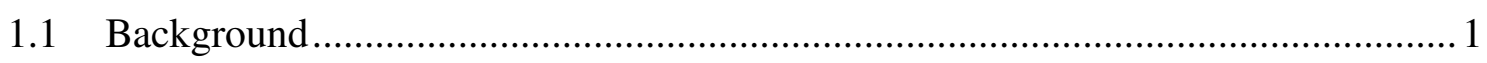

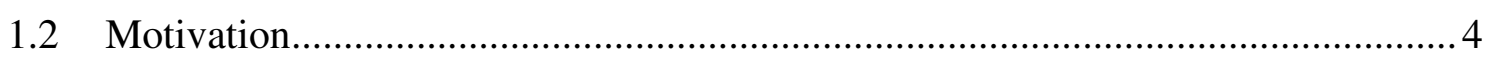

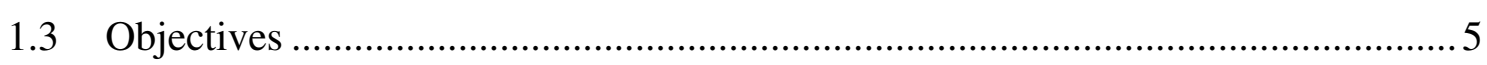

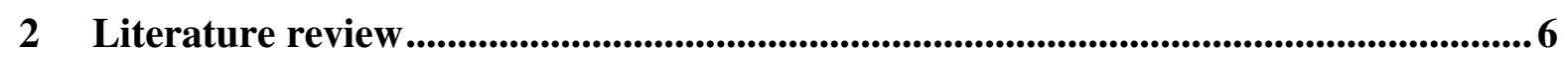

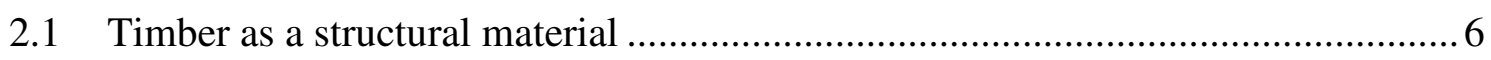

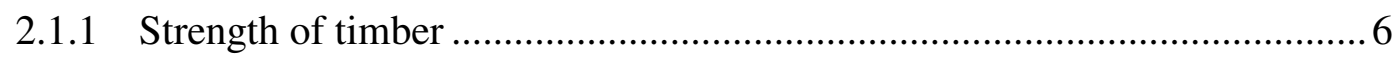

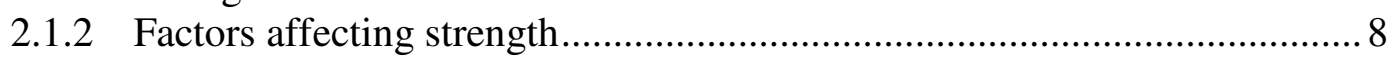

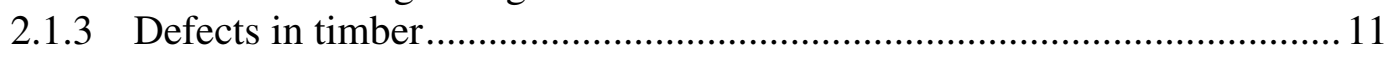

2.1.4 Important properties for roof truss design ........................................... 15

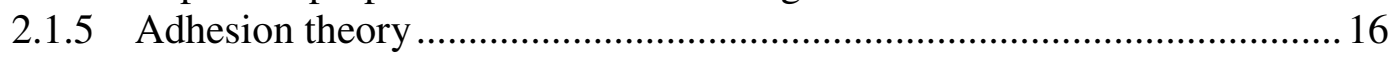

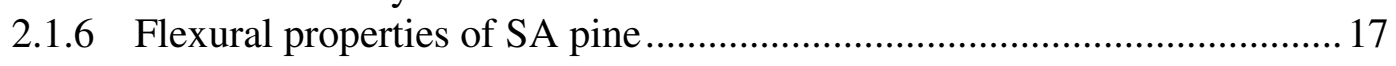

2.2 Mechanical and physical properties of young, green Eucalyptus grandis timber. 19

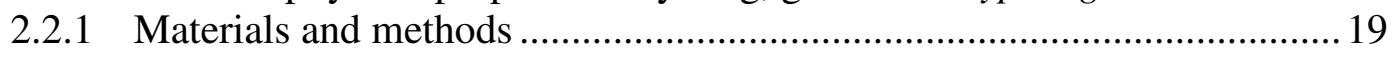

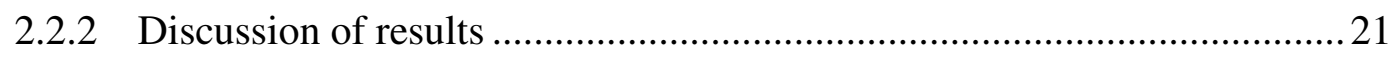

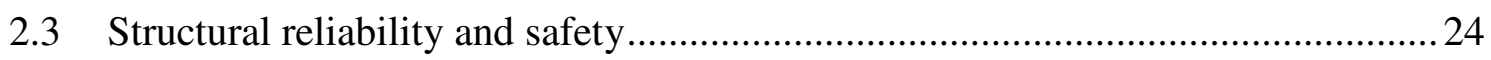

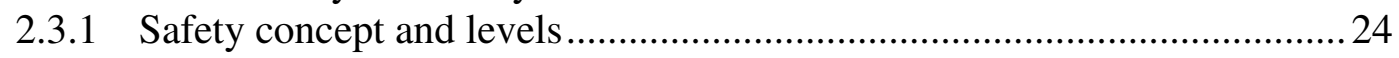

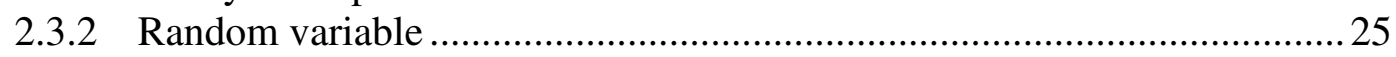

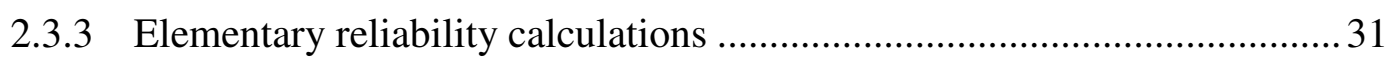

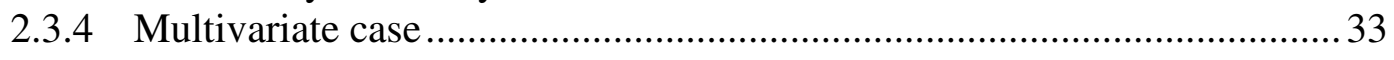

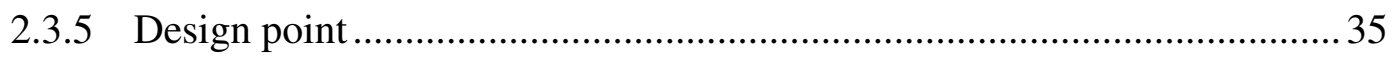

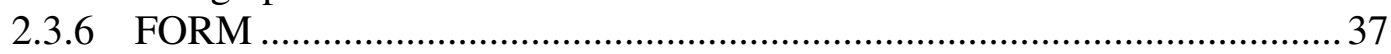

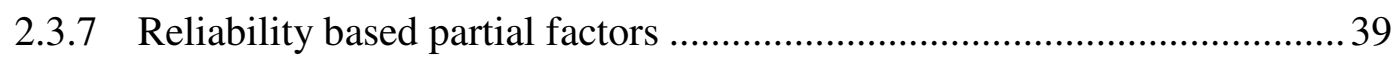

3 Materials and testing methodology .............................................................................44 44 


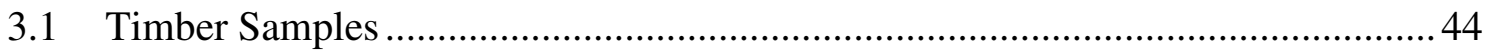

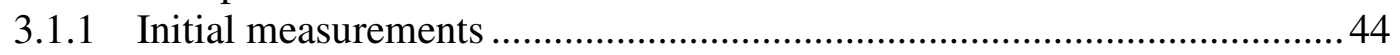

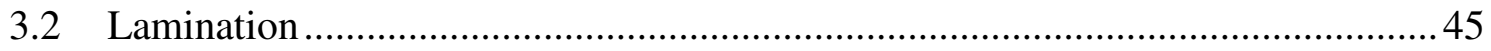

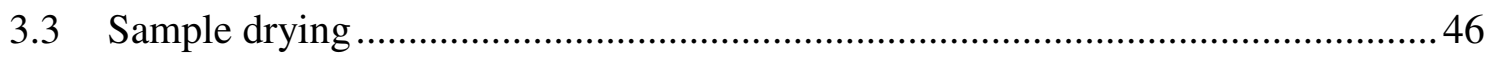

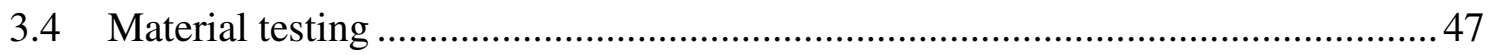

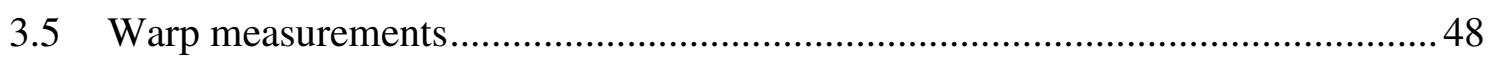

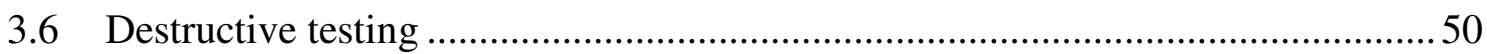

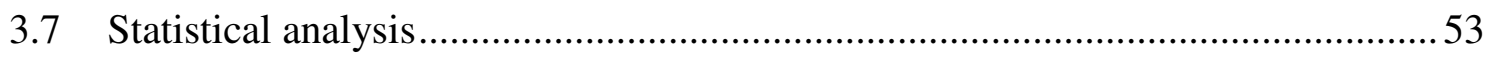

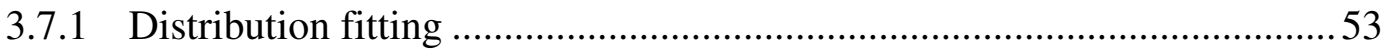

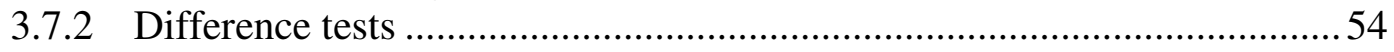

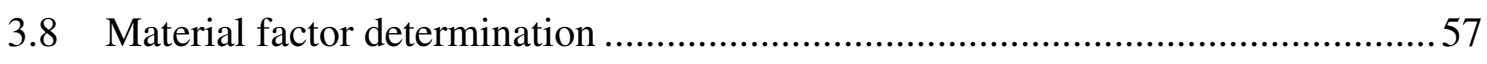

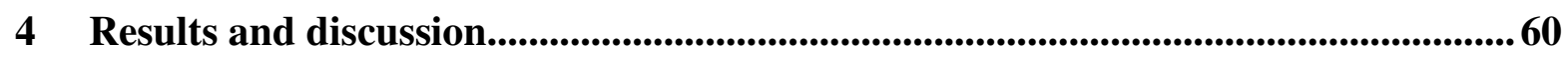

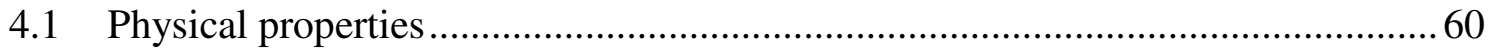

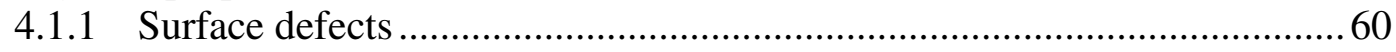

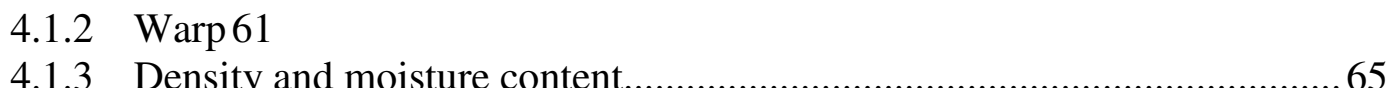

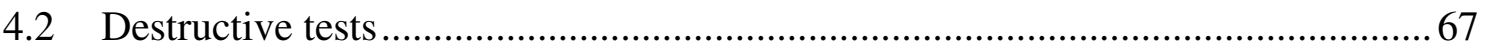

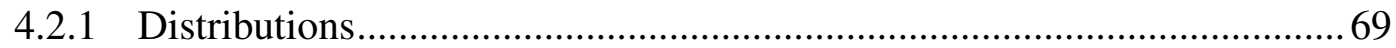

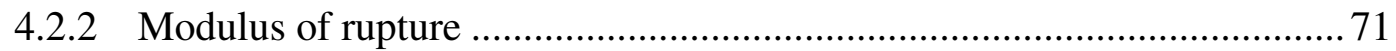

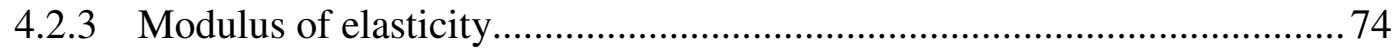

4.2.4 Correlation between MOR and MOE ..................................................... 77

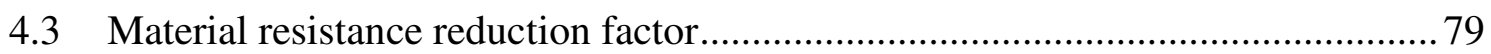

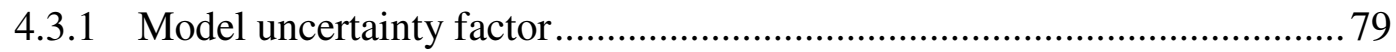

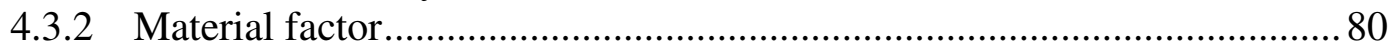

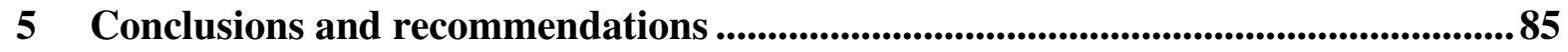

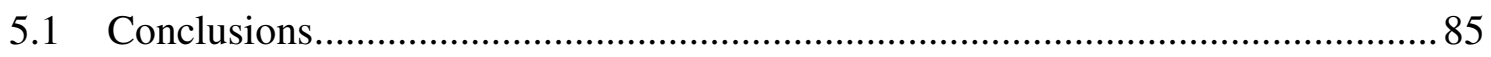

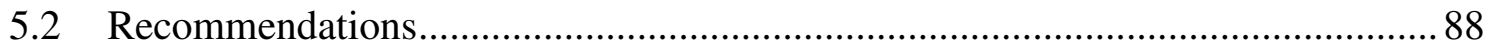

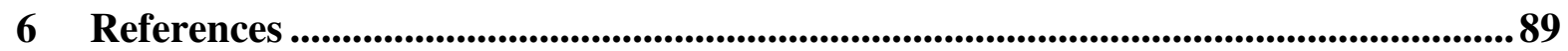




\section{List of figures}

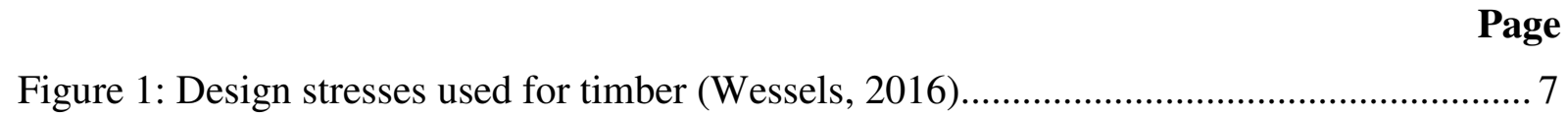

Figure 2: Illustration of orientation of growth stresses (Pröller, 2017) .................................. 12

Figure 3: The onset of drying stresses in initial stages of drying and then orientation reversal

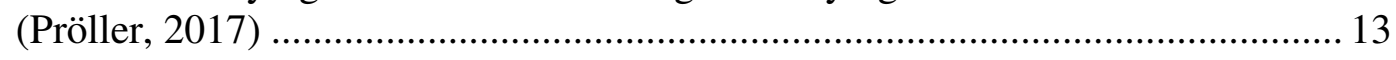

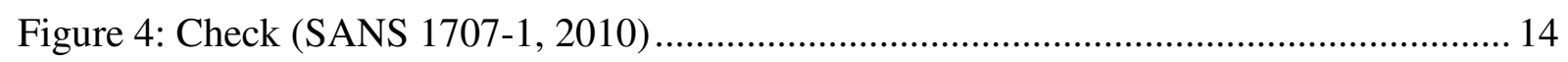

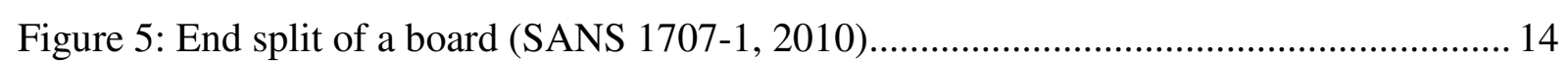

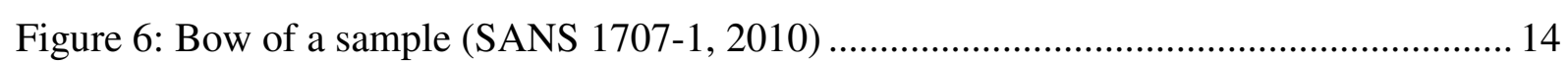

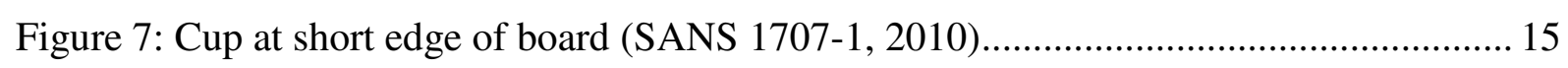

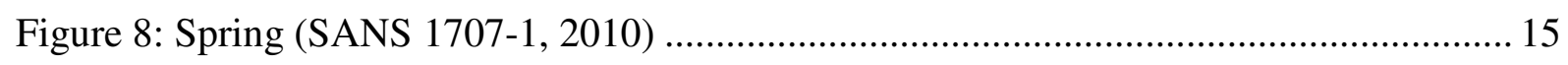

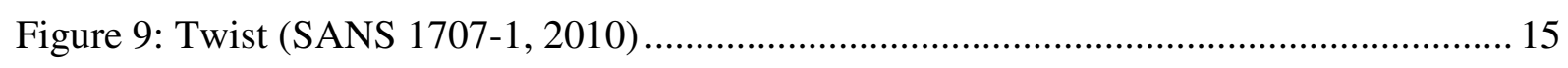

Figure 10: Probability density function for the standard normal distribution......................... 28

Figure 11: Comparison of probability density functions for normal and lognormal distributions (Holicky, 2009)

Figure 12: Illustration of probability density functions for normal and three-parameter lognormal distributions (Lenner, 2014) ....................................................... 30

Figure 13: Action effect $\mathrm{E}$ and resistance $\mathrm{R}$ probability density functions $\mathrm{f}(\mathrm{x})$; margin of safety

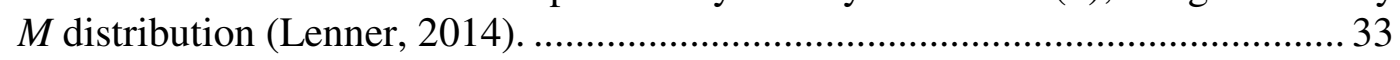

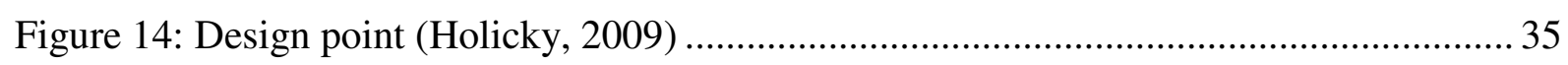

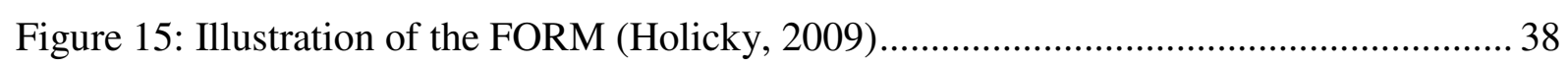

Figure 16: Schematic of the semi-probabilistic safety concept (Lenner, 2014)...................... 40

Figure 17: Relation between individual partial factors (Holicky, 2009)............................... 41

Figure 18: Surface defect marked at point of length measurement....................................... 45

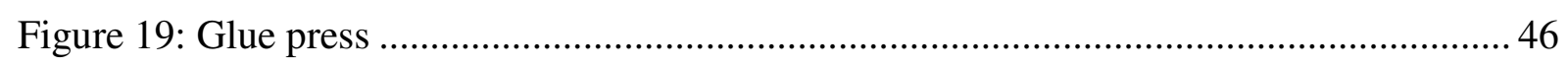

Figure 20: Mass reduction of selected samples during drying ........................................... 47

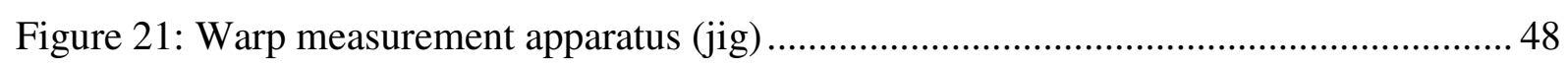

Figure 22: Measurement points using the warping jig as adapted from Pröller (2017).......... 49

Figure 23: Depiction of the four point bending test (SANS 6122, 2008) ............................... 50

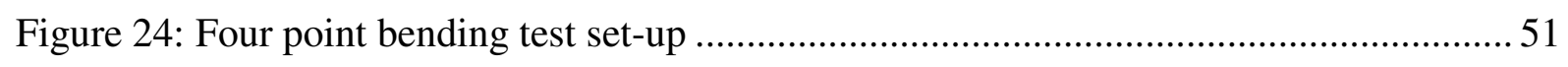

Figure 25: Force displacement graph with the two points used for MOE calculation............. 52

Figure 26: Distribution of bow results as a percentage of allowable bow .............................. 62

Figure 27: Distribution of cup results as a percentage of allowable cup ................................ 63 
Figure 28: Distribution of twist results represented as a percentage of allowable twist. 65

Figure 29: Distribution of density results recorded just prior to destructive testing 66

Figure 30: Distribution of moisture contents recorded just prior to destructive testing 67

Figure 31: Bending test - brash tension failure adjacent to a finger-joint 68

Figure 32: Bending test - diagonal tension failure originating at finger joint .68

Figure 33: Bending test - diagonal tension failure originating at defect .68

Figure 34: Bending test - localised cross grain tension failure. 69

Figure 35: Laminates MOE normal and lognormal distribution fits 69

Figure 36: Laminates MOR normal and lognormal distribution fits .70

Figure 37: Standard boards MOE normal and lognormal distribution fits .70

Figure 38: Standard boards MOR normal and lognormal distribution fits .70

Figure 39: Distribution of lowest $10 \%$ of MOR values $\left(5^{\text {th }}\right.$ percentile marked with bar)........ 72

Figure 40: Bootstrapped ANOVA comparison of the MOR results .73

Figure 41: Distribution of MOR results of the laminated and standard boards .73

Figure 42: Bootstrapped ANOVA results of the MOE means .75

Figure 43: Distribution of lowest $10 \%$ of MOE values $\left(5^{\text {th }}\right.$ percentile marked with bar) $) . . . . . .75$

Figure 44: Distribution of MOE results for the laminated and standard sets.......................... 76

Figure 45: Sample which achieved the outlying MOE result ............................................... 77

Figure 46: Correlation between MOR and MOE results for both sets..... 78

Figure 47: Change in material resistance reduction factor with respect to variation in model uncertainty coefficient of variation 80 


\section{List of tables}

Table 1: Characteristic stresses as provided in SANS 10163-1 (2003) .....

Table 2: MOR results of ungraded SA pine from various sources (36 x $111 \mathrm{~mm}$ boards) (Crafford and Wessels, 2011).

Table 3: MOE results of ungraded SA pine from various sources (36 x $111 \mathrm{~mm}$ boards) (Crafford and Wessels, 2011).

Table 4: Percentage of the 200 dry samples which did not conform to warp requirements (Crafford, 2013).

Table 5: Percentage of dry samples that would have been rejected due to checking and endsplitting requirements set out in SANS 1783-2 (2012) (Crafford, 2013).............. 22

Table 6: Mean shrinkage (\%) of the different age groups (Crafford, 2013) 22

Table 7: Results of destructive tests completed on the wet and dry green-glued finger-jointed E. grandis timber along with the corresponding characteristic grade stresses of SANS 10163-1 (2005) (Crafford, 2013) 23

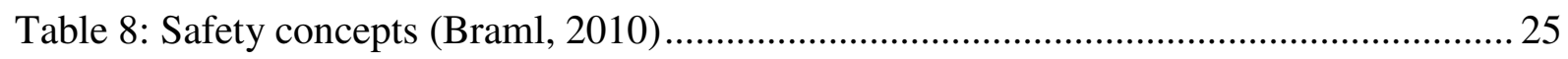

Table 9: Relationship between $P_{f}$ and $\beta$ (EN 1990, 2010) ................................................ 33

Table 10: Design values as provided in EN 1990 (2010) ..................................................... 41

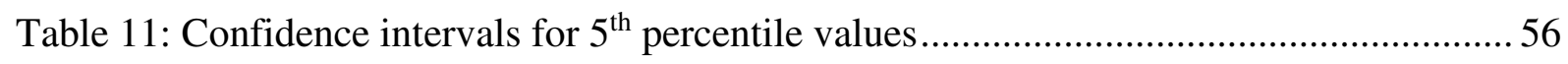

Table 12: Check defects recorded measured in wet and dry states ......................................6 60

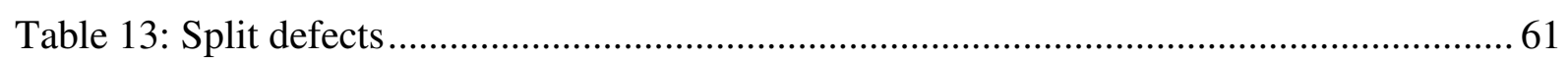

Table 14: Results for bow deformation of the laminated and standard sets ...........................62 62

Table 15: Results for cup deformation of the laminated and standard sets.............................63

Table 16: Results for twist deformation of the laminated and standard sets............................64

Table 17: Density results recorded just prior to destructive testing .......................................65

Table 18: Moisture content results recorded just prior to destructive testing ..........................66

Table 19: Basic statistics of MOR results of the laminated and standard sets........................ 72

Table 20: Basic statistics of MOE results of the laminated and standard sets ........................ 74

Table 21: Variation of material resistance reduction factor for changing model uncertainty coefficient of variation. .79

Table 22: Model uncertainty reduction factors $\varphi_{R d}$ relating to the two target reliability levels 80

Table 23: MOE material factors case $1-$ SLS thus $\beta=1.5$ and mean as characteristic ( $\left.E_{M}\right) . .82$

Table 24: MOE material factors case 2 - ULS thus $\beta=3.0$ and mean as characteristic ( $\left.E_{M}\right) .82$ 
Table 25: MOE material factors case $3-$ ULS thus $\beta=3.0$ and $5^{\text {th }}$ percentile as characteristic

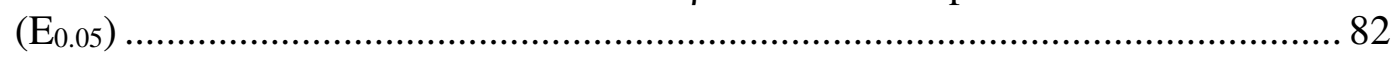

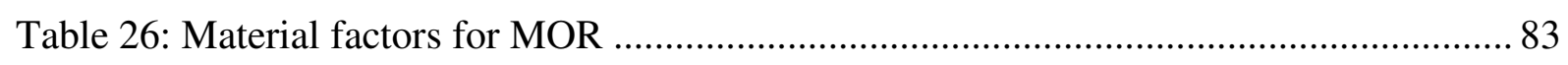




\section{List of symbols}

$\begin{array}{ll}\text { ANOVA } & \text { Analysis of variance } \\ b & \text { Thickness of test specimen } \\ C_{f D} & \text { Load coefficient for self-weight loads } \\ C_{f I} & \text { Load coefficient for imposed loads } \\ C_{f W} & \text { Load coefficient for wind loads } \\ \text { Comp// } & \text { Compression parallel to grain } \\ \text { Comp } \perp & \text { Compression perpendicular to grain } \\ \text { COV } & \text { Coefficient of variation } \\ D & \text { Deflection due to the increment in load } \\ E & \text { Action effect } \\ \text { EMC } & \text { Equilibrium moisture content } \\ F & \text { Load applied } \\ F_{5} & 5^{\text {th }} \text { percentile value } \\ f_{b} & \text { Characteristic bending stress } \\ f_{c} & \text { Compression parallel to grain } \\ f_{c p} & \text { Compression perpendicular to grain } \\ f_{t} & \text { Tension parallel to grain } \\ f_{t p} & \text { Tension perpendicular to grain } \\ \text { FSP } & \text { Fibre saturation point } \\ h & \text { Depth of the specimen } \\ j & \text { Position of the lower confidence limit } \\ \mathrm{k} & \text { Position of the upper confidence limit } \\ L & \text { Test span of the sample } \\ M & \text { Margin of safety } \\ \text { MOE } & \text { Modulus of elasticity } \\ \text { MOR } & \text { Modulus of rupture } \\ \text { MPa } & \text { Mega Pascal } \\ \text { MUR } & \text { Melamine urea formaldehyde resins } \\ \mathrm{N} & \text { Newton } \\ n & \text { Number of samples } \\ & \end{array}$


$P_{f} \quad$ Probability of failure

PUR Polyurethane adhesive resins

$R \quad$ Resistance

$\mathrm{R}^{2}$

Correlation coefficient

$R_{k}$

Characteristic resistance value

$R_{d}$

Design resistance

SANS South African national standards

SLS Serviceability limit state

T Thickness

U Standardized variable

$u \quad$ Standardized value

ULS Ultimate limit state

Coefficient of variation value

Vol Volume of the sample

W Width

$W_{D U} \quad$ Factored serviceability self-weight load effect

$W_{I U} \quad$ Factored serviceability imposed load effect

$W_{W U} \quad$ Factored wind load effect

$X$

Random variable

$x \quad$ Random value

$\mathrm{Z}_{\mathrm{e}} \quad$ Section modulus

$\alpha_{R} \quad$ Sensitivity factor

$\beta \quad$ Target reliability factor

$\gamma \quad$ Partial factor

$\gamma_{M} \quad$ Material resistance partial factor;

$\gamma_{R d} \quad$ Model uncertainty factor;

$\gamma_{m} \quad$ Material factor

$\alpha_{R} \quad$ is the sensitivity factor

$\varphi \quad$ Material resistance factor in SANS 10163-1

$\varphi_{R d} \quad$ Model uncertainty reduction factor

$\varphi_{M} \quad$ Material resistance reduction factor

$\varphi_{m} \quad$ Material reduction factor 


$\begin{array}{ll}\varphi(u) & \text { Probability density function } \\ \Phi(U) & \text { Distribution function } \\ \mu & \text { Mean } \\ \mu_{\theta R} & \text { Mean of the model uncertainty variable } \\ V_{\theta R} & \text { Coefficient of variation of the model uncertainty (COV) } \\ \sigma^{2} & \text { Variance } \\ \sigma & \text { Standard deviation } \\ \rho & \text { Density of the specimen } \\ \rho_{R E} & \text { Correlation coefficient } \\ \omega_{x} & \text { Skewness }\end{array}$




\section{Introduction}

\subsection{Background}

South Africa is deemed to be a timber scarce country with only $1 \%$ of the total land area being used for commercial forestry (DAFF, 2012). Of this area, Pinus and Eucalyptus are the main genera planted and account for $51 \%$ and $40 \%$ of the forestation land area respectively with the remaining $9 \%$ being used for other species (DAFF, 2015). A shortage in structural timber is predicted for the near future as an investigation into the demand and supply of softwood sawlogs and sawn timber completed by Crickmay and Associates (2004) had noted a $27 \%$ undersupply of structural timber in 2004 which was projected to reach $53 \%$ by 2033 . The decline in afforestation is a contributing factor which is predominately due to the lack of suitable land and restrictions on expansion of plantations due to water usage legislation introduced by the government. Many formerly state owned forests have been privatised where the owners tend to favour short rotation crops for the production of pulpwood which provides a steady cash flow over the longer crop rotations required for softwood sawlogs (DAFF, 2015).

Timber imports are currently limited to species not available in South Africa as noted by Chamberlain et al. (2005), but with the lower cost of structural timber in the United States of America and Europe, imported timber could become more economically competitive with local products. This is an issue as approximately 170000 employment opportunities are created by the forestry sector with about 850000 citizens depending on jobs created by the sector for a living in predominantly rural areas where there is few other alternatives (DAFF, 2015). Thus a vast amount of people would be without employment or an income if South Africa was to become a net importer of structural timber. This possible loss of employment and decreasing supply has caused the local market to investigate alternative species and processing methods to be used for structural timber production in order to remain competitive with foreign import markets. A proposed solution of decreasing the rotation age of the Pinus patula, which is the predominantly used species for structural timber production, was deemed to not be a feasible solution by Dowse (2010). Dowse had found that the young Pinus patula timber exhibited very 
low stiffness values which did not comply with the modulus of elasticity (MOE) requirements prescribed in SANS 10163-1 (2003) for any of the mechanical or physical grades.

Hardwood species such as Eucalyptus grandis could be utilized to mitigate the shortage in structural timber as it is the predominate locally grown hardwood species in the country with approximately 270000 ha of plantation area (DWAF, 2009). The fast growing Eucalyptus grandis is commonly used for pulpwood and paper products with around 2 million tons of bone dry Eucalyptus grandis wood chips being exported in 2003 (Chamberlain et al., 2005). This could equate to roughly 1 million tons of value added structural timber which would also produce additional employment opportunities due to the labour intensive nature of structural timber supply when compared to pulpwood production (DAFF, 2012).

Eucalyptus grandis is not frequently used for structural timber production due to the inherent tendency of the mature trees to exhibit defects such as checks and split during felling, sawing and drying processes along with the presence of brittle heart. The high levels of growth stresses present in mature trees increase the possibility of end splits to occur after felling (Wand, 1990). Lower levels of growth stresses are present in young Eucalyptus grandis which decreases the onset of split defects. Using engineered timber such as finger-jointed timber or timber laminated together with adhesives can help solve issues commonly experienced with this material. One component polyurethane adhesives have recently been commercially used for the wet fingerjointing of timber (where the moisture content is above fibre saturation point $\approx 30 \%$ ) allowing for shorter or smaller trees to be used to manufacture longer length elements without requiring kiln drying before gluing.

A company called Biligom International (Pty) Ltd has created and patented a method of processing moist Eucalyptus grandis timber. The process involves finger-jointing young Eucalyptus grandis timber while the moisture content is above fibre saturation point. The trees used for this process are relatively young, with a rotation age of 5 to 18 years, as to reduce the possible growth defects. The young trees are felled and then left in the field to dry for approximately six weeks. Then the trees are processed into short dimensional timber before finger-jointing the timber using a polyurethane adhesive to produce market related lengths. The 
Biligom timber can then be used to manufacture roof trusses in the green state and allowed to dry once fixed in place within the roof.

An investigation was completed by Crafford (2013) to determine if the young, finger-jointed Eucalyptus grandis would be suitable for use as a structural component and more specifically in roof trusses. Destructive testing was completed to determine the characteristic strengths in the wet and dry states along with recording any defects present in the material. Positive results were obtained with structural grade S7 being achieved for the flexural strength and stiffness properties of the timber with a low variability in results when compared to equivalent SA pine. Issues had arose in terms of twist and check defects where many of the samples had defects above rejection limits prescribed in SANS 1783-2 (2012). Following the findings obtained by Crafford (2013), full scale trusses were tested by MiTek Industries SA (Pty) Ltd who have since endorsed the Biligom product and included the Biligom characteristic values in their truss fabrication software for use with the Biligom material. Biligom timber has been accredited with a unique structural grade rating by the South African Technical Auditing Service (SATAS) which is comparable to structural grade S7 of SA pine. This allows for less timber to be required when compared to grade S5 SA pine for the design of an equivalent roof area.

The low variability in strength results recorded by Crafford (2013) has led to the consideration of determining a specific material resistance reduction factor for the young, finger-jointed Eucalyptus grandis which could be included in SANS 10163-1 as currently only a single material resistance partial factor is included in the code. It is believed that the decreased variability experienced with this material would result in a less conservative material resistance partial factor allowing for less material to be used to achieve an equivalent level of safety in design. Another processing method has also been devised at Stellenbosch University which involves the face lamination of the young, finger-jointed Eucalyptus grandis when in the wet state. This is done with the aim to further mitigate the onset of defects commonly experienced with Eucalyptus grandis and to reduce the variability in strength results of the material which would result in a more visually appealing value added product which could be used for multiple structural applications along with roof trusses. 
The SANS 10163-1 design code for the structural use of timber prescribes the use of the limitstates design method, also referred to as the load and resistance factor design method. The limit state of a structure refers to the condition where the structure no longer satisfies its design criteria. In South Africa a Type 1: Semi-Probabilistic reliability method is used, where partial factors are applied to both the resistance and load sides of the limit state inequality. Partial factors are applied to the variables in the limit state equation where the action effect $E$ is to be lower than or equal to the structural resistance $R$ to ensure structural safety. The material resistance partial factor $\gamma_{M}$ is applied to the structural resistance component by dividing the material characteristic strength by the partial factor which effectively reduces the characteristic resistance value to account for the model uncertainty, variability and statistical uncertainty in material resistance test results. In some cases the inverse of the material resistance partial factor is applied by multiplying the material characteristic strength by the inverse of the partial factor which is then called a reduction factor. The partial factor applied to action effect component increases the action effect value used in design. The objective of the limit states design method is to ensure that the resistance of the structure remains larger than any applicable load combination applied to the structure. Thus ensuring that the structure can withstand all actions that are deemed likely to occur during the design life while remaining suitable for the intended use.

\subsection{Motivation}

Currently a singular material resistance reduction factor is prescribed for all structural timber in SANS 10163-1 (2003). This factor is believed to be overly conservative for use with the young, finger-jointed Eucalyptus grandis as the factor was determined for softwoods which has been found to have a higher variability in strength results when compared to the Eucalyptus grandis (Crafford, 2013). A more accurate material specific reduction factor could be less conservative which would allow for truss manufacturers to use less material while still satisfying the limit state equation for the structure. Thus allowing for an efficient use of the resource. Further processing of the young, finger-jointed Eucalyptus grandis by face laminating two beams has the potential to further increase the material resistance reduction factor and also ameliorate defects commonly experienced when using the species for structural purposes. This could result in a value added product with a more realistic material specific partial factor, better 
visual appeal and better strength properties to be used for multiple structural applications including roof trusses.

\subsection{Objectives}

The objectives of this research project are described below:

- Determine the material resistance properties of green finger-jointed Eucalyptus grandis timber that (a) has been face laminated and (b) a standard set of the green finger-jointed Eucalyptus grandis.

- Calculate material resistance partial factors for green finger-jointed Eucalyptus grandis timber that (a) has been face laminated and (b) a standard set of the green finger-jointed Eucalyptus grandis and compare these factors with the existing material resistance factor in the SANS 10163-1 timber design code.

- Determine and compare the defect development of both sets in the wet and dry states. 


\section{Literature review}

\subsection{Timber as a structural material}

Timber is widely used as a structural material with $50 \%$ of South Africa's sawmill production being used for structural purposes, predominantly for use in the construction of roof trusses (Prion, 2004). Unlike its steel counterpart, timber does not exhibit equivalent properties in all directions. It is an orthotropic and heterogeneous material. The heterogeneous aspect refers to how the physical and mechanical properties can vary through the volume of the material while the orthotropic aspect refers to how the properties are different in the directions of the three perpendicular axes.

\subsubsection{Strength of timber}

Six strength design values are used when designing a timber structure according to the SANS design codes. These six design stresses used are namely: tension parallel to grain $\left(f_{t}\right)$, compression parallel to grain $\left(f_{c}\right)$, tension perpendicular to grain $\left(f_{t p}\right)$, shear parallel to grain $\left(f_{v}\right)$, compression perpendicular to grain $\left(f_{c p}\right)$ and bending $\left(f_{b}\right)$. The illustration below depicts the orientation of the different design stresses. 


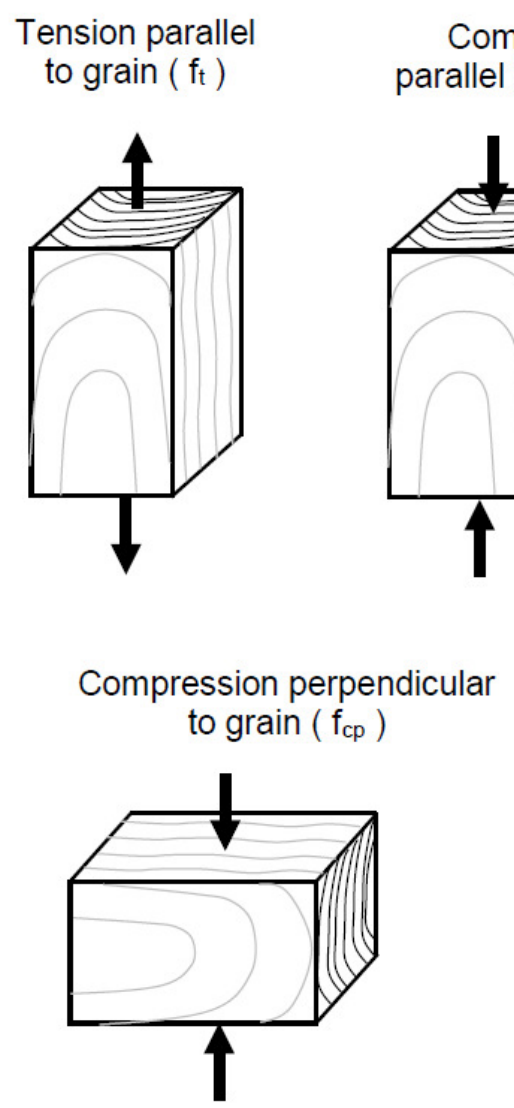

Compression parallel to grain $\left(f_{c}\right)$
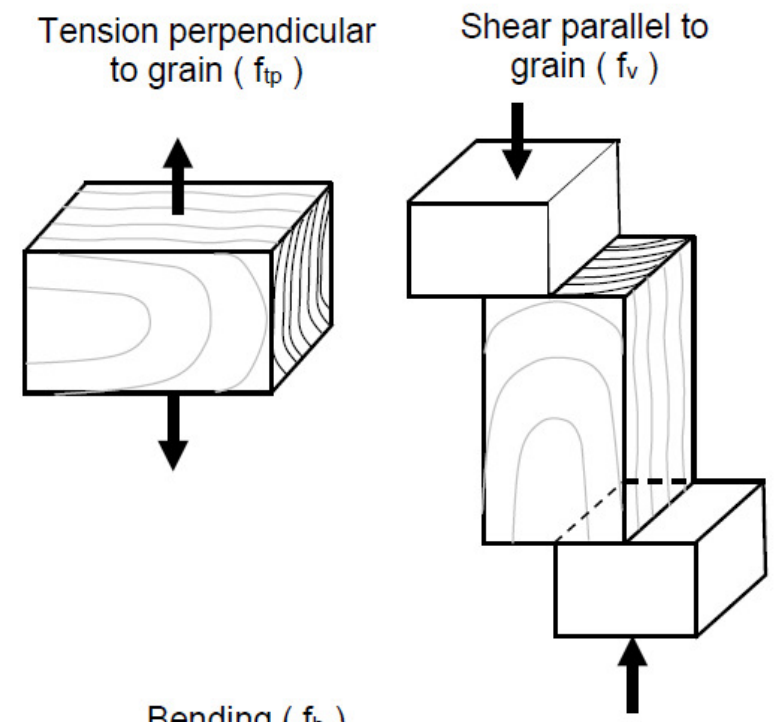

Bending $\left(f_{b}\right)$
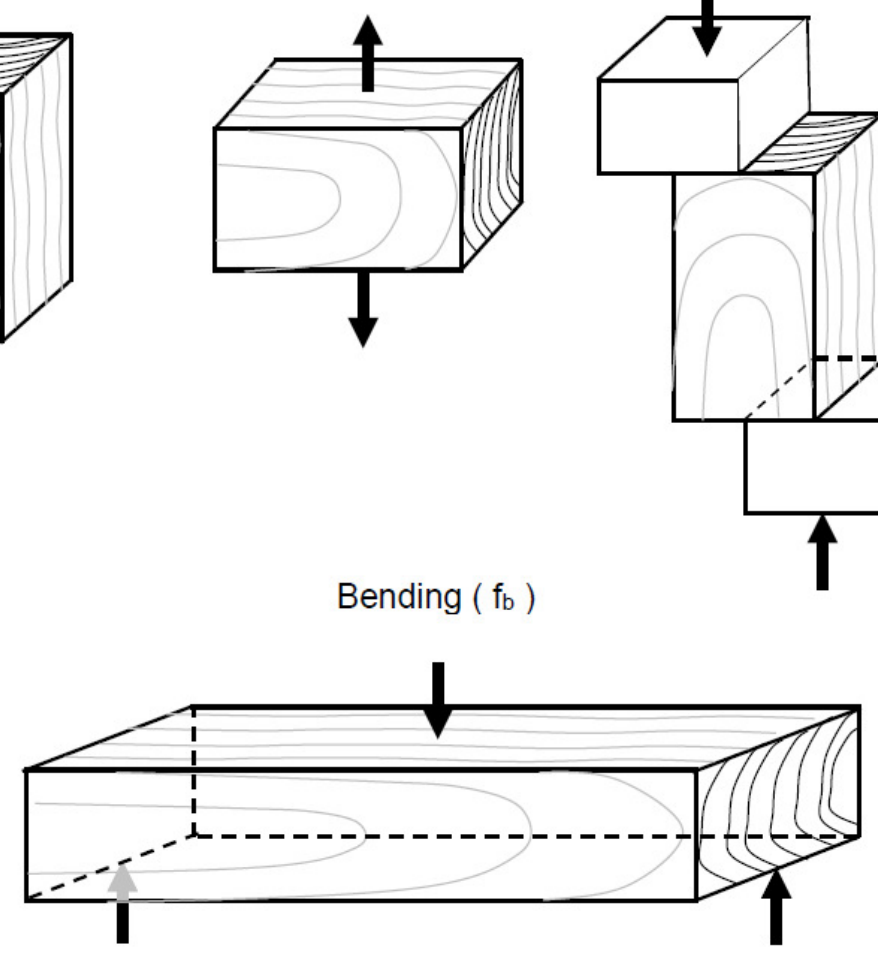

Figure 1: Design stresses used for timber (Wessels, 2016).

The characteristic stresses prescribed in the SANS 10163-1 (2003) timber design code are shown in Table 1 for the four grades of structural SA pine lumber used in South Africa. The $5^{\text {th }}$ percentile value is used as the characteristic value for all of the material properties apart from the modulus of elasticity where the mean is used as the characteristic value in the current version of SANS 10163-1. Bending perpendicular to grain is not listed in the design code as it is such a weak property of timber and thus designers do not stress timber in this orientation. Shear perpendicular to grain is another strength property which is excluded from SANS 10163-1 (2003) as the timber will fail in compression or tension before it would fail due to perpendicular shear as the material is weaker in compression and tension than shear perpendicular to grain. 
Table 1: Characteristic stresses as provided in SANS 10163-1 (2003)

\begin{tabular}{|c|c|c|c|c|c|c|c|}
\hline \multicolumn{8}{|c|}{ Values in megapascals } \\
\hline 1 & 2 & 3 & 4 & 5 & 6 & 7 & 8 \\
\hline Grade $^{2)}$ & $\begin{array}{c}\text { Bending } \\
f_{\mathrm{b}}\end{array}$ & $\begin{array}{c}\text { Tension } \\
\text { parallel } \\
\text { to grain } \\
f_{\mathrm{t}}\end{array}$ & $\begin{array}{c}\text { Tension } \\
\text { perpendicular } \\
\text { to grain } \\
f_{\mathrm{tp}}\end{array}$ & $\begin{array}{c}\text { Compression } \\
\text { parallel to } \\
\text { grain } \\
L_{\mathrm{e}} / b=0 \\
f_{\mathrm{c}}\end{array}$ & $\begin{array}{c}\text { Compression } \\
\text { perpendicular } \\
\text { to grain } \\
f_{c \mathrm{p}}\end{array}$ & $\begin{array}{l}\text { Shear } \\
\text { parallel } \\
\text { to grain } \\
f_{\mathrm{v}}\end{array}$ & $\begin{array}{c}\text { Modulus } \\
\text { of } \\
\text { elasticity } \\
E\end{array}$ \\
\hline $\begin{array}{r}5 \\
7 \\
10 \\
14\end{array}$ & $\begin{array}{l}11,5 \\
15,8 \\
23,3 \\
32,4\end{array}$ & $\begin{array}{r}6,7 \\
10,0 \\
13,3 \\
19,1\end{array}$ & $\begin{array}{l}0,36 \\
0,51 \\
0,73 \\
1,04\end{array}$ & $\begin{array}{l}18,0 \\
22,8 \\
26,2 \\
35,3\end{array}$ & $\begin{array}{r}4,7 \\
6,7 \\
9,1 \\
12,9\end{array}$ & $\begin{array}{l}1,6 \\
2,0 \\
2,9 \\
4,0\end{array}$ & $\begin{array}{r}7800 \\
9600 \\
12000 \\
16000\end{array}$ \\
\hline
\end{tabular}

1) These stresses apply to visually, mechanically or proof-graded timber that complies with SANS 1783-2 (grades 5,7 or 10 ), SANS 1460 , grades $5,7,10$ and 14 as appropriate.

2) Grade stresses given here are for a range of grades beyond those covered in current SANS standards. The intention is to cater for any special purpose grade that could be introduced.

NOTE 1 Designers should check the availability of any grade they wish to specify.

NOTE 2 SANS 1460 refers to both hardwoods and softwoods. In the case of laminated timber, use the appropriate grade stress for the applicable grade of timber.

Amdt 2

\subsubsection{Factors affecting strength}

Various factors can affect the strength of timber used within structures which could positively or negatively affect the values used in the design. The five main factors which affect the strength of timber are namely: duration of load, moisture content, size effect, pressure treatment and load sharing (Dinwoodie, 2000). The variations in strength caused by these factors are accounted for in SANS 10163-1 (2003) through the use of partial material factors that are applied within design calculations. This effectively reduces or increases the characteristic value depending on the material property in question. These factors are only used in certain applicable cases whereas the material resistance factor denoted by $\varphi$ in SANS 10163-1 (2003) is applied to the characteristic value regardless of other factors affecting the strength of the element under consideration. This material resistance factor $\varphi$ accounts for the variability in the material properties and the uncertainty in prediction of member resistance. A factor of 0.68 is prescribed in SANS 10163-1 (2003) for structural timber where SA pine is the predominant structural timber used in South Africa. An equivalent factor for the material under investigation in this study shall be determined in later chapters and is referred to as the material resistance partial 
factor which is denoted by $\gamma_{M}$. The factors of $\gamma_{m l}$ to $\gamma_{m 5}$ discussed in this chapter are not to be confused with the material factor of $\gamma_{m}$ which accounts for the inherent variability of the material strength and statistical uncertainty of the strength results that shall be discussed in greater detail further in this study. The method of applying the material resistance factor and partial material factors are shown in Equation 1 for the calculation of ultimate moment resistance or rectangular sections as provided in SANS 10163-1 (2003). Where here the material resistance factor is multiplied in the equation while the characteristic bending strength is divided by the partial factors.

$$
M_{r}=\varphi \cdot Z_{e} \cdot \frac{f_{b}}{\gamma_{m 1} \cdot \gamma_{m 2} \cdot \gamma_{m 3} \cdot \gamma_{m 5}}
$$

Where:

$M_{r} \quad$ is the ultimate moment resistance of a member;

$\varphi \quad$ is the material resistance factor;

$f_{b} \quad$ is the characteristic bending stress;

$Z_{e} \quad$ is the section modulus;

$\gamma_{m l} \quad$ is the partial material factor for load duration;

$\gamma_{m 2} \quad$ is the partial material factor for load sharing;

$\gamma_{m 3}$ is the partial material factor for stressed volume;

$\gamma_{m 5}$ is the partial material factor for pressure treatment.

The duration that a load is designed to be applied to the structure has an effect on the strength of the timber elements which it is applied to. This is known as the duration of load (DOL) effect. The DOL effect for elements that are stressed parallel to the grain is lower than for elements stressed in tension perpendicular to the grain. The moisture content and size of the timber has an influence on the magnitude of the DOL effect where a higher moisture content causes a decrease in the duration to failure while an increase in the size of the element increases the time to failure (Thelandersson and Larsen, 2003). Due to the DOL having a significant effect on the strength of timber, it has been accounted for in the design code through the application of the DOL partial material factor denoted by $\gamma_{m l}$ which is used in the design equations to decrease the characteristic strength of the timber. The DOL partial factor can be calculated using Equation 2 as in SANS 10163-1 (2003). 


$$
\gamma_{m 1}=\frac{C_{f D} W_{D U}+C_{f I} W_{I U}+C_{f W} W_{W U}}{W_{D U}+W_{I U}+W_{W U}}
$$

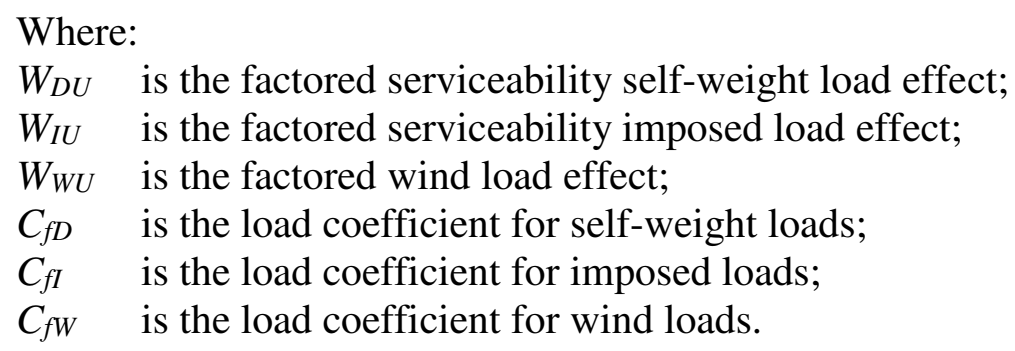

Due to the interconnected nature of structures, loads are often carried by a multitude of elements within the structural system which is known as load sharing. This allows for an increase in load that can be carried by the system than what could be carried by each single element. Thus the design code allows for the increase of the characteristic strength of an element when load sharing occurs. As stated in SANS 10163-1 (2003), for the case where uniformly distributed loads act together in a manner that they are restrained to an equivalent deflection, and where the applied loads have a spacing of less than $600 \mathrm{~mm}$, a partial material factor of $\gamma_{m 2}=0.87$ may be used to account for the load sharing.

The size effect of timber comes about if there is a choice between two pieces of timber with equivalent cross sections but with one having a longer length than the other. The longer member has a higher probability of exhibiting strength decreasing defects. This situation is analogous when two pieces with equivalent lengths and thicknesses but different depths are compared. The thickness of two opposing timber element does not have an effect on the strengths of the elements (Madsen, 1992). Only the length effect is accounted for in SANS 10163-1 (2003) with the use of the partial material factor $\gamma_{m 3}$ which can be calculated for beam and truss elements as shown in Equation 3 and Equation 4 below where $L$ is the span length of the truss or beam.

$$
\begin{gathered}
\text { Trusses: } \gamma_{m 3}=0.87+0.015 L \\
\text { Beams }: \gamma_{m 3}=0.85+0.03 L
\end{gathered}
$$

Moisture content has been found to have an adverse effect on most strength properties of structural timber with the exception of tensile strength which the moisture content does not 
affect (Thelandersson and Larsen, 2003). Studies completed by Madsen (1992) had determined that the bending strength of structural timber is compromised at an increased moisture content, but only in the upper region of the strength distribution and thus not affecting the $5^{\text {th }}$ percentile characteristic values. Madsen (1992) had found that the compressive strength perpendicular to grain is greatly effected in the characteristic strength zone of the distribution. These moisture effects are accounted for in SANS 10163-1 (2003) through the application of a partial factor of $\gamma_{m 4}=1.33$ for instances where the moisture content of the timber could occasionally exceed $20 \%$ during the service life of the element. For cases where the moisture content will remain below $20 \%$ a factor of 1.0 is applied. The application of the partial factor of 1.33 reduces the characteristic strength by $24.8 \%$ for members with high moisture contents.

Timber elements are commonly pressure treated in order to increase resistance against the ingress of termites, micro-organisms and the onset of fungal decay. This process is completed using waterborne chemicals such as copper-chrome-arsenate. Pressure treatment has been found to have a negative effect on all strength properties of structural timber (Hesp and Watson, 1964). Due to the strength reduction caused by the pressure treatment, a partial material factor has been included in the SANS 10163-1 (2003) code of $\gamma_{m 5}=1.11$ thus reducing all characteristic strength values by $9.91 \%$ in cases where pressure treatment has been used.

\subsubsection{Defects in timber}

A disadvantage commonly associated with the use of timber as a structural material is the defects which may be present in the end product. A wood defect is defined as "any irregularity or deviation from the qualities that make wood suitable for a particular purpose" (Panshin et al., 1964). These defects are developed naturally due to the growth process of the tree and can be caused or aggravated by the processing of the trees into dimensional lumber. The defects analysed in this study are warp, cup, split and check with the aim of reducing the onset of these defects for the timber in question. A brief explanation is thus provided as to how the defects originate followed by a definition of the relevant defects.

\subsubsection{Growth-induced defects}

As a tree grows, layers of new cells are introduced to the outside of existing stem tissue. During the final development stages of these new cells, they shrink in length and are thus laid in tension 
which compresses the adjacent interior tissue. This then produces longitudinal growth stresses which are fundamental in keeping in the tree upright (Panshin, De Zeeuw and Brown, 1964). Figure 2 shows the tension in the outer sections of the tree with the compression at the core. The increased growth rate of Eucalyptus Grandis can lead to a larger portion of core-wood when compared to slower growing species (Dinwoodie, 2000; Walker et al., 1993).

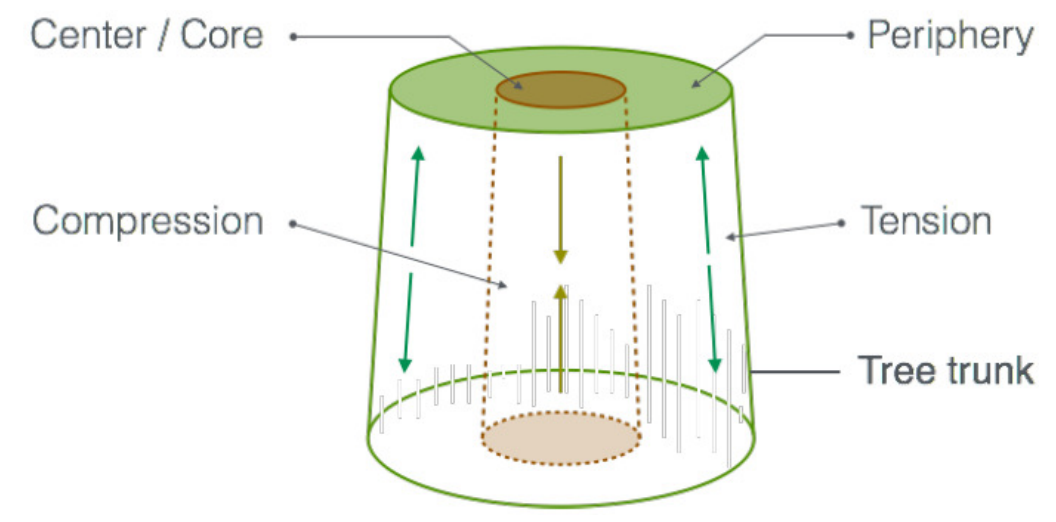

Figure 2: Illustration of orientation of growth stresses (Pröller, 2017)

The growth stresses formed during the maturation of the trees are released during felling and processing of the trees into sawn lumber. This release of growth stresses causes warp in the form of bow, twist and spring. Material originating from younger trees are more likely to warp as a result of the steeper stress gradient within the stem. Bow is caused by the longitudinal growth stresses while twist is a result of spiral grain. Spiral grain is described as the spiral orientation of fibres around the stem as opposed to being parallel to it (Shmulsky and Jones, 2011). Spring occurs if one of the two shorter ends of the board contains core wood which exhibits increased longitudinal shrinkage.

\subsubsection{Drying defects}

Once a tree is felled it can begin to dry. The drying occurs due to the hygroscopicity of wood which allows the moisture level in the wood to strive to become balanced with the moisture level of its surroundings. Once this level is reached it is referred to as equilibrium moisture content (Panshin, De Zeeuw and Brown, 1964). When the moisture content reaches below fibre saturation point, shrinkage begins to occur as the water exits the cells. 
During drying the moisture content at the surface is less than at the core of the wood which initiates a gradient of moisture between the wood's core and surface as the moisture exits the wood. This moisture gradient then causes so-called "drying stresses" to develop (Bergman, 2010). Drying stresses form during the beginning phases of drying as the outer sections of the wood dry first and subsequently shrink while the wet core remains at the same size and thus restricting the shrinkage of the outer shell. Tension then forms in the shell while compression forms in the core. The shell can shrink to an extent where it sets in its condition when drying occurs too rapidly.

At a later stage in the drying process, the core wood will dry and subsequently shrink. In the case where initial shrinkage occurred too rapidly, the core wood is restrained by the now set outer shell which reverses the stress orientation in the wood as depicted by Figure 3. Drying stresses formed in the initial stage can cause surface fractures in the form of checks and end splits (Bergman, 2010). End splits are caused by the rapid drying at the end of the board as a result of the fast movement of moisture in the longitudinal direction.

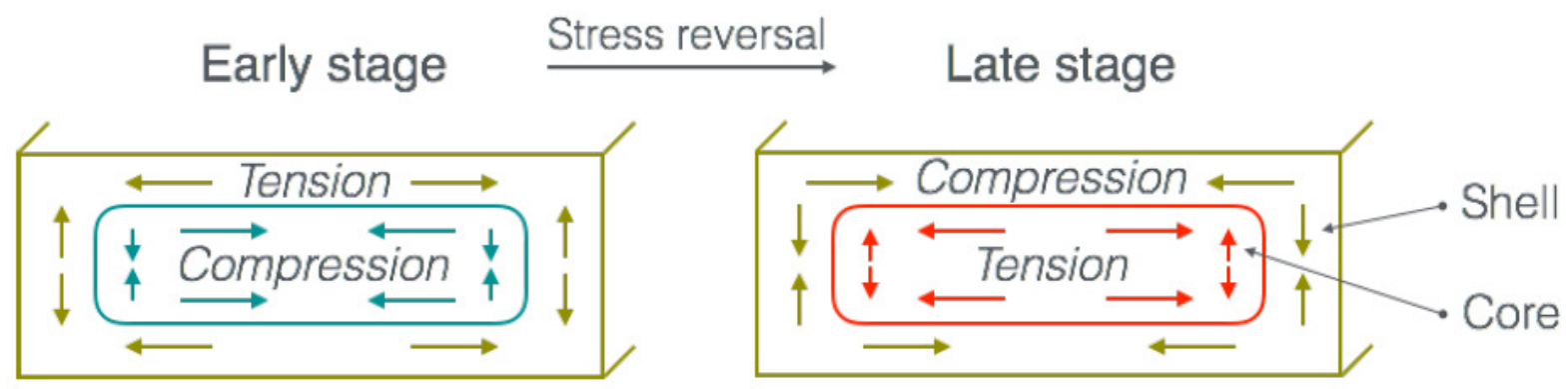

Figure 3: The onset of drying stresses in initial stages of drying and then orientation reversal (Pröller, 2017)

\subsubsection{Defects analysed}

The check is defined as a "separation of the wood fibres along the grain of wood that forms a crack or fissure but does not extend through a piece from one face to the opposite face" and is represented in Figure 4 (SANS 1707-1, 2010). 


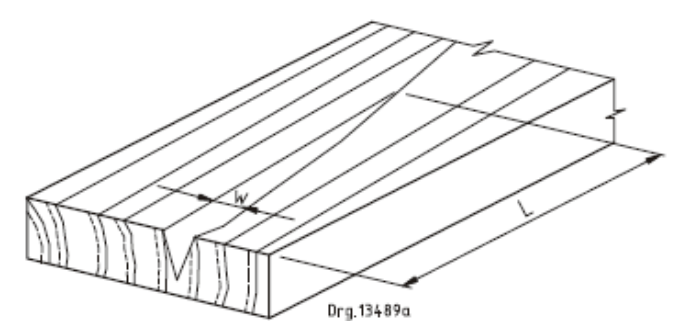

Figure 4: Check (SANS 1707-1, 2010)

Split is a "separation of the wood fibres along the grain of the wood that forms a crack or fissure that extends through a piece from one face to the opposite face" as depicted in Figure 5 (SANS 1707-1, 2010).

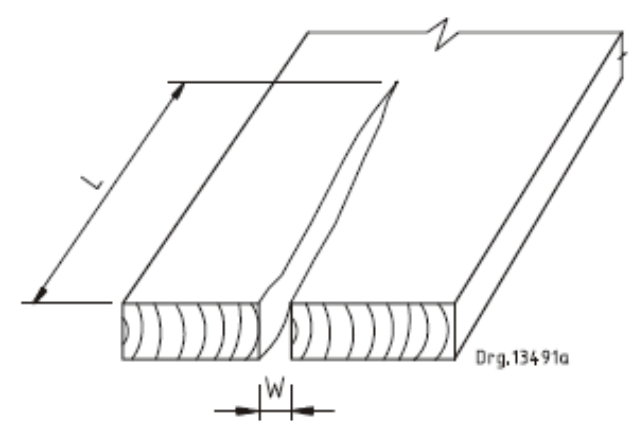

Figure 5: End split of a board (SANS 1707-1, 2010)

The warp is deemed to be "any departure (in the form of bow, cup, spring or twist, or any combination of these) from a true plane surface of a piece" (SANS 1707-1, 2010). Bow is one of the manifestations of warp which is shown in Figure 6 and is defined to be "lengthwise curvature, in its own plane, of an edge of a piece".

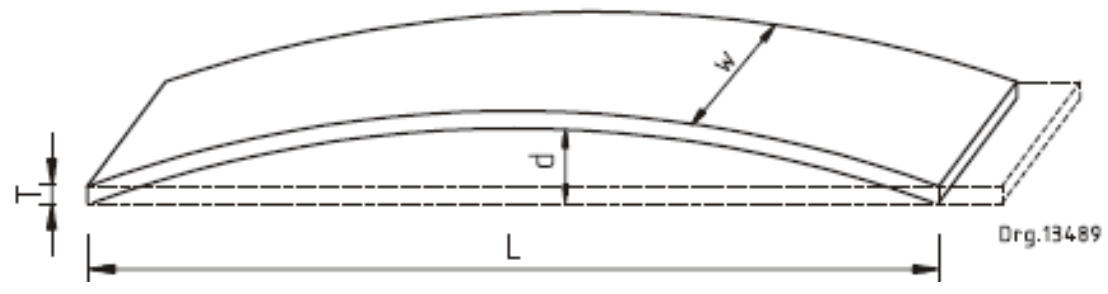

Figure 6: Bow of a sample (SANS 1707-1, 2010)

Cup is "curvature that occurs in the transverse section of a piece of timber" as depicted in Figure 7. 


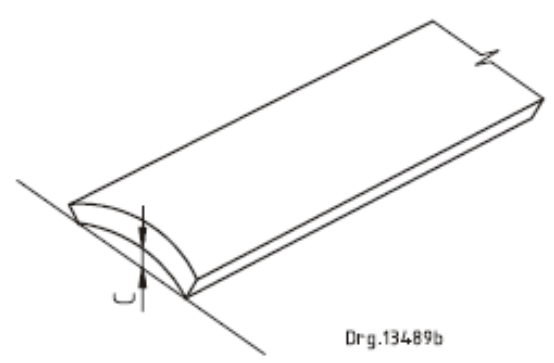

Figure 7: Cup at short edge of board (SANS 1707-1, 2010)

Spring, as shown in Figure 8 is a "lengthwise curvature, in its own plane, of the face side of a piece".

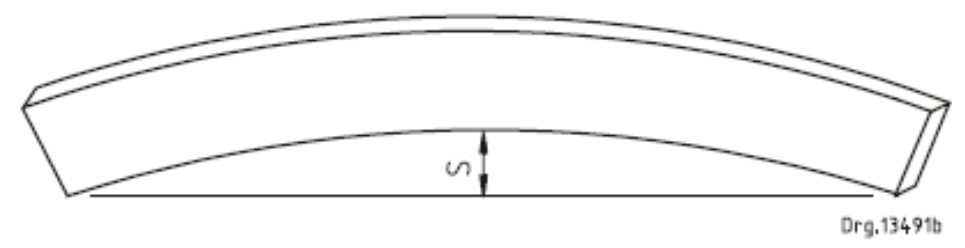

Figure 8: Spring (SANS 1707-1, 2010)

Twist is a "form of warp that appears as a lengthwise spiral distortion in a piece" which is shown in Figure 9 (SANS 1707-1, 2010).

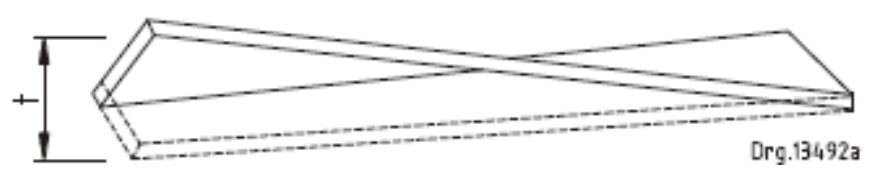

Figure 9: Twist (SANS 1707-1, 2010)

\subsubsection{Important properties for roof truss design}

In structural timber design codes, values for six different strength properties and a modulus of elasticity value are specified for use in design. This can pose a problem when a new material needs to be investigated as the testing of all of the mechanical properties is often prohibitively expensive or time consuming for researchers or companies to do. Thus to achieve the size of data sets required to obtain accurate results, only one or two of the properties are commonly investigated. It is of value then to determine which property is most critical for the end use of the material being evaluated. 
Approximately $75 \%$ of South African sawn lumber is graded to be used for structural purposes, the construction of roof trusses is the largest end use of this lumber (Crickmay and Associates, 2014). An investigation was completed by Wessels and Petersen (2015) to determine which property is most influential in the design of nail-plated roof trusses. The relative capacity utilization of the relative strength and stiffness characteristics of roof truss members from 30 randomly selected roof truss designs were analysed.

Of the material properties investigated, the bending strength (MOR) was found to be the most influential. It was thus suggested that the flexural strength of a material be analysed for cases where roof trusses are the end use of the material. This is advantageous as the modulus of elasticity can be obtained concurrently when the modulus of rupture of a sample is tested. The modulus of elasticity is deemed to be a very good individual predictor of timber strength (Thelandersson and Larsen, 2003).

\subsubsection{Adhesion theory}

Adhesives are used as an alternative to bolted or other mechanical connections to produce bonded timber products. By bonding the timber certain properties can be homogenised, various dimensional products can be created and lower quality timber can be used to produce value added products. Adhesives are commonly used in the production of engineered timber elements such as cross laminated timber (CLT), finger-jointed boards, particle board, glulam and plywood (Gardner et al., 2014; Sterley, 2004).

The adhesive bonding is able to occur due to the porosity of the wood. This porosity allows the viscous adhesive to be absorbed into the cellular structure of the timber where it sets to provide the bond strength (Gardner et al., 2014). Mechanical interlocking is the term used to define the physical interaction between the adhesive and cellular structure. The adhesive enters into the tissue of the wood either through "gross penetration" or "cell wall penetration" (Kamke \& Lee, 2007). Gross penetration refers to the forced flow of adhesive into the cell lumina as a result of the compression applied to the timber during clamping. Cell wall penetration is defined as the diffusion of the adhesive into the cell structure due to the opposing elements within the adhesive and wood striving to reach a neutral state (Kamke \& Lee, 2007). Thus the possible penetration 
of the adhesive into the wood and subsequent bond strength is limited by the porosity of the wood along with the clamp time and clamping pressure applied during gluing.

There are two main adhesive types which are predominantly used in the structural timber industry, melamine urea formaldehyde resins (MUR) and polyurethane resins (PUR). The MUR adhesives consist of potentially harmful carcinogen-containing formaldehydes which has led to the increased popularity of PUR adhesives (Crespell and Gagnon, 2010). One-component polyurethane adhesives (1C-PUR) were introduced into the structural timber industry over two decades ago and have since been widely accepted as the adhesive of choice when producing engineered timber products (Lehringer and Gabriel, 2014). Benefits noted compared to traditionally used MUR adhesives include the fact that no mixing is required, lower press times are needed, invisible bond-lines are formed, quick bonding at room temperature and a long shelf life. Ductile bond-lines are another positive characteristic compared to MUR adhesives which causes a higher fracture strength of the system while reducing peak stresses at the interface between the wood tissue and adhesives.

The 1C-PUR adhesives enable "green-gluing" (gluing when the moisture content of the wood is above fibre saturation point) as the moisture in the wood acts as the second component of the adhesive system which causes "moisture curing". This is advantageous as the gluing can take place at the saw-mill without the need of first drying the timber and thus streamlining the production flow.

\subsubsection{Flexural properties of SA pine}

An investigation into the strength properties of ungraded structural SA pine from various resources around South Africa was completed by Crafford and Wessels (2011). A total of 1833 SA pine specimens physical properties were measure before being destructively tested in flexure. This was done with the aim of (a) evaluating the bending strength and stiffness of a representative set of SA pine, (b) to evaluate a new structural grading system and (c) to compare and test calculation methods provided in SANS 6122 (2008).

The MOR results obtained for tests completed on un-graded boards with dimensions of $36 \mathrm{x}$ $111 \mathrm{~mm}$ (thickness $\mathrm{x}$ width) are shown in Table 2 along with the MOE results being provided 
in Table 3. Shown here all sawmills achieved high variation in MOR results with sawmill 1 having the best COV of $35.7 \%$ and sawmill 3 having the largest variability on $44.7 \%$. Three of the sawmills had bending strengths above the required 5th percentile value of $15.8 \mathrm{MPa}$ for structural grade S7. Sawmill 3 conformed to the requirements of S5 (11.5 MPa) while sawmill 5 only achieved a 5 th percentile MOR value of $11.1 \mathrm{MPa}$ which is below the requirement of grade S5. It is interesting to note the variation of results obtained between the sawmills from the different regions as the same species is being grown. These select results are listed here as they are of similarly sized specimens as the engineered Eucalyptus grandis tested in this study which allows for comparisons to be drawn.

Table 2: MOR results of ungraded SA pine from various sources (36 x $111 \mathrm{~mm}$ boards) (Crafford and Wessels, 2011)

\begin{tabular}{|c|c|c|c|c|}
\hline MOR & $\begin{array}{c}\text { Mean } \\
(\mathbf{M P a})\end{array}$ & $\begin{array}{c}\text { Std Dev } \\
\text { (MPa) }\end{array}$ & $\begin{array}{c}\text { COV } \\
(\%)\end{array}$ & $\begin{array}{c}\text { 5th Perc } \\
\text { (MPa) }\end{array}$ \\
\hline Sawmill 1 & 39.6 & 14.1 & 35.7 & 21.0 \\
\hline Sawmill 2 & 35.6 & 15.7 & 44 & 17.2 \\
\hline Sawmill 3 & 35.6 & 15.9 & 44.7 & 15.0 \\
\hline Sawmill 4 & 37.5 & 16.1 & 42.8 & 19.2 \\
\hline Sawmill 5 & 27.3 & 11.5 & 43.8 & 11.1 \\
\hline
\end{tabular}

Table 3: MOE results of ungraded SA pine from various sources (36 x $111 \mathrm{~mm}$ boards) (Crafford and Wessels, 2011)

\begin{tabular}{|c|c|c|c|c|}
\hline MOE & $\begin{array}{c}\text { Mean } \\
\text { (MPa) }\end{array}$ & $\begin{array}{c}\text { Std Dev } \\
\text { (MPa) }\end{array}$ & $\begin{array}{c}\text { COV } \\
(\mathbf{\%})\end{array}$ & $\begin{array}{c}\text { 5th Perc } \\
(\mathbf{M P a})\end{array}$ \\
\hline Sawmill 1 & 9961 & 1854 & 18.6 & 6732 \\
\hline Sawmill 2 & 8273 & 2066 & 25 & 5488 \\
\hline Sawmill 3 & 7899 & 2160 & 27.3 & 4534 \\
\hline Sawmill 4 & 8060 & 2491 & 30.9 & 4512 \\
\hline Sawmill 5 & 6876 & 2182 & 31.7 & 3438 \\
\hline
\end{tabular}

Poorer results were obtained for the stiffness of the SA pine where only one sawmill had achieved a $5^{\text {th }}$ percentile value above grade S7 limits (5700 MPa) and one sawmill conforming to grade S5 requirements of a $5^{\text {th }}$ percentile above $4630 \mathrm{MPa}$. The remaining three sawmills had not achieved results high enough to qualify for any of the structural grades. A large spread in variation of results was noted with the best performing sawmill having a COV of $18.6 \%$ as opposed to the worst performing sawmill with a COV of $31.7 \%$. 


\subsection{Mechanical and physical properties of young, green Eucalyptus grandis timber}

A study was completed by Crafford (2013) to determine the potential of young, green fingerjointed Eucalyptus grandis lumber for the use as a structural component in roof trusses. The objectives of this study were:

- Determine the characteristic strength and stiffness values of unseasoned and dried fingerjointed Eucalyptus boards and determine the variation between the different ages and dimensions of the timber;

- Investigate variation in density, warp and checking in the timber when dried in a simulated roof-space environment;

- Evaluate the potential of this product to be used as a structural element in roof trusses.

The materials, methods, results and conclusions of this study are discussed in this chapter.

\subsubsection{Materials and methods}

The timber used for the investigation was provided by the Diggersrest mill in Limpopo province in South Africa with an age distribution of 5,11 and 18 years. The trees were felled and left in the field for 6 weeks during the wet season of the area. The felled lumber was then processed into dimensional timber of $50 \times 76 \mathrm{~mm}$ and $38 \times 114 \mathrm{~mm}$. As part of the Biligom concept, major defects were removed from the timber by cross-cutting sections of major defects and then finger-jointing the boards back together in the green state. Once the finger-jointed bonds had cured for 40 minutes, the timber was planned to structural size timber with dimensions of $48 \mathrm{x}$ $73 \mathrm{~mm}$ and $36 \times 111 \mathrm{~mm}$. The processed timber was then wrapped in plastic to prevent drying during transportation and delivered to Stellenbosch University.

Upon arrival the 220 long length boards were divided into two groups, one destined for testing in the green state (moisture content above fibre saturation point) while the other group was tested in the dry state (moisture content below fibre saturation point). The boards were then processed into 720 specimens to be destructively tested. The concept for the timber is that in practice the roof trusses would be manufactured and placed in the roof space in the wet state where they would subsequently dry while fixed in place. With the aim of replicating the 
conditions of the roof space, the batch of timber that was to be tested under dry conditions was placed in a greenhouse to dry for approximately nine weeks allowing for equilibrium moisture content to be reached.

The group of specimens that were to be used for bending tests in the dry state were measured before and after drying to determine the extent of warp, checking, splitting and shrinkage in the specimens. These dimensions were taken using an electronic calliper allowing for the shrinkage to be determined. The warp of the specimens including bow, cup and twist as defined in were measured on an apparatus which consisted of three equal length index pins which support the board at three of the four corners allowing for the deformation to be measured. Surface defects such as cracks, checks and splitting found on the specimens were measured for maximum length, width and position.

The bending parallel to grain destructive testing were completed using an Instron testing apparatus which was set-up for four point bending tests. The specimens were orientated with random defect placement for both the wet and dry test batches as prescribed by the SANS 6122 (2008) standards. A total of 200 specimens were tested in bending while an equivalent number was tested in tension parallel to grain according to the method prescribed in SANS 6122 (2008). Bending tests were completed on the dry batch before drying while wet to a low stress level of 6.3 MPa to allow for the modulus of elasticity (MOE) to be measured. The MOE could then be determined using the destructive testing in the dry state to allow for a direct comparison to be made between the wet and dry states of the same specimens.

Compression parallel to grain, shear, tension and compression perpendicular to grain destructive tests were completed with random defect placement according to the AZ/NZS 4063 (2010) standard. It was decided to use random defect placement for these tests as the new SANS 6122 (2008) draft version had prescribed random defect placement but was not yet published at the time of the study thus the decision was made to complete the tests according to the AZ/NZS 4063 (2010) specifications.

The maximum moisture content method (Diana Smith) was used to calculate the basic density for small wood samples was followed for the density calculation (Smith, 1954). Density samples were cut as $20 \mathrm{~mm}$ wide pieces from each laminate in the destructively tested samples. 
These density samples were cut from defect free areas of the laminates and additionally allowed for the moisture content at the time of testing to accurately be determined.

\subsubsection{Discussion of results}

Virtually no specimens in the green state failed the limitations set out in SANS 1783-2 (2012) for checking, split and warp. This attribute is considered to be valuable for this resource as the timber is to be fixed in place in the green state, full scale truss models are to be tested in order to determine if any drying defects could affect the truss structures. The testing of the full scale trusses was completed by MiTek Industries SA (Pty) Ltd who have since endorsed the material and included it into their roof truss design software.

The warping defects of bow, spring, twist and cup were analysed once the specimens had dried under the severe conditions of the green house. The percentage of boards not conforming to the SANS 1783-2 (2012) requirements for warping defects are shown in Table 4 below.

Table 4: Percentage of the 200 dry samples which did not conform to warp requirements (Crafford, 2013)

\begin{tabular}{|c|c|c|c|c|c|c|c|c|}
\hline Warp & Bow & Spring & \multicolumn{3}{|c|}{ Twist } & \multicolumn{3}{|c|}{ Cup } \\
\hline $\begin{array}{c}\text { Dimension Group } \\
(\mathbf{m m})\end{array}$ & Total & Total & Total & $43 \times 73$ & $36 \times 111$ & Total & $43 \times 73$ & $36 \times 111$ \\
\hline Rejected (\%) & 0 & 0 & 30 & 45 & 14 & 0.5 & 1 & 0 \\
\hline
\end{tabular}

Although approximately $30 \%$ of the specimens did not conform to the twist limitations, it did perform considerably better than young Pinus Patula as tested by Dowse (2010) with a failure rate of $57 \%$. This could be attributed to the finger-jointing of the young Eucalyptus grandis resource assisting to average out the twist in the boards as not all laminates in the board will twist to the same extent or in the same direction.

The percentage of boards from the dry sample set that would have been rejected due to checking and end splitting according to the SANS 1783-2 (2012) requirements are shown in Table 5. The visual aspect of these defects are not of particular concern for the desired use of this resource as it is to be used within roof structures. The higher level of checking experienced in the group 
consisting of the smaller dimensional timber is believed to be caused by the larger overall portion of the board consisting of the pith material.

Table 5: Percentage of dry samples that would have been rejected due to checking and end-splitting requirements set out in SANS 1783-2 (2012) (Crafford, 2013)

\begin{tabular}{|c|c|c|c|c|c|c|}
\hline Defect & \multicolumn{3}{|c|}{ Checks } & \multicolumn{3}{c|}{ End-splits } \\
\hline Dimension Group (mm) & Total & $43 \times 73$ & $36 \times 111$ & Total & $43 \times 73$ & $36 \times 111$ \\
\hline Rejected (\%) & 35,5 & 54 & 17 & 1.5 & 1 & 2 \\
\hline
\end{tabular}

The mean shrinkage of the different age group boards is listed in Table 6 . The shrinkage of the boards was measured as being the percentage of dimensional decrease of the boards from the green to dry state, thus a combination of radial and tangential shrinkage was represented.

Table 6: Mean shrinkage (\%) of the different age groups (Crafford, 2013)

\begin{tabular}{|c|c|c|c|}
\hline Age (years) & $\mathbf{5}$ & $\mathbf{1 1}$ & $\mathbf{1 8}$ \\
\hline Shrinkage (\%) & 2.1 & 2.9 & 3.3 \\
\hline Number & 40 & 120 & 40 \\
\hline
\end{tabular}

The results obtained from the destructive tests of the wet and dry samples completed in accordance to the SANS 6122 (2008) and AS/NZ 4063 (2010) are displayed in Table 7. The required characteristic stress values for each structural grade for the various strength properties are also provided in the table for SA pine (SANS 10163-1, 2005). 
Table 7: Results of destructive tests completed on the wet and dry green-glued fingerjointed $E$. grandis timber along with the corresponding characteristic grade stresses of SANS 10163-1 (2005) (Crafford, 2013)

\begin{tabular}{|c|c|c|c|c|c|c|c|c|c|c|c|}
\hline \multirow{2}{*}{$\begin{array}{l}\text { Strength } \\
\text { Property }\end{array}$} & \multicolumn{4}{|c|}{ Wet Specimens } & \multicolumn{4}{|c|}{ Dry Specimens } & \multicolumn{3}{|c|}{$\begin{array}{c}\text { SANS } \\
\text { Characteristic } \\
\text { Grade Value }\end{array}$} \\
\hline & $\mathbf{n}$ & Min & $\begin{array}{l}\text { 5th } \\
\text { Perc }\end{array}$ & Mean & $\mathbf{n}$ & Min & $\begin{array}{l}\text { 5th } \\
\text { Perc }\end{array}$ & Mean & & Perc & Mean \\
\hline $\begin{array}{c}\text { Bending } \\
\text { (MPa) - MOR }\end{array}$ & 100 & 14.9 & 20.8 & 37.1 & 100 & 19.5 & 25.9 & 43.7 & \begin{tabular}{|l|} 
S5 \\
S7 \\
S10 \\
\end{tabular} & $\begin{array}{l}11.5 \\
15.8 \\
23.3 \\
\end{array}$ & - \\
\hline $\begin{array}{c}\text { Modulus of } \\
\text { Elasticity } \\
\text { (MPa) }\end{array}$ & 100 & 5355 & 7041 & 9900 & 100 & 5945 & 7334 & 9826 & \begin{tabular}{|l|} 
S5 \\
S7 \\
S10 \\
\end{tabular} & $\begin{array}{l}4630 \\
5700 \\
7130 \\
\end{array}$ & $\begin{array}{r}7800 \\
9600 \\
12000 \\
\end{array}$ \\
\hline $\begin{array}{c}\text { Tensile } \| \\
\text { (MPa) }\end{array}$ & 100 & 3.3 & 14.9 & 21.1 & 100 & 11.3 & 14.1 & 20.7 & \begin{tabular}{|l|} 
S5 \\
S7 \\
S10
\end{tabular} & $\begin{array}{r}6.7 \\
10 \\
13.3 \\
\end{array}$ & - \\
\hline $\begin{array}{c}\text { Tensile } \\
\text { (MPa) }\end{array}$ & 40 & 0.2 & 0.48 & 0.9 & 40 & 0.28 & 0.3 & 1.04 & \begin{tabular}{|l|} 
S5 \\
S7 \\
S10 \\
\end{tabular} & $\begin{array}{l}0.36 \\
0.51 \\
0.73 \\
\end{array}$ & - \\
\hline $\begin{array}{c}\text { Compression } \\
\|(\mathbf{M P a})\end{array}$ & 40 & 15.4 & 19.3 & 24 & 40 & 24.8 & 24.8 & 26.3 & \begin{tabular}{|l|} 
S5 \\
S7 \\
S10 \\
\end{tabular} & $\begin{array}{r}18 \\
22.8 \\
26.2 \\
\end{array}$ & - \\
\hline $\begin{array}{c}\text { Compression } \\
\cdot(\mathrm{MPa})\end{array}$ & 40 & 3.85 & 4.16 & 5.8 & 40 & 2.92 & 3.91 & 7.75 & \begin{tabular}{|l} 
S5 \\
S7 \\
S10
\end{tabular} & $\begin{array}{l}4.7 \\
6.7 \\
9.1 \\
\end{array}$ & - \\
\hline $\begin{array}{c}\text { Shear } \\
\text { Strength } \\
\text { (MPa) }\end{array}$ & 40 & 1.55 & 2.21 & 3.6 & 40 & 2.15 & 2.7 & 2.3 & \begin{tabular}{|l} 
S5 \\
S7 \\
S10
\end{tabular} & $\begin{array}{r}1.6 \\
2 \\
2.9\end{array}$ & - \\
\hline
\end{tabular}

The timber specimens exhibited strong bending strength (MOR) results in both the wet and dry state achieving characteristic values above the grade $\mathrm{S} 7$ requirements for the wet samples and above the grade S10 requirements for the dry samples. The minimum values recorded were above the grade S7 fifth percentile requirements which provides confidence in the strength of the material for cases where little to no load sharing occurs. High MOE values were obtained when compared to young or even mature pine. Commonly a small amount of grade S7 is achieved for MOE in testing of mature pine while the young finger-jointed resource achieved the grade $\mathrm{S} 7$ fifth percentile requirements. 
The tensile strength parallel to grain strength achieved grade S10 strength requirements and appears unaffected by the variation in moisture content. During the testing of tensile parallel to grain, all the finger-joints in the board are loaded thus showing that the finger-joints have adequate strength characteristics. Low values were obtained for tensile perpendicular to grain strength. This is of little concern for the design of roof trusses as the nail plate connections are not affected by this property. The low values could cause concern if bolt connections are used as checking defects could cause poor strength in the connection.

Compression perpendicular to the grain exhibited values below the required strength for grade S5. The strength value for compression perpendicular to grain is of little importance for the design of nail platted roof trusses. Shear results conformed to grade S7 requirements for the wet and dry tests with the mean of the dry group being statistically significantly lower than the wet group.

\subsection{Structural reliability and safety}

\subsubsection{Safety concept and levels}

Safety concepts that are used to govern structural design are used to guarantee a minimum performance of a structure. Four main safety concepts are used, each with varying methods of preventing structural failure, damage or serviceability limit failure of the structure. These concepts have the fundamental basis of the numerical relationship between the load applied and resistance of the structure. The background information provided in this chapter is based on more detailed observations on the subject described in the Reliability Handbook (2005), Reliability analysis for structural design (Holicky, 2009), EN 1990 (2010), Faber (2007) and additional information provided by the Joint Committee on Structural Safety (JCSS, 2001) in their probabilistic model codes and course content.

The first approach, Level 0, is known as the conventional deterministic concept which makes use of a single "global" safety factor. This method does not individually modify the elements involved in the limit state equation. The Level 1, semi probabilistic approach is the most widely used safety concept and is taken as standard. The Level 1 approach allows for the load effect and resistance variables to be modified individually by a respective partial factor in the limit 
state equation. This allows for variations in the characteristics of the elements effecting the resistance of load of the structure to be treated individually. A reliability index $\beta$ (target reliability) is used for the Level 2 probabilistic approximation safety concept. The reliability index is used to predict the possibility of events occurring which could result in structural failure. The remaining safety concepts are listed in Table 8 along with the concepts discussed above. The semi-probabilistic Level 1 safety concept is the most widely used in South African structural design codes and is thus used as the standard safety concept for this study. Basic concepts of structural reliability theory is discussed followed by the concepts involved in obtaining material partial factors is to be described in the following section.

Table 8: Safety concepts (Braml, 2010)

\begin{tabular}{|c|c|c|c|}
\hline Safety Concept & Level & Reliability Dimension & General Equation \\
\hline $\begin{array}{c}\text { Conventional } \\
\text { deterministic }\end{array}$ & 0 & Central safety factor $\gamma$ & $\begin{array}{c}\gamma=R / E \geq \operatorname{code} \gamma \\
(R=\text { Resistance, E=Load })\end{array}$ \\
\hline Semi probabilistic & 1 & $\begin{array}{c}\text { Partial safety factors for } \\
\text { resistance } R\left(\gamma_{R}\right) \text { and for the load } E\left(\gamma_{E}\right)\end{array}$ & $R / \gamma_{R} \leq \gamma_{s} \cdot E$ \\
\hline $\begin{array}{c}\text { Probabilistic } \\
\text { approximation }\end{array}$ & 2 & Reliability index $\beta$ & existing $\beta$ - required $\beta \geq 0$ \\
\hline $\begin{array}{c}\text { Probabilistic } \\
\text { accuracy }\end{array}$ & 3 & Probability of failure $P_{f}$ & permissible $P_{f}$ - exist. $P_{f} \geq 0$ \\
\hline $\begin{array}{c}\text { Economic } \\
\text { optimum }\end{array}$ & 4 & $\begin{array}{c}\text { Permissible probability of failure } P_{f}, \\
\text { required reliability index } \beta\end{array}$ & optimization reliability \\
\hline
\end{tabular}

\subsubsection{Random variable}

A random variable $X$ is defined as being a variable that can attain only one value $x$ which is formerly unknown when a set of conditions $\pi$ are realised during the occurrence of a random event. These outcomes commonly depend on variables which are not fully understood, thus random variables are used to describe realisations in structural engineering, for example, the force obtained at failure of a concrete test specimen loaded under certain conditions (Holicky, 2009). A population consists of all the possible realisations of a random variable and can be described by a distribution of probabilities. The probability that a random variable $X$ will be less than or equal to $x$ is described by the distribution function $F_{x}(x)$ as shown below: 


$$
F_{x}(x)=P(X \leq x)
$$

The probability density function $f_{x}(x)$ is defined by the derivative of the cumulative distribution function. The probability density function also describes the probability of $x$ occurring within an interval $\left(x_{1}, x_{2}\right)$ through the integration of the surface within the interval. The integral of the probability density function is equal to 1 within its definition domain.

$$
\begin{gathered}
f_{x}(x)=\frac{d F(x)}{d x} \\
F_{x}(x)=\int_{-\infty}^{x} f(u) d u \\
P\left(x_{1}<x<x_{2}\right)=\int_{x_{1}}^{x_{2}} f(x) d x
\end{gathered}
$$

Moment parameters are frequently used to describe the random variables along with distribution functions and probability density functions. The mean $\mu$ is deemed to be the fundamental moment parameter and is defined by the first order moment about the origin.

$$
\mu=\int x f(x) d x
$$

The variance $\sigma^{2}$ is a measure of the dispersion of the random variable relative to the mean. This is the second moment of the distribution function.

$$
\sigma^{2}=\int(x-u)^{2} f(x) d x
$$

The standard deviation of the random, variable is denoted by the square root of the variance.

$$
\sigma=\sqrt{\sigma^{2}}
$$

The coefficient of variation $V$ is a dimensionless parameter which describes the population as a ratio of the standard deviation to the mean. 


$$
V=\frac{\sigma}{\mu}
$$

This provides a measure of the relative dispersion of the population. It however should not be used in situations where the mean is close to zero, as the coefficient of variation will thus tend to infinity. In such cases it is advised that the standard deviation be used to indicate the dispersion. In the practical analysis of a sample set, it is necessary to determine which distribution function is the most suitable for use for the modelling.

\subsubsection{Normal Distribution}

The normal distribution is deemed to be one of the most important distribution functions and is commonly used to model various random variables in structural engineering, describing loads, mechanical properties and geometrical properties. It has a symmetric distribution and can be defined on an unlimited interval $-\infty<x<\infty$ and is dependent on only two parameters, namely the mean $\mu$ and standard deviation $\sigma$. The symbolic notation of $\mathrm{N}(\mu, \sigma)$ is used for the normal distribution. The exponential expression provided below is the numerical definition of the probability density function for a random variable $X$.

$$
F_{x}(x)=\frac{1}{\sigma_{x} \sqrt{2 \pi}} \exp \left[-\frac{1}{2}\left(\frac{x-\mu_{x}}{\sigma_{x}}\right)\right]
$$

The standardised form of the normal distribution has great practical use. The standard normal distribution has a distribution function with a mean of zero and a standard deviation of one. The standardized variable is given as $U$ and is determined from the actual variable using the Equation 13 provided below.

$$
U=\frac{x-\mu_{x}}{\sigma_{x}}
$$

Here $\mu_{x}$ and $\sigma_{x}$ are the mean and standard deviation of the actual variable $X$. This standard normal distribution is denoted by $\mathrm{N}(0,1)$. The probability density function is provided below for the standard normal variable, accompanied by a Figure 10 of the standardized normal distribution. 


$$
\varphi(u)=\frac{1}{\sqrt{2 \pi}} \exp \left(-\frac{u^{2}}{2}\right)
$$

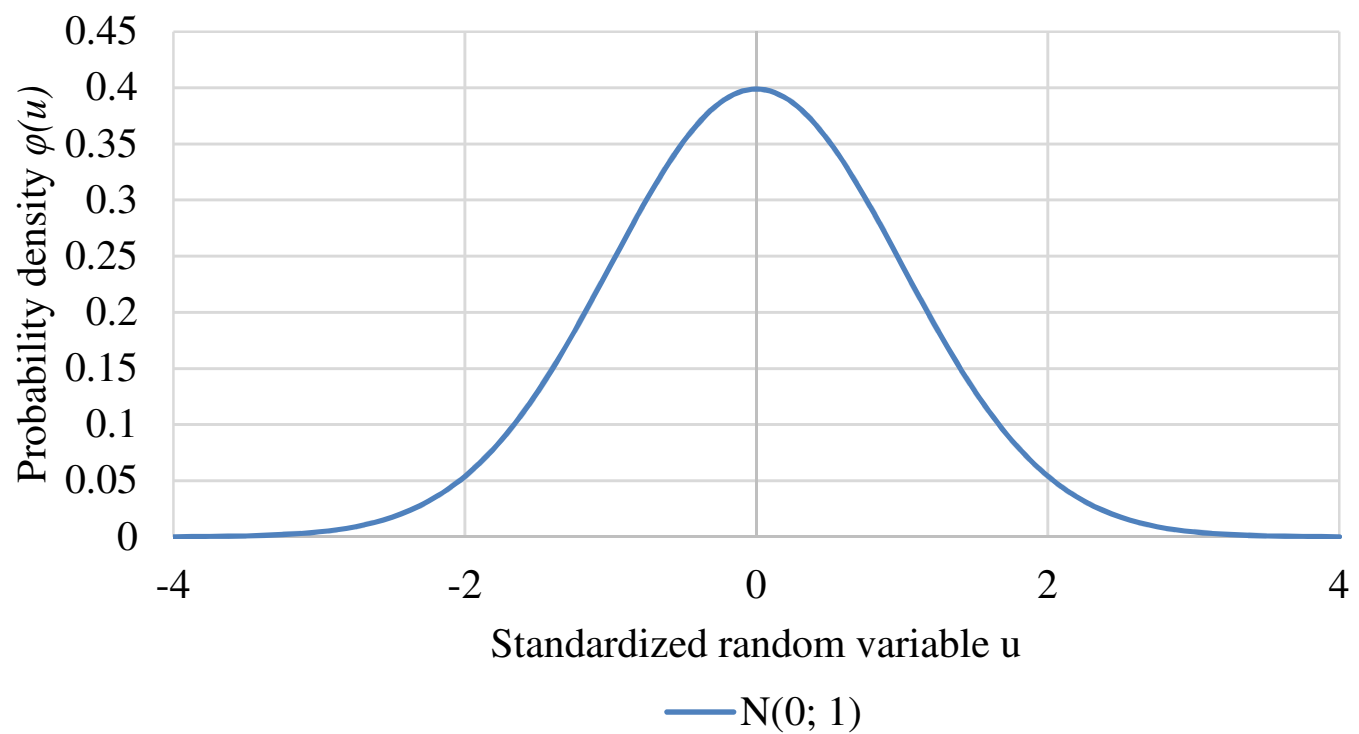

Figure 10: Probability density function for the standard normal distribution

\subsubsection{Lognormal Distribution}

The lognormal distribution is a commonly used distribution function in structural engineering. It has a one-sided distribution with a limit interval of $x_{0}<x<\infty$ or $-\infty<x<x_{o}$ which is a positive characteristic for describing cases such as the flexural strength of a material which could not be negative. Another useful characteristic of the lognormal distribution is that it can be used to depict unsymmetrical distributions. This distribution is regularly denoted as $\mathrm{LN}(\mu, \sigma, \omega)$ where the mean $\mu$, standard deviation $\sigma$ and skewness $\omega$ describe the distribution. A random variable $X$ is deemed to have a lognormal distribution if the transformed variable has a normal distribution.

$$
Y=\ln X
$$

When the skewness of the distribution is not taken into account, the distribution is referred to as the 2-parameter lognormal distribution. The cumulative and probability density functions are 
depicted in Equation 17 and Equation 18 with the accompanying parameters in Equation 19 and Equation 20.

$$
\begin{gathered}
F_{x}(x)=\Phi\left(\frac{\ln \left(\frac{x}{\xi}\right)}{\delta}\right) \\
f_{x}(x)=\frac{1}{x \delta \sqrt{2 \pi}} \exp \left(-\frac{1}{2}\left(\frac{\ln \left(\frac{x}{\xi}\right)}{\delta}\right)^{2}\right) \\
\delta^{2}=\ln \left(V_{x}^{2}+1\right) \\
\xi=\frac{\mu_{x}}{\sqrt{V_{x}+1}}
\end{gathered}
$$

The probability density functions for the normal and lognormal distributions are displayed in Figure 11 for equivalent parameters. This figure depicts the asymmetrical nature of the lognormal distributions and the one-sided values when compared to the normal distribution.

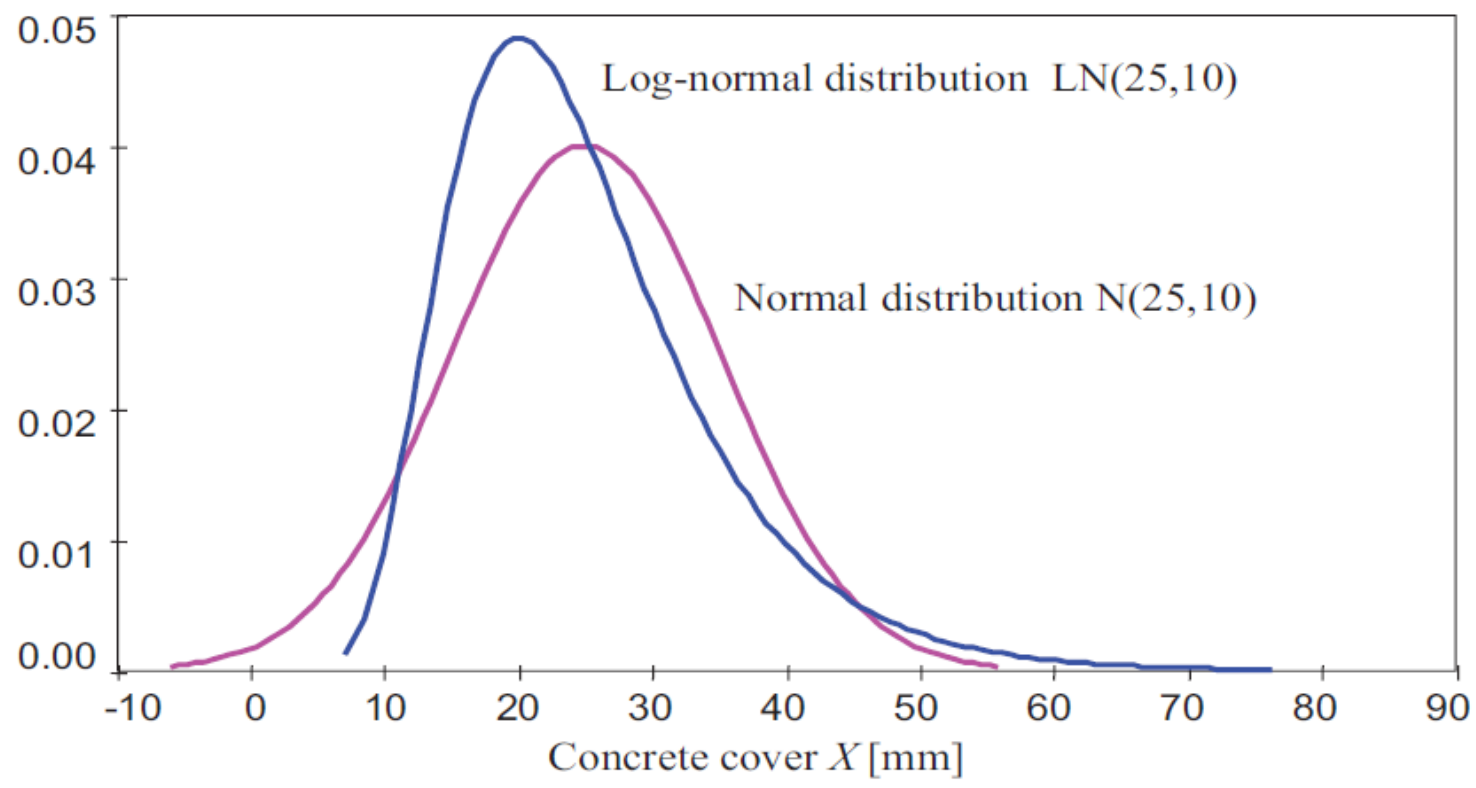

Figure 11: Comparison of probability density functions for normal and lognormal distributions (Holicky, 2009) 
The transformed variable for the 3-parameter lognormal distribution is expressed in Equation 21 where the skewness $\omega_{x}$ is taken into account through the introduction of the lower or upper bound parameter $x_{o}$.

$$
Y=\ln \left|X-x_{o}\right|
$$

Here the lower or upper bound parameter can be expressed as shown in Equation 22 using the mean $\mu_{x}$, standard deviation $\sigma_{x}$ and the coefficient $c$ which is determined by the skewness $\omega_{x}$.

$$
\begin{gathered}
x_{o}=\mu_{x}-\frac{\sigma_{x}}{c} \\
\omega_{x}=c^{3}+3 c^{3} \\
c=\left(\sqrt{\omega_{x}^{3}+4}+\omega_{x}\right)^{\frac{1}{3}}-\left(\sqrt{\omega_{x}^{3}+4}+\omega_{x}\right)^{\frac{1}{3}} \cdot 2^{\frac{-1}{3}}
\end{gathered}
$$

Figure 12 shows the influence of the introduction of the skewness on the lognormal distribution.

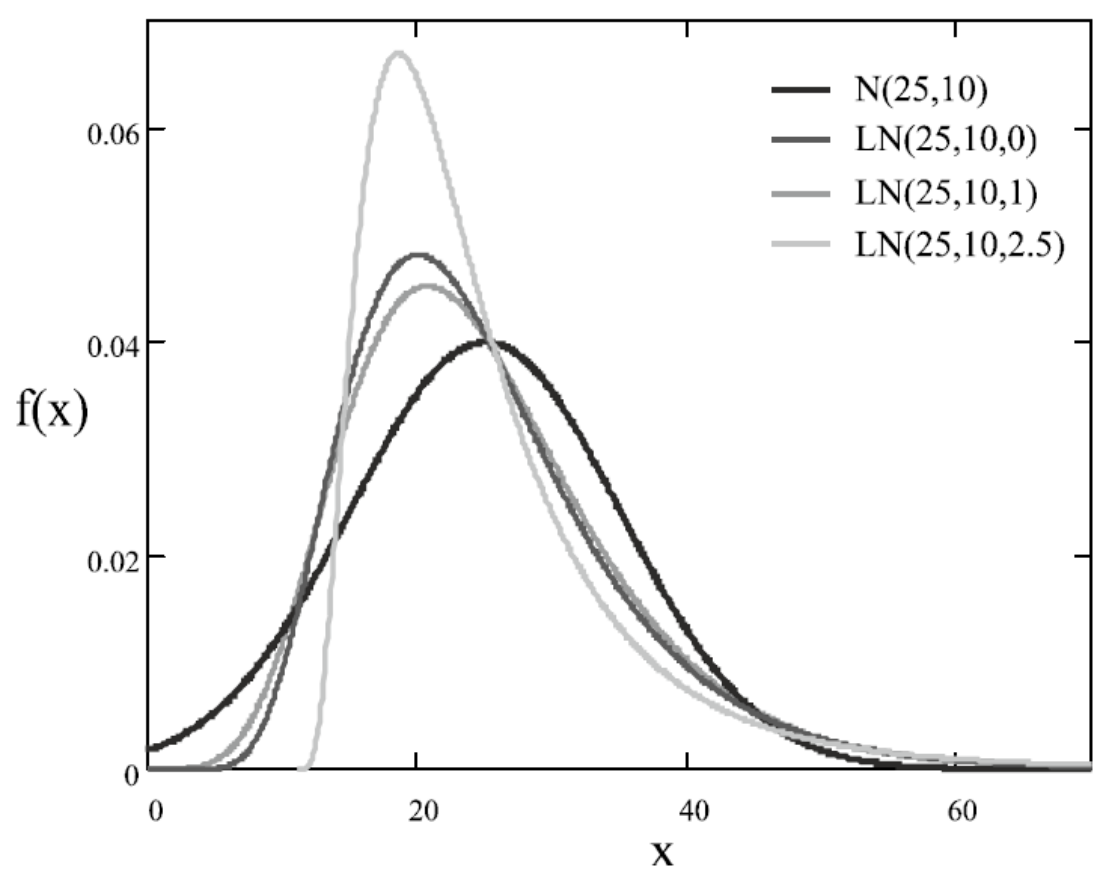

Figure 12: Illustration of probability density functions for normal and three-parameter lognormal distributions (Lenner, 2014) 
The normal and lognormal distributions are the only distributions utilized in this study and are thus discussed in detail. For further definitions on the remaining distribution functions commonly encountered in structural engineering, the reader may consult (Holicky, 2009).

\subsubsection{Elementary reliability calculations}

The fundamental association to be analysed during structural reliability calculations is the relationship between the action effect $E$ and resistance $R$. The basic requirement is that the resistance is to exceed the action effect as described by the equality in Equation 25.

$$
E<R
$$

This inequality describes the safe (satisfactory) state of a structural element where as if the inequality is not satisfied it is assumed that failure of the element would occur. Thus a definitive distinction is produced between the failure and safe states as depicted by Equation 26 .

$$
R-E=0
$$

An assumption of a definitive boundary between failure and safe states may not always be practical for all structural elements and materials. A margin of safety $M$ is introduced by assuming that both of the basic variables, action effect $E$ and resistance $R$, are normally distributed. Equation 27 then represents the evaluation of the action effect and resistance relationship.

$$
M=R-E
$$

The margin of safety then has a normal distribution with moment parameters as described in Equation 28 and Equation 29.

$$
\begin{gathered}
\mu_{M}=\mu_{R}-\mu_{E} \\
\sigma_{M}{ }^{2}=\sigma_{R}{ }^{2}+\sigma_{E}{ }^{2}+2 \rho_{R E} \cdot \sigma_{R}{ }^{2} \cdot \sigma_{E}{ }^{2}
\end{gathered}
$$

Here $\rho_{R E}$ represents the correlation coefficient between the resistance and action effect variables. $R$ and $E$ can often be assumed to be mutually independent in structural engineering 
applications which results in $\rho_{R E}=0$. The margin of safety can be expressed as a probability of failure as the inequality described in Equation 25 may not always be guaranteed. Thus the relationship in Equation 30 is formulated for the probability that the resistance is surpassed by the action effect for a given structural element or alternatively a negative value for the margin of safety could be obtained.

$$
P_{f}=P(E>R)=P(M<0)
$$

The problem may then be reduced to the evaluation of the distribution function $\Phi(M)$ for the realization where $m=0$ which results in the probability of the safety margin to be negative.

$$
P_{f}=P(M<0)=\Phi_{M}(0)
$$

The transformation of the safety margin variable $M$ into the standardised variable $U$ is generally used to obtain the $\Phi(M)$ distribution function. Equation 32 displays the required realisation of $u_{0}$.

$$
u_{0}=\frac{0-\mu_{M}}{\sigma_{M}}=\frac{-\mu_{M}}{\sigma_{M}}
$$

Thus the probability of failure is expressed as shown in Equation 33.

$$
P_{f}=\Phi_{M}(0)=\Phi_{M}\left(u_{0}\right)
$$

The value of $-u_{0}$ is referred to as the reliability index $\beta$ when a normal distribution is assumed for $M$. The probability of failure is then expressed as:

$$
P_{f}=\Phi_{M}(-\beta)
$$

The reliability index can then be given by the relationship in Equation 35 as a result of Equation 31 and Equation 34.

$$
\beta=\frac{\mu_{M}}{\sigma_{M}}=\frac{\mu_{R}-\mu_{E}}{\sqrt{\sigma_{R}^{2}+\sigma_{E}^{2}+2 \rho_{R E} \cdot \sigma_{R}^{2} \cdot \sigma_{E}^{2}}}
$$


For this case the variables $E$ and $R$ are deemed to be mutually exclusive and thus the $\rho_{R E}=0$. The reliability index can thus be obtained as the distance of the mean $\mu_{M}$ from the origin in terms of the standard deviation $\sigma_{M}$ as depicted by Figure 13.
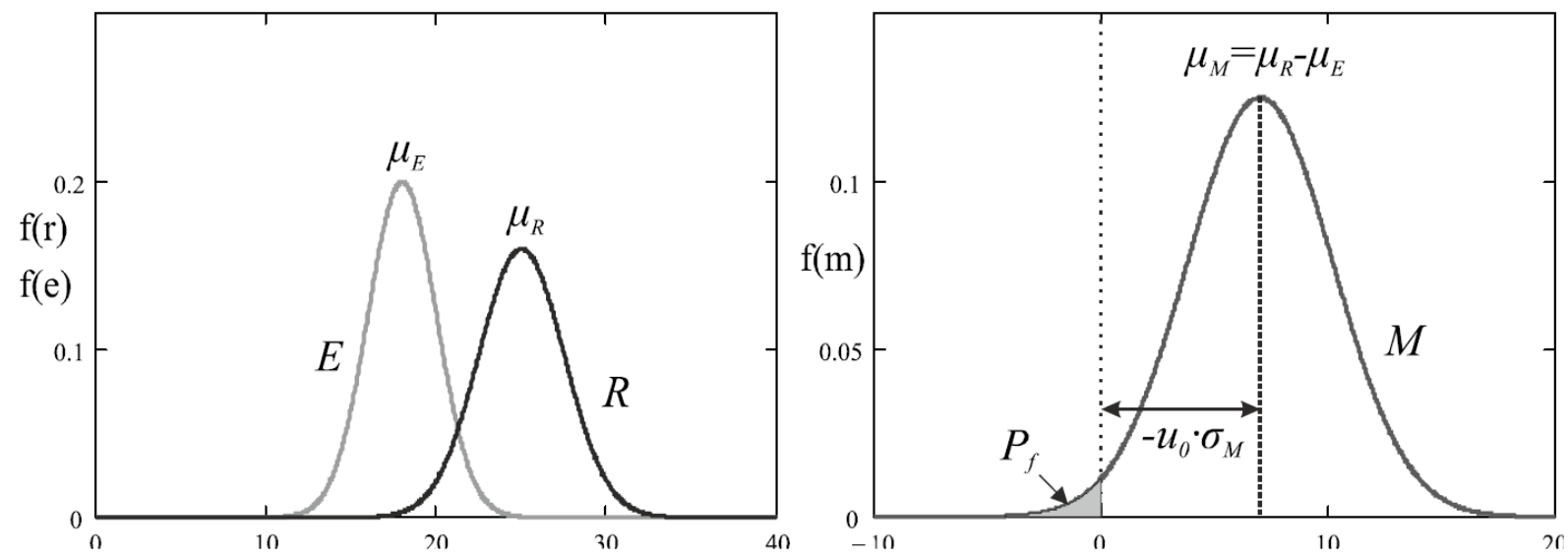

Figure 13: Action effect $E$ and resistance $R$ probability density functions $f(x)$; margin of safety $M$ distribution (Lenner, 2014).

The reliability index can thus inversely be represented by Equation 36 in terms of the probability of failure where $-\Phi^{-1}\left(P_{f}\right)$ denotes the inverse of a standardized normal distribution.

$$
\beta=-\Phi^{-1}\left(P_{f}\right)
$$

The relationship between $\beta$ and $P_{f}$ is represented in Table 9 as supplied as Table C1 in EN 1990 (2010).

Table 9: Relationship between $P_{f}$ and $\beta$ (EN 1990, 2010)

\begin{tabular}{|c|c|c|c|c|c|c|c|}
\hline$P_{f}$ & $10^{-1}$ & $10^{-2}$ & $10^{-3}$ & $10^{-4}$ & $10^{-5}$ & $10^{-6}$ & $10^{-7}$ \\
\hline$\beta$ & 1.28 & 2.32 & 3.09 & 3.72 & 4.27 & 4.27 & 5.20 \\
\hline
\end{tabular}

\subsubsection{Multivariate case}

The fundamental case which has been discussed above where the two random variables are normally distributed is not realistic for all structures. Thus the load and resistance can also be described as functions of basic variables represented by a vector $X$ with realisations $x$ as depicted in Equation 37 and Equation 38 (Faber, 2007). 


$$
\begin{gathered}
X=\left[X_{1}, X_{2}, X_{3}, \ldots . ., X_{n}\right] \\
x=\left[x_{1}, x_{2}, x_{3}, \ldots . . x_{n}\right]
\end{gathered}
$$

The functions of the resistance and loading in terms of the vector $X$ are shown in Equation 39 and Equation 40.

$$
\begin{aligned}
& R=f_{1}(X) \\
& E=f_{2}(X)
\end{aligned}
$$

Thus the margin of safety can be expressed as in Equation 41.

$$
M=R-E=f_{1}(X)-f_{2}(X)=g(X)
$$

The margin of safety is now a function and no longer a simple normally distributed variable. The function $g(X)$ introduced here is referred to as the limit state function which is an indicator of the structural behaviour. There are typically two outcomes, a state of failure where realisations of the random variables $X$ result in $g(X) \leq 0$ as depicted in Equation 42 or the converse safe state which is depicted in Equation 43.

$$
\begin{aligned}
& g(X)=g\left(X_{1}, X_{2}, X_{3}, \ldots . X_{n}\right) \leq 0 \\
& g(X)=g\left(X_{1}, X_{2}, X_{3}, \ldots . X_{n}\right)>0
\end{aligned}
$$

Setting $g(X)=0$ defines a $(n-1)$ dimensional hyper surface in the basic variable space spanned by the $n$ basic variables as noted by Faber (2007). The hyper surface represents the failure surface which separates realisations $x$ of the basic variables $X$ which result in failure from the realizations which result in the safe state referred to as the safe domain. Equation 44 provides and expression of the failure probability (Faber, 2007).

$$
P_{f}=\int_{g(x) \leq 0} f_{x}(x) d x
$$


Here the $f_{X}(x)$ represents the joint probability density function for $X$, the random variables. There is no trivial solution to the integral in Equation 44 and a solution can only be obtained for certain special cases. Thus approximation methods have been developed with the First Order Reliability Method otherwise referred to as FORM being the most widely used.

\subsubsection{Design point}

For this simplified determination of the design point, the basic variables described above of $E$ and $R$ are assumed to be independent and normally distributed. As depicted in Figure 14 the concentric circles represent the joint probability distribution function while the limit state function is assumed to be linear. Here the assumption of normality for the distribution and limit state functions allows for a simple solution of the determination of the design values. For cases where the random variables are not normally distributed, they are normalised into the standard normal space which is discussed in the following chapter.

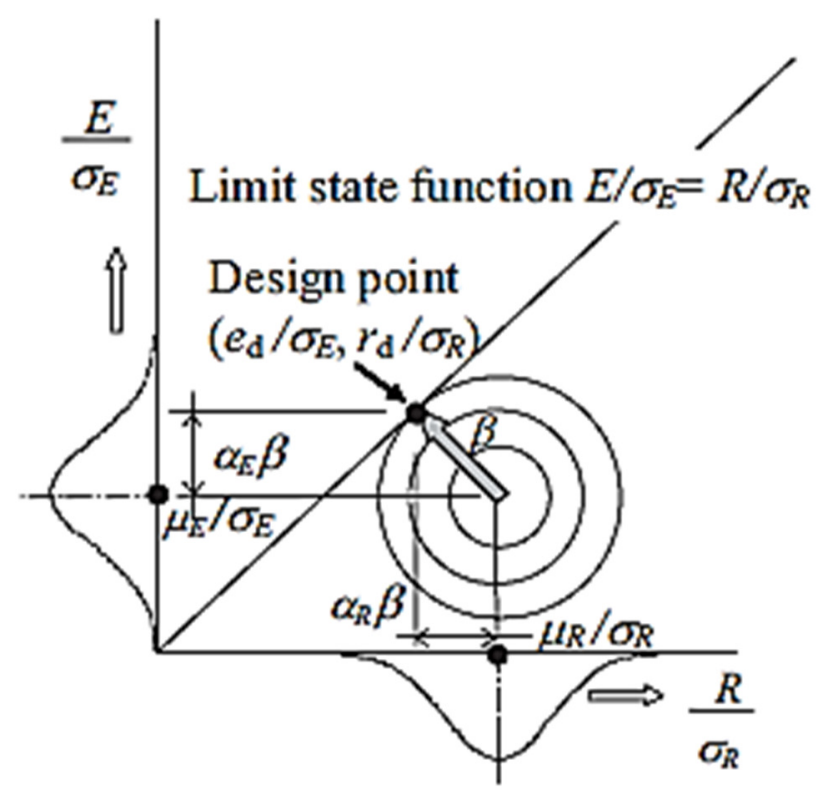

Figure 14: Design point (Holicky, 2009)

The linear limit state function represented by the diagonal line in Figure 14 is the border between the "safe region" and "failure region" where the Equation 26 is satisfied below the line and invalid above the line. The design point is the point on the limit state function which is 
nearest to the mean/centroid $\left(\mu_{E}, \mu_{R}\right)$ of the joint probability density function. The design point coordinates are thus provided by Equation 45 and Equation 46.

$$
\begin{aligned}
& r_{d}=\mu_{R}-\alpha_{R} \cdot \beta \cdot \sigma_{R} \\
& e_{d}=\mu_{E}-\alpha_{E} \cdot \beta \cdot \sigma_{E}
\end{aligned}
$$

Here the linear distance between the design point and the centroid of the probability distribution function is referred to as the reliability index $\beta$ as provided in Equation 47. The $\alpha_{R}$ and $\alpha_{E}$ factors denote the sensitivity factors which represent the influence that each of the variables has on the reliability index (directional cosines) and are depicted in Equation 48 and Equation 49.

$$
\begin{gathered}
\beta=\frac{\mu_{R}-\mu_{E}}{\sqrt{\sigma_{R}^{2}+\sigma_{E}^{2}}} \\
\alpha_{E}=\frac{\sigma_{E}}{\sqrt{\sigma_{R}^{2}+\sigma_{E}^{2}}} \\
\alpha_{R}=\frac{\sigma_{R}}{\sqrt{{\sigma_{R}^{2}}^{2}+{\sigma_{E}^{2}}^{2}}}
\end{gathered}
$$

Fixed values are provided for the sensitivity factors in EN 1990 (2010) and by extension in the SANS codes as shown in Equation 50 and Equation 51. This assumption is conservative if the inequality in Equation 52 holds true.

$$
\begin{gathered}
\alpha_{E}=-0.7 \\
\alpha_{R}=0.8 \\
0.16<\frac{\sigma_{E}}{\sigma_{R}}<7.6
\end{gathered}
$$

For cases where this condition is not satisfied, a sensitivity factor of $\alpha= \pm 1.0$ is to be applied for the variable which exhibits the greater standard deviation (EN 1990, 2010). The design 
values of the action effect and resistance can be found using Equation 53 and Equation 54 as fractiles of the standard normal distribution.

$$
\begin{gathered}
P\left(R \leq r_{d}\right)=\Phi\left(-\alpha_{R} \cdot \beta_{T}\right)=\Phi\left(-0.8 \cdot \beta_{T}\right) \\
P\left(E>e_{d}\right)=\Phi\left(\alpha_{E} \cdot \beta_{T}\right)=\Phi\left(-0.7 \cdot \beta_{T}\right)
\end{gathered}
$$

\subsubsection{FORM}

The FORM is a widely used reliability method and is also used in EN 1990 (2010) as a basis for design value determination. This method was originally developed by Hasofer and Lind (1974) with a fundamental assumption of the limit state being linear (linearized) with normally distributed random variables that are mutually independent. This is not always the case for the random variables in structural engineering and thus they are to be transformed into a standard normal distribution with a mean of zero and a unity variance. As mentioned by Bucher (2011), the transformation is generally possible for all variables and that the Rosenblatt transformation may be used for most instances. Under the assumption of the multivariate case, the main steps of the FORM method are summarised below.

- The variables are transformed into the standard normal space as standardised normal variables $U$ as shown in Figure 15 with the limit state function $G(x)=0$ being transformed into $G(u)=0$ for the linear case and $G^{\prime}(u)=0$ for a non-linear limit state.

- A Taylor expansion is used to approximate the failure surface $G^{\prime}(u)=0$ at a chosen point.

- The design point is the point nearest to the origin on the failure surface and is determined iteratively.

- The distance between the design point and the origin is represented by the reliability index $\beta$ which is determined through iterative optimisation which then gives the failure probability $P_{f}=\Phi(-\beta)$. 

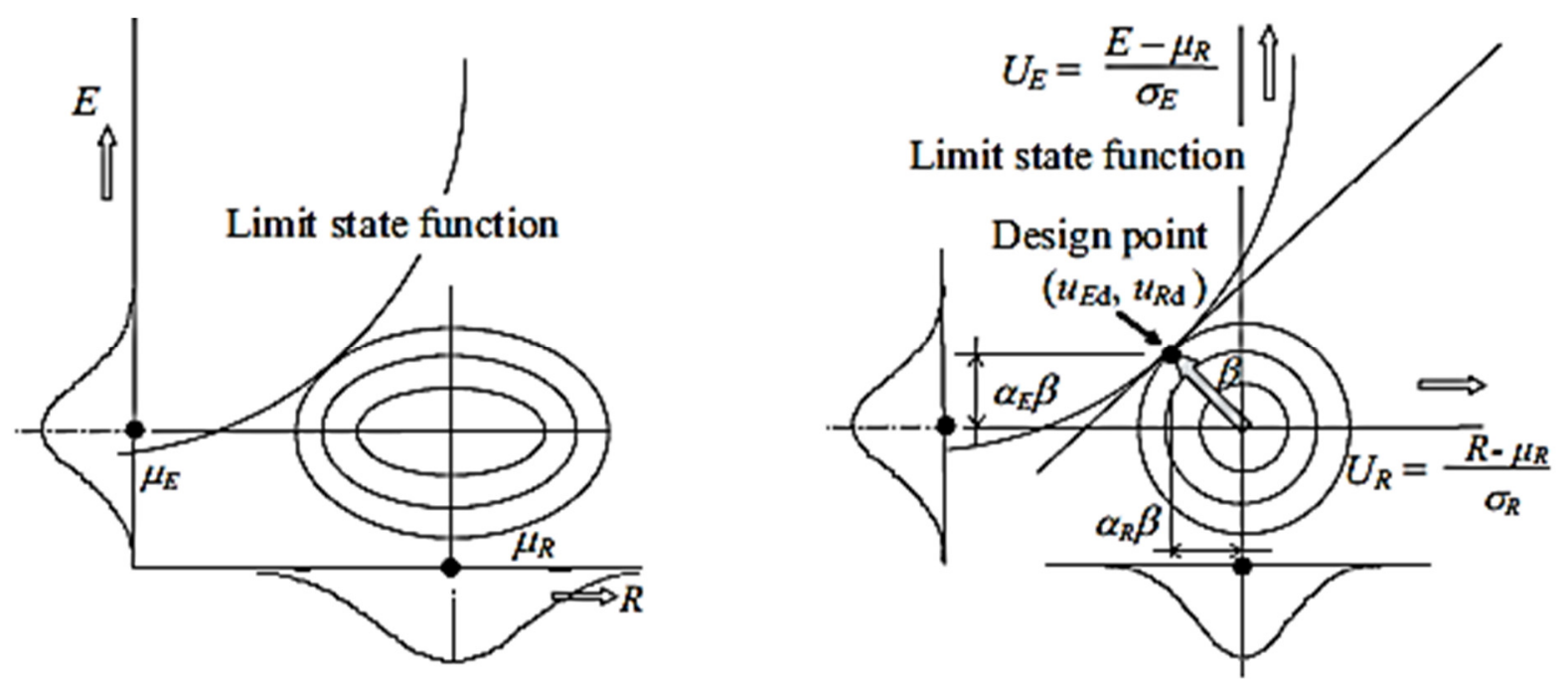

Figure 15: Illustration of the FORM (Holicky, 2009)

For the illustration of the method of transformation to the standard normal space, the simple case of a linear failure surface $\mathrm{g}(u)=0$ is considered. This allows for a simple solution of the determination of the design values $e^{*}$ and $r^{*}$. Equation 55 and Equation 56 are used to transform the variables into the normal space while the limit state is evaluated in Equation 57.

$$
\begin{gathered}
U_{1}=\frac{R-\mu_{R}}{\sigma_{R}} \\
U_{2}=\frac{E-\mu_{E}}{\sigma_{E}} \\
G=R-E=\left(U_{1} \cdot \sigma_{R}+\mu_{R}\right)-\left(U_{2} \cdot \sigma_{E}+\mu_{E}\right)=0
\end{gathered}
$$

The Hesse normal form which is used for calculating distances in a higher dimension space provides the solution in Equation 58.

$$
-\frac{\left(\mu_{R}-\mu_{E}\right)}{\sqrt{\sigma_{R}^{2}+\sigma_{E}^{2}}}-\frac{U_{1} \cdot \sigma_{R}}{\sqrt{\sigma_{R}^{2}+\sigma_{E}^{2}}}-\frac{U_{2} \cdot \sigma_{E}}{\sqrt{\sigma_{R}^{2}+\sigma_{E}^{2}}}=0
$$

The design point is situated on the failure surface $g(u)=0$ at the point which is nearest to the origin. The coordinates of this point can then be obtained through the transformation back into the original space where the design values are represented by $r^{*}$ and $e^{*}$ as shown in Equation 59 
and Equation 60. These design values are the realisations of the resistance and action effect where failure would occur with the highest probability.

$$
\begin{aligned}
& r^{*}=\mu_{R}-\alpha_{R} \cdot \beta \cdot \sigma_{R} \\
& e^{*}=\mu_{E}-\alpha_{E} \cdot \beta \cdot \sigma_{E}
\end{aligned}
$$

For cases where the limit state is non-linear as depicted in Figure 15, the determination of a solution is not a trivial process. Performing a linearization of the failure surface at the design point represented in normalized space is a solution method suggest by Hasofer and Lind (1974). The location of the design point can then be found iteratively by solving the optimisation problem presented in Equation 61.

$$
\beta=\min _{u \in\{g(u)=0\}} \sqrt{\sum_{i=1}^{n} u_{i}^{2}}
$$

Here $\beta$ represents the shortest distance from the origin to the design point where the direction is depicted by the outward normal vector $\alpha$. The components of this vector are the sensitivity factors indicating the influence of each of the components, similar to the linear case. The result of the optimisation problem will be exact if the failure surface is linear which is in this case approximated due to the non-linear failure surface.

\subsubsection{Reliability based partial factors}

Here the general fundamental problem of two normally distributed mutually independent variables will be considered. As above, the limit state is defined as in Equation 62 .

$$
M=R-E
$$

The semi-probabilistic design method incorporates partial factors which are applied to both the resistance and load effect variables to ensure adequate structural reliability. With the introduction of the partial factors for the action effect and resistance, the limit state can then be re-written as depicted in Equation 63 


$$
\gamma_{R} R_{c k}-\left(\gamma_{G} G_{c k}+\gamma_{Q} Q_{c k}\right)=0
$$

Where:

$\gamma_{R} \quad$ is the resistance partial factor;

$R_{c k} \quad$ is the characteristic resistance;

$\gamma_{G} \quad$ is the permanent action partial factor;

$G_{c k} \quad$ is the characteristic permanent action;

$\gamma_{Q} \quad$ is the variable action partial factor;

$Q_{c k} \quad$ is the characteristic variable action.

Figure 16 can be used to describe the used semi-probabilistic design concept with the shown action effect $\mathrm{E}$ and resistance $\mathrm{R}$ variables. The probability of failure is represented by the distance between the means of the two variable and their distribution parameters as is the case shown in Equation 53 and Equation 54 which can be used to determine the design values. A larger reliability index will be a result of an increased distance between the peaks which results in a lower expected probability of failure.

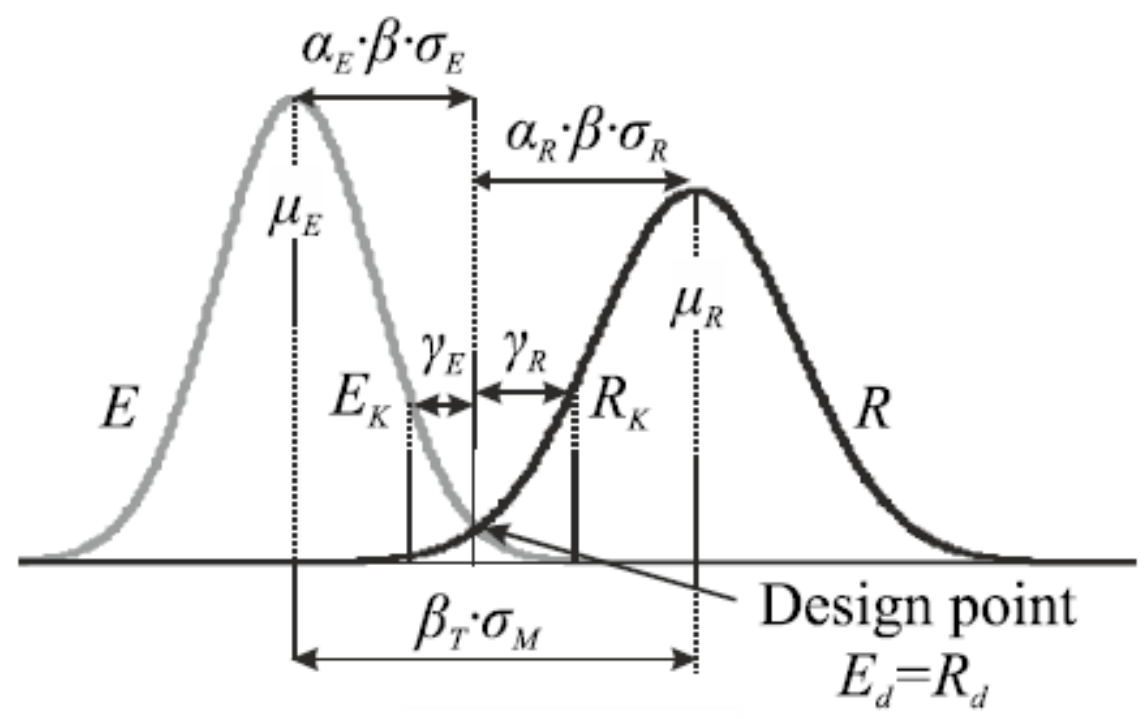

Figure 16: Schematic of the semi-probabilistic safety concept (Lenner, 2014)

These partial factors generally consist of two components as schematically represented by Figure 17. One component accounts for the model uncertainties while the other is a reliability based partial factor which accounts for the intrinsic variability of the random variables. The reliability based partial factors are of particular importance for this study and are investigated further. 


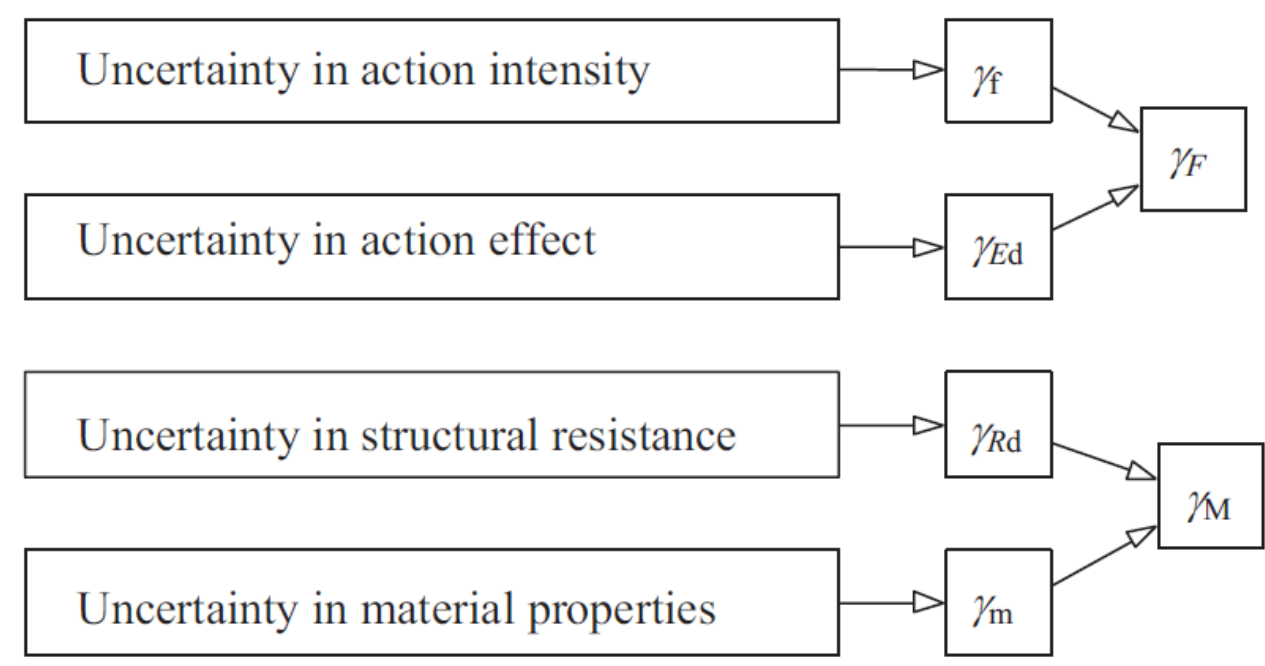

Figure 17: Relation between individual partial factors (Holicky, 2009)

As provided in EN 1990 (2010), Table 10 can be used for the determination of design values of variables which have the provided distributions.

Table 10: Design values as provided in EN 1990 (2010)

\begin{tabular}{|c|c|}
\hline Distribution & Design Value \\
\hline Normal & $\mu-\alpha \cdot \beta \cdot \sigma$ \\
\hline Lognormal & $\mu \exp (-\alpha \cdot \beta \cdot \sigma)$ \\
\hline & $u-\frac{1}{\alpha} \ln (-\ln \Phi(-\alpha \cdot \beta))$ \\
Gumbel & $u=\mu-\frac{0.577}{\alpha} ; \alpha=\frac{\pi}{\sigma \sqrt{6}}$ \\
\hline
\end{tabular}

It may be required for certain cases that a specific structural behaviour is to be maintained with respect to its probability of failure. To achieve this, the target reliability index $\beta_{T}$ can be used to set the distance between the mean values of the variables. Thus the target reliability index can dictate the resistance required if the loading is known or the maximum possible loading if the resistance is known. The modified design value is shown in Equation 64 for the case where the variables are normally distributed.

$$
X_{d}=\mu_{X}-\alpha_{X} \cdot \beta_{T} \cdot \sigma_{X}
$$


The design values are generally not listed directly in design codes but instead characteristic values are used to represent the load and resistance variables. The resistance commonly utilises a characteristic value which corresponds to a $5 \%$ quantile value while the action effect generally uses a range from $90 \%$ to $98 \%$. Equation 65 and Equation 66 can be used to determine the characteristic values using a standard normal distribution function as represented by $\Phi(x)$.

$$
\begin{gathered}
R_{k}(x)=\Phi^{-1}(x) \cdot \sigma_{R}+\mu_{R} \\
E_{k}(x)=-\Phi^{-1}(x) \cdot \sigma_{E}+\mu_{E}
\end{gathered}
$$

The method of obtaining the desired partial factor suggested in EN 1990 (2010) is to divide the design value of the action effect variable by its respective characteristic value with the inverse of this being used for resistance variables. This is shown in Equation 67 and Equation 68. The partial factors represents the distance between the characteristic value and the design value as shown in Figure 16. Thus the partial factors essential increase the action effect characteristic value and decrease the resistance characteristic value so that they are equivalent at the design point.

$$
\begin{aligned}
& \gamma_{E}=\frac{E_{d}}{E_{k}(x)}=\frac{\mu_{E}-\alpha_{E} \cdot \beta_{T} \cdot \sigma_{E}}{\mu_{E}-\Phi^{-1}(x) \cdot \sigma_{E}} \\
& \gamma_{R}=\frac{R_{k}(x)}{R_{d}}=\frac{\Phi^{-1}(x) \cdot \sigma_{R}+\mu_{R}}{\mu_{R}-\alpha_{R} \cdot \beta_{T} \cdot \sigma_{R}}
\end{aligned}
$$

It is evident from the equations above that the target reliability index and stochastic properties of the random variables have a great effect on the resulting partial factor. The shown equations were formulated for a normal distribution while the same method can be used for other distribution functions. Equation 69 and Equation 70 show the simplified expressions for determining the partial factors for the case where the mean is taken as the characteristic value.

$$
\gamma_{E}=\frac{E_{d}}{E_{k}}=\frac{\mu_{E}-\alpha_{E} \cdot \beta_{T} \cdot \sigma_{E}}{\mu_{E}}=1+0.7 \cdot \beta_{T} \cdot V_{E}
$$




$$
\gamma_{R}=\frac{R_{k}}{R_{d}}=\frac{\mu_{R}}{\mu_{R}-\alpha_{R} \cdot \beta_{T} \cdot \sigma_{R}}=\frac{1}{1-0.8 \cdot \beta_{T} \cdot V_{R}}
$$

Equation 71 and Equation 72 show the expressions for the determination of the partial factors for if a lognormal distribution was used for an equivalent case of the mean being used as the characteristic value.

$$
\begin{gathered}
\gamma_{E}=\frac{E_{d}}{E_{k}}=\frac{\mu_{E} \exp \left(-\alpha_{E} \cdot \beta_{T} \cdot V_{E}\right)}{\mu_{E}}=\exp \left(0.7 \cdot \beta_{T} \cdot V_{E}\right) \\
\gamma_{R}=\frac{R_{k}}{R_{d}}=\frac{\mu_{R}}{\mu_{R} \exp \left(-\alpha_{R} \cdot \beta_{T} \cdot V_{R}\right)}=\frac{1}{\exp \left(-0.8 \cdot \beta_{T} \cdot V_{R}\right)}
\end{gathered}
$$




\section{Materials and testing methodology}

\subsection{Timber Samples}

The lumber used in this investigation was procured from Biligom International (Pty) Ltd whose plantations are located in the Tzaneen area of Limpopo, South Africa. The manufacturing process of the unseasoned, wet finger-jointed Eucalyptus grandis dimensional lumber, referred to as Biligom lumber, begins with the felling of the Eucalyptus grandis trees of ages between six to eight years old. The felled trees are then left in the plantation for approximately six weeks which is deemed to equalize the moisture distribution throughout the timber, stabilizing growth stresses (Crafford, 2013). These green logs are then processed into dimension timber where the long length boards are then horizontally finger jointed (fingers visible on narrow edge of board) planed and cross cut into market related dimensions. This material is sold as green timber with a moisture content above $30 \%$.

A total of 300 wet finger-jointed Eucalyptus grandis specimens with dimensions of $36 \times 102 \times 2000$ mm (T x W x L) were delivered to the Western Cape depot of Biligom. Of that, a set of 200 specimens were split into 18 × $102 \times 2000 \mathrm{~mm}$ and $14 \times 102 \times 2000 \mathrm{~mm}$ specimens where $4 \mathrm{~mm}$ of thickness was lost as sawdust. The 200 pieces of $18 \mathrm{~mm}$ thickness were glued together face-wise to create a set of 100 face laminated specimens of $36 \mathrm{~mm}$ thickness (referred to as the "laminates"). The off-cut 14 x 102 x $2000 \mathrm{~mm}$ were stored for use in future research. The remaining 100 non-laminated samples with dimensions of $36 \times 102 \times 2000 \mathrm{~mm}$ were the control set, further referred to as "standard" boards in this investigation. Thus both the face-laminated and standard sets had an equivalent thickness of $36 \mathrm{~mm}$ once the lamination process was completed. Equivalent dimensions between the two sets were used to ensure that no size effect could cause discrepancies in the strength comparisons of the two sets.

\subsubsection{Initial measurements}

During initial processing, the two sets were kept in the wood workshop at the Department of Forestry and Wood Science of Stellenbosch University to ensure that all samples were exposed to identical environmental conditions. Each of the samples were weighed in the green state 
(moisture content above fibre saturation point). The maximum width and length of surface defects (split and check) were measured and marked for each sample. These defects were marked to ensure that the same defect was measured once drying was completed as depicted in Figure 18.

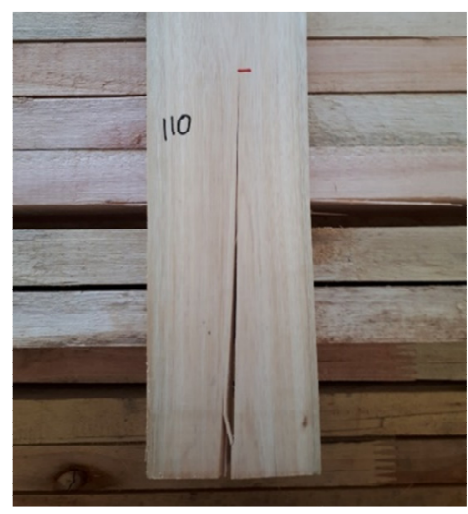

Figure 18: Surface defect marked at point of length measurement

\subsection{Lamination}

For this investigation "Loctite HB S709 Purbond" a one-component polyurethane adhesive (1C PUR) was used. This adhesive was selected as it was the only commercial moisture-curing 1C PUR adhesive being distributed in South Africa at the time of the study and thus it is representative of what would be utilized in practice. An investigation was completed by Pröller (2017) to determine if sufficient bond strength would be achieved using this adhesive with wet Eucalyptus grandis. Adequate bond strength was achieved and thus this was deemed to be suitable for the desired application in this study.

The face lamination was completed in groups of 24 boards per lamination cycle resulting in 12 laminates being completed per cycle. The 1C PUR adhesive was applied to a single face of 12 of the boards in each set by pouring it onto the boards and spreading the glue using an adhesive scraper. The adhesive was poured out of equal volume containers for each lamination cycle to allow for an even spread rate between the sets. Immediately after adhesive application the corresponding 12 boards were placed onto their counterparts and positioned into the gluing press which is shown in Figure 19. 


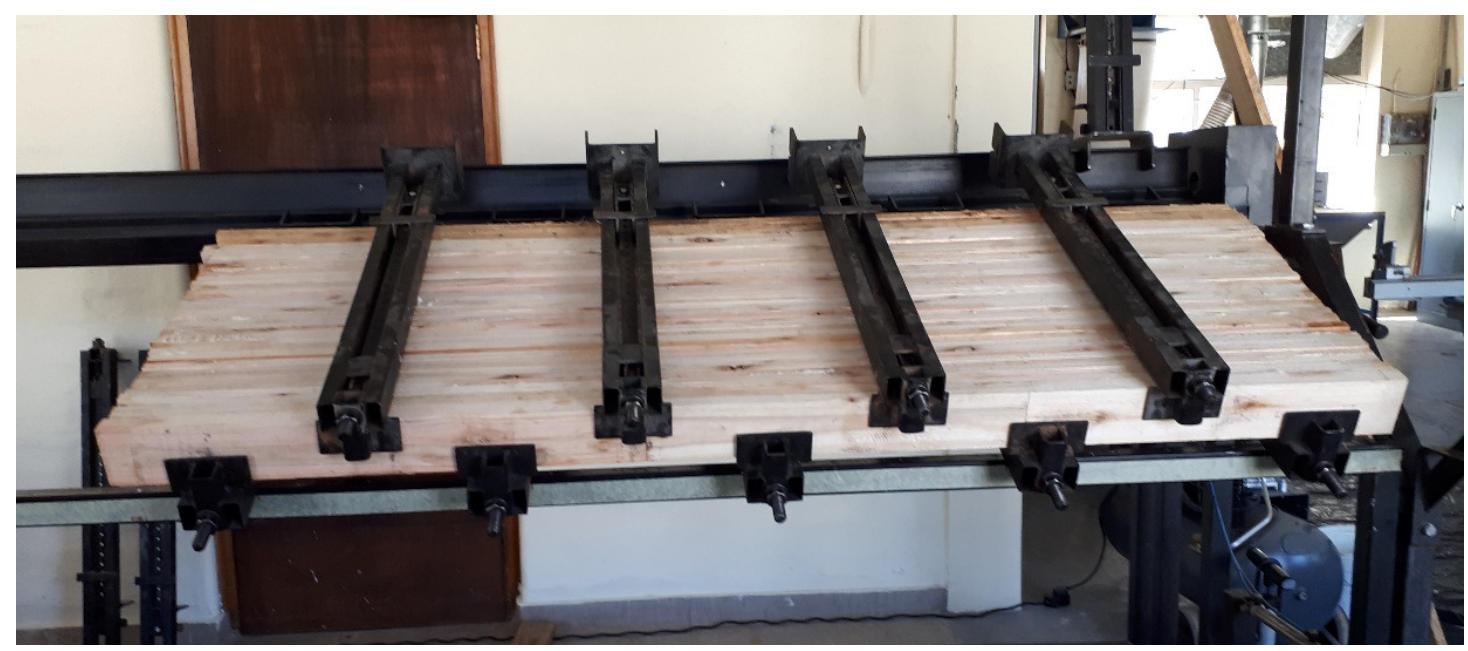

Figure 19: Glue press

Five equally spaced clamps were used on the underside of the samples while a further four clamps were spaced at centre points on the top side of the samples between the bottom clamps. An outer board was placed onto the outer ends of the laminates which came into contact with the clamps to ensure that the samples would not be damaged by the clamp plates and to evenly distribute the clamping pressure. The upper clamps were tamped down before tightening to assist in aligning the laminates. Once all the clamps were positioned they were incrementally tightened one at a time until all clamps were sufficiently tight. A torque wrench was used in the final tightening phase to ensure that each clamp supplied equivalent pressure to the samples. The adhesive application and clamping commenced for approximately 15 minutes per set which is below the assembly time of the adhesive. Each set was then left in the press to cure for a minimum of 90 minutes before disassembly.

It should be noted that both the adhesive application process and the clamping system was not of the quality and consistency possible with modern industrial equipment. However, since the glue line was not under severe stress during bending tests, or expected to fail during testing, the available system was deemed acceptable for this experiment.

\subsection{Sample drying}

Once the lamination process was complete, the samples were then transported to the greenhouse (drying tunnel). The samples were stacked with a gap of approximately $10 \mathrm{~mm}$ between them 
using "stickers" to separate each layer to ensure that sufficient air flow could pass each of the samples. As noted by Crafford (2013) the drying conditions in the greenhouse are considered to be severe with temperatures reaching above $50{ }^{\circ} \mathrm{C}$ and humidity equalling $30 \%$ being experienced in March. Similar conditions were experienced for this investigation during the drying phase which took place during March and April of 2018. Five samples were selected from each of the two sets at various layers of the stacked material. These samples were weighed on a weekly basis in order to monitor the decrease in mass of each sample over the drying period and to determine when equilibrium moisture content was reached. Figure 20 shows the decrease in mass of the ten samples until the curves reach a plateau which signals that equilibrium moisture content was reached.

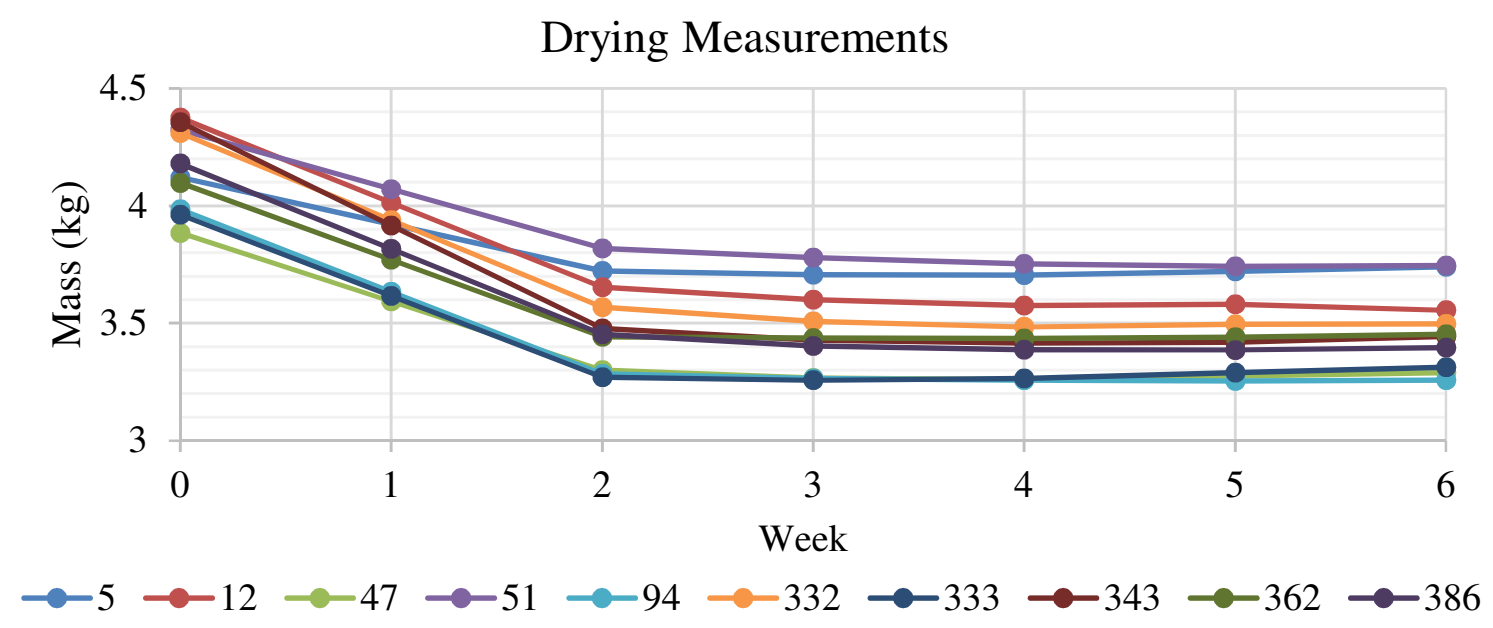

Figure 20: Mass reduction of selected samples during drying

\subsection{Material testing}

After six weeks in the greenhouse the samples had reached equilibrium moisture content and were transported to the material testing laboratory at the Department of Forestry and Wood Science of Stellenbosch University. Here the samples which were then in their dry state (moisture content below fibre saturation point) were prepared for destructive testing. A series of measurements were taken on each sample before testing could commence. Each sample was weighed along with the width and thickness dimensions being recorded using an electronic hand calliper at three points along the sample allowing for the average dimensions of each 
sample to be noted. The moisture content was measured for each specimen using an electronic moisture meter. These measurements were taken on each side of the laminated samples in order to produce an average moisture content. As done in the wet state, the maximum width and thickness of splits and checks were measured at the demarcated points which were noted in the wet state or where new defects had occurred during drying.

\subsection{Warp measurements}

The warp of a timber element is defined as being "any departure (in the form of bow, cup, spring or twist, or any combination of these) of a true or plane surface or piece" (SANS 1707-1, 2010). See Figure 6 to Figure 9 for a visual representation of each type of warp. In this investigation, the bow, cup and twist of each sample was measured using a custom-made warp measuring apparatus (jig) which is shown in Figure 21. The jig has three equal length vertical pins, the specimen is placed onto the pins on three of the four corners of the specimen thus allowing one of the corners of the sample to be unsupported. A weight is placed on top of the sample at the end containing two pins which provides stability during measurement.

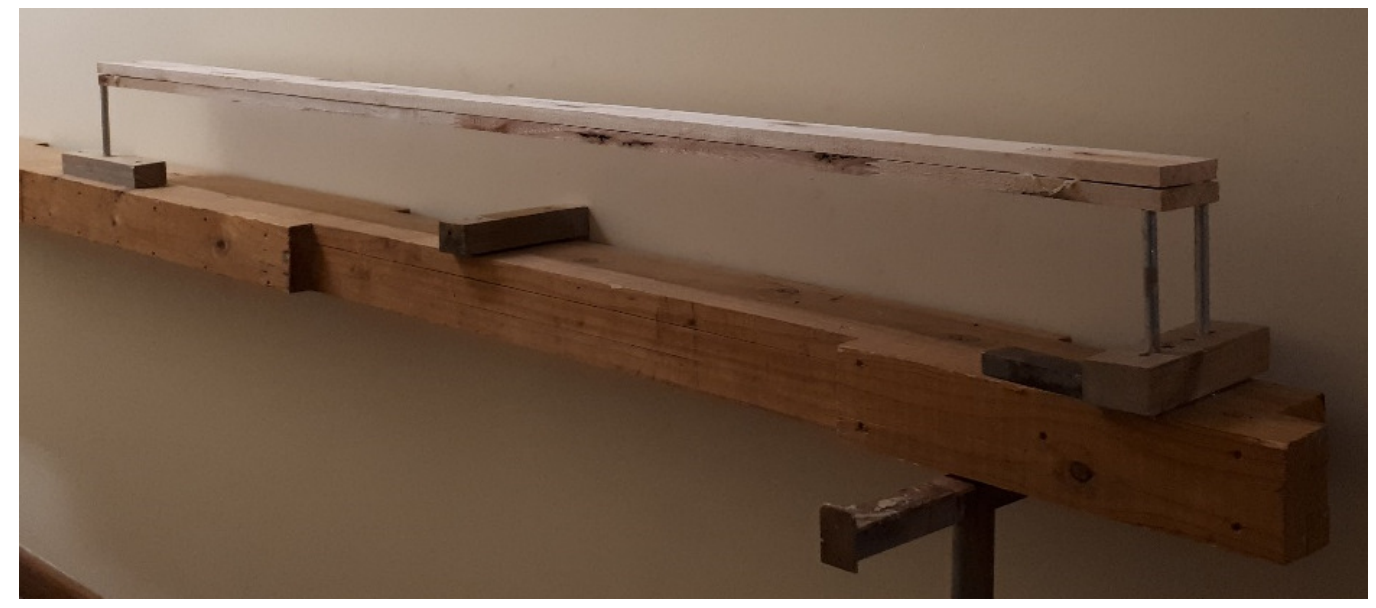

Figure 21: Warp measurement apparatus (jig)

Four measurements were taken for each sample. The distance between the surface of the warping jig and the underside of the sample was taken at both sides of the sample's centre point labelled as measurement points 1 and 2 in Figure 22. Secondly the distance was recorded at the free corner of the sample as indicated by measurement point 3 (Distances at points 1,2 and 3 are measured in millimetres). The two centre measurements were used to calculate the bow 
while the corner measurement was used to determine the twist of the specimen. The three pins at points $\mathrm{A}, \mathrm{B}$ and $\mathrm{C}$ are of equal length at $160 \mathrm{~mm}$ long. Equation 73 and Equation 74 are used to determine the bow and twist of each board respectively. Here the bow is recorded in millimetres while the twist is recorded in degrees.

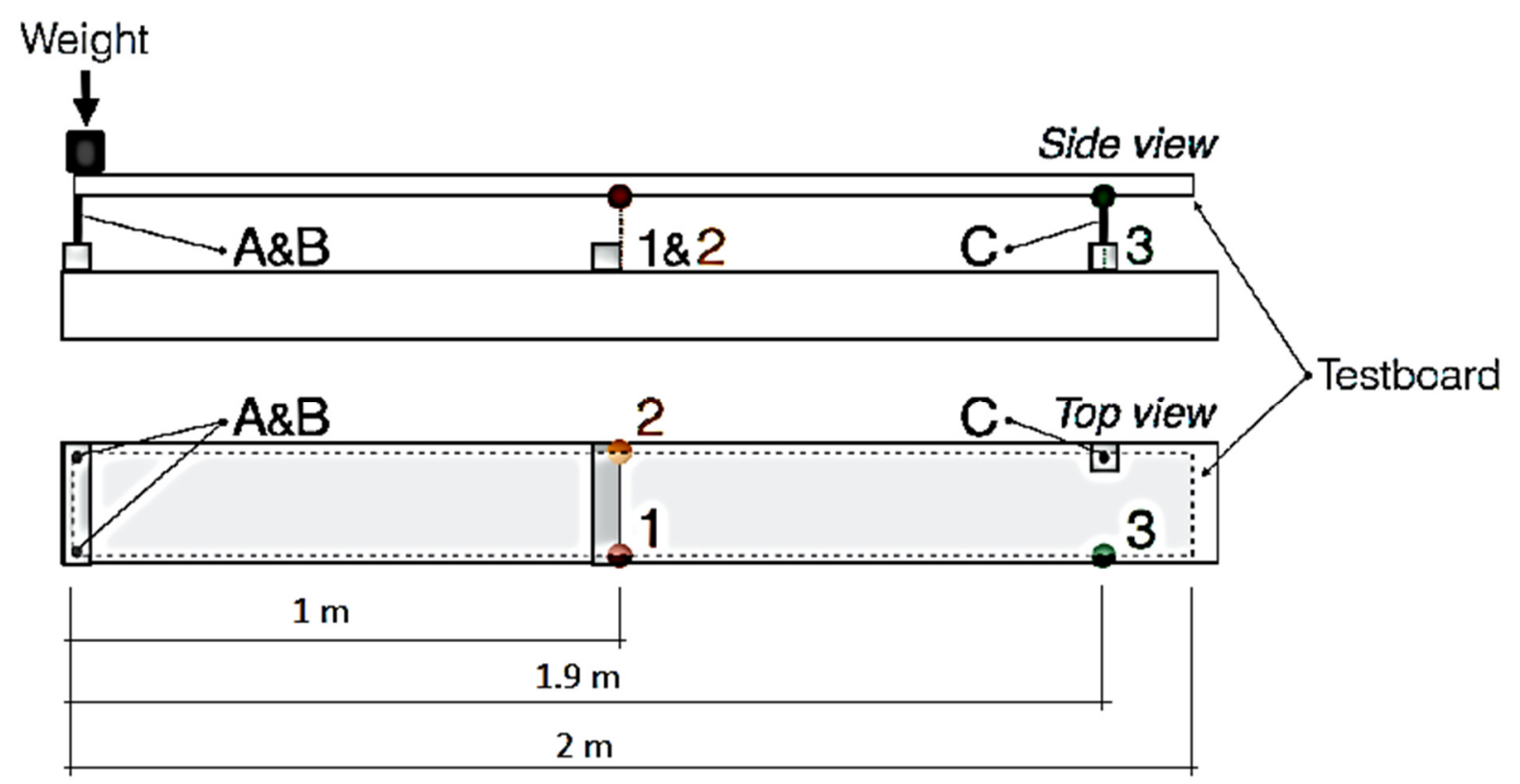

Figure 22: Measurement points using the warping jig as adapted from Pröller (2017)

$$
\begin{gathered}
\text { Bow }=\left|160-\left(\frac{P 1+P 2}{2}\right)\right| \\
\text { Twist }=\sin ^{-1}\left(\frac{\text { Board Width }}{|160-P 3|}\right)
\end{gathered}
$$

The cup was measured by aligning the end of the sample with the end of the jig face down and recording the maximum distance between the top corner of the jig and the bottom corner of the sample. The cup measurement was taken at the short end of the sample. Spring was not recorded in this investigation due to occasional imperfect alignment of the laminated samples which would affect accuracy of spring measurements. 


\subsection{Destructive testing}

Bending tests were completed on each of the 200 samples in accordance with SANS 6122 (2008). The tests were carried out at the strength testing laboratory at the Department of Forestry and Wood Science of Stellenbosch University using an Instron testing machine. A four point bending test was used with a test span of $1800 \mathrm{~mm}$ as prescribed in SANS 6122 (2008) which is depicted in Figure 23.

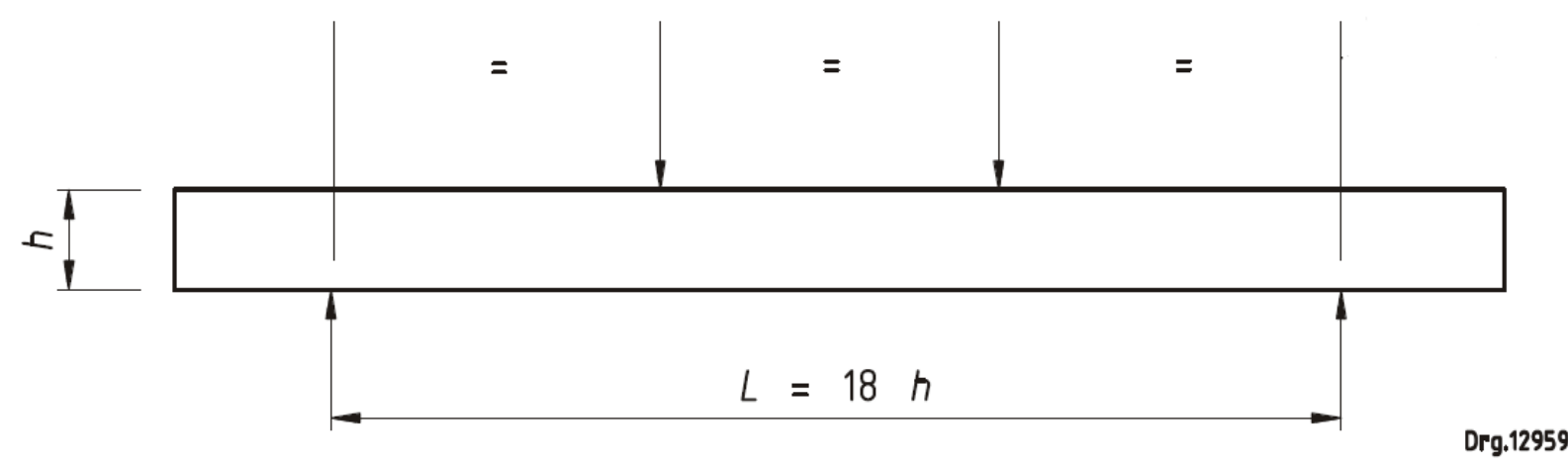

Figure 23: Depiction of the four point bending test (SANS 6122, 2008)

The required test span is to be equal to the height of the specimen multiplied by 18 , an average specimen height of $100 \mathrm{~mm}$ was used throughout the tests to avoid adjusting the test set-up for each sample. The compression and tension edges of the specimen were chosen at random in order to avoid any biased placement of defects which could be present on either edge. This test procedure allows for the MOE and MOR of each specimen to be calculated. The test set-up is shown in Figure 24 of a sample which had undergone destructive testing. Each sample was photographed post-test to allow for later consultation if any anomalies in results had arisen. 


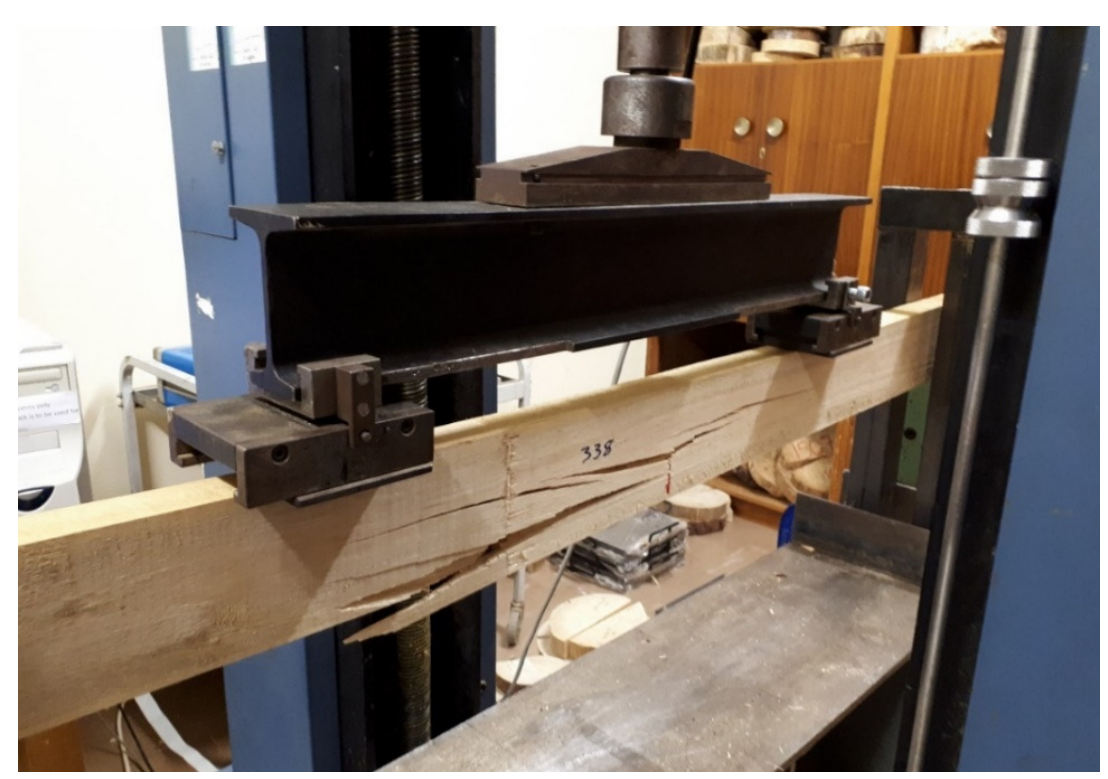

Figure 24: Four point bending test set-up

The following equation was used to calculate the MOE of the samples using the load and deflection results obtained from the Instron testing machine. The MOE was determined in accordance to SANS 6122 (2008). Equation 75 is used for the MOE calculation for the case of rectangular samples where the deflection is measured as the movement of the Instron cross-head.

$$
M O E=\frac{F L^{3}}{5.4 b h^{3} D}
$$

Where:

MOE is the static modulus of elasticity measured on edge at third span [MPa];

$F \quad$ is the increment of load below the proportional limit $[\mathrm{N}]$;

$L \quad$ is test span of the sample [mm];

$b \quad$ is thickness of test specimen [mm];

$h \quad$ is depth of the specimen [mm];

$D \quad$ is the resulting increment in deflection due to the increment in load $F$ [mm].

The points which are to be used to obtain the increment in load and deflection for the MOE calculation are not specified in SANS 6122 (2008) and thus had to be chosen. A pre-load of $200 \mathrm{~N}$ is however specified in the code, but it has been determined that there is fluctuations in the force displacement curve in the $200 \mathrm{~N}$ region (noise in the data output) using the testing equipment at Stellenbosch University. Thus a larger lower limit of $400 \mathrm{~N}$ was chosen as the 
initial calculation point due to this point being located on the linear portion of the force displacement graph for all samples. The upper limit of the fixed range was chosen to be the point at $2400 \mathrm{~N}$ as this force is near to what would produce a stress equivalent to the grade S5 $5^{\text {th }}$ percentile bending strength for the sample's dimensions.

An alternative method to this fixed range is to use a range of between $10 \%$ and $40 \%$ of the failure load of the sample, this is the method suggested in AS/NZ 4063 (2010). In this case, using a calculation point at $40 \%$ of failure load far exceeds the $5^{\text {th }}$ percentile bending strength for most structural grades and this method was found to produce MOE values $3 \%$ higher than when using a fixed range below the $5^{\text {th }}$ percentile values as described above (Crafford and Wessels, 2011). Thus to avoid any over estimation of MOE which could cause higher than anticipated deflection in structures, the fixed range between the $400 \mathrm{~N}$ and $2400 \mathrm{~N}$ points was used as the calculation points in this study. The points for the fixed range used are depicted in Figure 25.

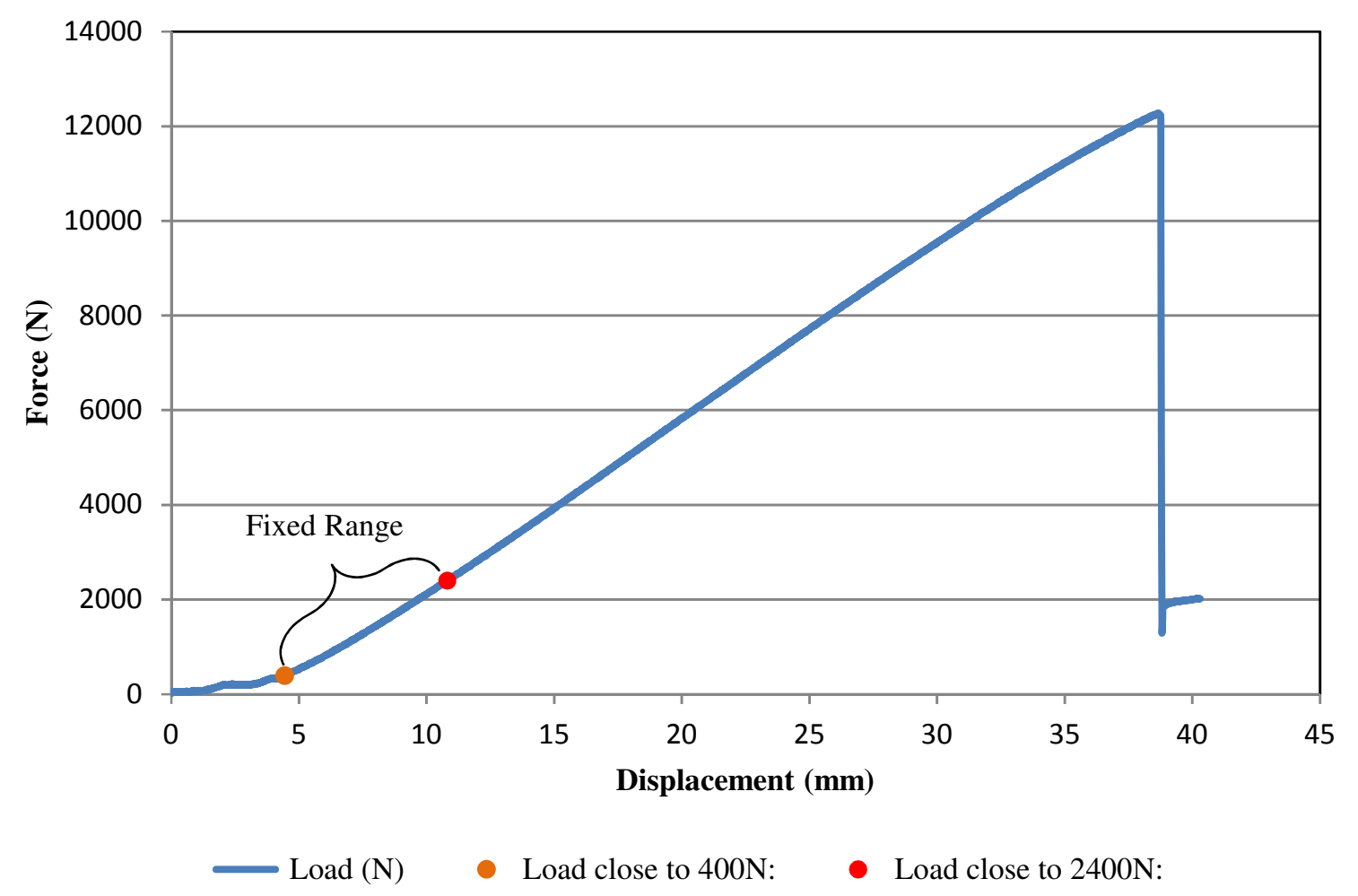

Figure 25: Force displacement graph with the two points used for MOE calculation 
The MOR was calculated using Equation 76 below which is prescribed in SANS 6122 (2008).

$$
M O R=\frac{F L}{b h^{2}}
$$

Where:

$M O R$ is the modulus of rupture of the specimen (bending strength) [MPa];

$F \quad$ is the load at failure $[\mathrm{N}]$;

$L \quad$ is the test span of the sample [mm];

$b \quad$ is thickness of test specimen [mm];

$h \quad$ is depth of the specimen [mm].

The density of each sample was calculated using the density, mass and volume relationship as described in Equation 77.

$$
\rho=\frac{M}{V o l}
$$

Where:

$\rho \quad$ is the air dry density of the specimen $\left[\mathrm{Kg} / \mathrm{m}^{3}\right]$;

$M \quad$ is the mass of the sample at the air dry moisture content $[\mathrm{Kg}]$;

$\mathrm{Vol}$ is the volume of the sample at the air dry moisture content $\left[\mathrm{m}^{3}\right]$.

\subsection{Statistical analysis}

\subsubsection{Distribution fitting}

The MOE and MOR results obtained for each sample serve as a basis for fitting distribution functions. Once the data had been compiled, it was imported into Statistica, a data analysis software. Determining which distribution best represents each data set is of importance as it dictates how other desired results are to be determined. For this investigation the normal and lognormal distributions were considered for use. The JCSS probabilistic model code (2001) denotes that the lognormal distribution should be used for the MOR and MOE properties of structural timber. Normal and lognormal distributions were fitted to the data sets using chi-square tests to determine if they would be suitable for use, for the p-value associated with a 0.05 significance level.

The chi-square goodness of fit test is used to compare the obtained values to expected values. In this case the test is used to determine the similarity between the sample distribution and an 
expected distribution, where the normal and lognormal distributions were modelled as the expected distributions. These tests are completed with a null hypothesis that the distributions are not statistically significantly different to each other and an alternative hypothesis that there is a significant difference between the distributions. A p-value is returned as an outcome of the test and is used as the decision making parameter in terms of rejecting or accepting the null hypothesis. The p-value is compared to a pre-defined significance level which results from the required confidence level. If one requires that there is to be a $95 \%$ confidence that the correct hypothesis is chosen, a significance level of $5 \%$ is then used ( $\mathrm{SL}=1-\mathrm{CL}$ ). This significance level represents that there is a $5 \%$ probability that the incorrect hypothesis is chosen (Walpole et al., 2012).

For this case if the p-value obtained from the goodness of fit test is lower than the chosen 0.05 limit of the significance level, the null hypothesis is rejected and a significant difference is then recorded between the sample distribution and the expected distribution. The inverse is true when the p-value is larger than 0.05 it is then taken that the sample distribution fits the expected distribution at a $95 \%$ confidence level (Walpole et al., 2012).

\subsubsection{Difference tests}

Analysis of variance (ANOVA) tests is a statistical test that are used to determine if there is a significant difference between the means of two or more data sets. This method is commonly used in scientific investigations for determining if a change in variable or multiple variables has a significant effect on the outcome of performed tests. In this case the inclusion of face lamination is the differentiating variable. In a similar manner to the goodness of fit tests, the ANOVA tests are used to either accept or reject a null hypothesis of there being statistical significant similarity between the means of the sets. The null hypothesis decision is once again made by analysing the p-value which is an output of the ANOVA test. Here the null hypothesis is accepted when a p-value above the 0.05 significance level is achieved. Two fundamental assumptions are made in the formulation of ANOVA tests which are that the sets are to be normally distributed and have similar variances (Walpole et al., 2012). 
In this case the sample sets are deemed to have lognormal distributions and thus bootstrapped ANOVA tests were applied when analysing the variation in the resulting means of the laminated and standard sets. Using bootstrapping techniques allows for the tests to be completed for sets which do not conform to the assumptions required for the use of the standard ANOVA test (Xu et al., 2013). The similarity of the sets is indicated by the letters on top of each set's bar, as shown in Figure 40 and Figure 42. Sets that have the same letters have statistically significant similarity of means while sets which have different letters do not have similar means.

A comparison was made to determine if there was a statistically significant difference between the laminates and standard board's $5^{\text {th }}$ percentile values. This was done due to the $5^{\text {th }}$ percentile value being used as the characteristic strength value for MOR for structural timber as prescribed in SANS 6122 (2008). The $5^{\text {th }}$ percentile value is also often used as a characteristic value for the MOE in design even though the mean value is prescribed in the current version of SANS 10163-1 (2005). Thus the comparison was completed for the MOE values along with the MOR values. As the finger-jointed materials tested in this study do not yet have characteristic values listed in the SANS codes, the comparison was completed to determine if one value should be prescribed for the materials or if values for the laminates and standard boards should be listed separately if a statistically significant difference is found.

These comparisons were made by determining distribution free confidence intervals for the $5^{\text {th }}$ percentile values at the $95 \%$ confidence level. The comparison was completed by ordering each of the sets and determining the confidence intervals for each using the formulation shown below (Hollander and Wolfe, 1999). Thus, if the confidence intervals for the sets under consideration over-lap, the sets are deemed to not be statistically significantly different at the $95 \%$ confidence level. Here the ordered variables within the set are denoted by $Y$ while $j$ denotes the position of the lower confidence limit and $k$ refers to the position of the upper confidence limit. The value used for $n$ is 100 which is the number of values in the set and $p$ is 0.05 signifying the $5^{\text {th }}$ percentile value which is the point of interest here. 


$$
\begin{gathered}
C I\left(\xi_{0.05}\right)_{0.95}=\left[Y_{j}, Y_{k}\right] \\
j=n p+0.5-\frac{Z_{\alpha}}{2} \sqrt{n p(1-p)} \\
k=n p+0.5+\frac{Z_{\alpha}}{2} \sqrt{n p(1-p)}
\end{gathered}
$$

In Table 11 the confidence intervals for the laminated and standard sets overlap for both the MOR and MOE. The overlap represents the intersection of values between the sets, for example in the MOR results the confidence interval for the laminated set ranges from 30.21 to 38.62 while the standard board's confidence interval ranges from 22.36 to 34.92 with an overlap of these confidence intervals between 30.21 and 34.92. This intersection of the confidence intervals indicates that the $5^{\text {th }}$ percentile values for the laminated and standard sets are statistically significantly similar for both material properties at the $95 \%$ confidence level.

Table 11: Confidence intervals for $5^{\text {th }}$ percentile values

\begin{tabular}{|c|c|c|c|c|}
\hline \multirow{2}{*}{$\begin{array}{c}\text { Confidence } \\
\text { Limit }\end{array}$} & \multicolumn{2}{|c|}{ MOR (MPa) } & \multicolumn{2}{c|}{ MOE (MPa) } \\
\cline { 2 - 5 } & Laminates & Standard & Laminates & Standard \\
\hline Lower & 30.21 & 22.36 & 6884 & 7905 \\
\hline Upper & 38.62 & 34.92 & 8363 & 8418 \\
\hline Overlap & \multicolumn{3}{|c|}{ Yes } & \multicolumn{3}{c}{ Yes } \\
\hline
\end{tabular}

The method of selecting the $5^{\text {th }}$ percentile value prescribed in SANS 6122 (2008) involves selecting the value at position $F_{5}$ in a ranked data set obtained by rounding the value calculated in Equation 80 to the nearest whole number. It should be noted that this method is not necessarily most effective when using small data sets $(\mathrm{n}=100)$ as determined by Crafford and Wessels (2011). For cases where large gaps are present in the lower tail of the data set, a misrepresentation of the $5^{\text {th }}$ percentile could occur due to the variation between data points. Method 3 of 4 prescribed in AS/NZ 4063 (2010) is possibly more appropriate for use as it prescribes linear interpolation to determine the $5^{\text {th }}$ percentile value when the result of $F_{5}$ does not result in a whole number. The method prescribed in SANS 6122 (2008) was however adhered to in this study but care was taken when determining the value for the small data sets used here as it was checked visually using Figure 39 and Figure 43. 


$$
F_{5}=0.05(n-1)
$$

\subsection{Material factor determination}

The partial factor for material resistance $\gamma_{M}$ can be defined as the product of $\gamma_{m}$ and $\gamma_{R d}$ as shown in Equation 82 (Holicky, 2009). The partial factor calculation produces a value greater than 1 and thus the inverse of the partial factor known as the material resistance reduction factor $\varphi_{M}$ which is expressed in Equation 83. The reduction factor shall be reported further in this study as to be comparable to the existing material resistance factor of 0.68 for structural timber in SANS 10163-1 (2003).

$$
\gamma_{M}=\gamma_{R d} \gamma_{m}
$$

Where:

$\gamma_{M}$ is the material resistance partial factor;

$\gamma_{R d}$ is the model uncertainty factor;

$\gamma_{m}$ is the material factor.

$$
\varphi_{M}=\frac{1}{\gamma_{M}}=\varphi_{m} \varphi_{R d}
$$

Where:

$\varphi_{M} \quad$ is the material resistance partial factor;

$\gamma_{M}$ is the material resistance partial factor;

$\varphi_{R d}$ is the model uncertainty reduction factor;

$\varphi_{m} \quad$ is the material reduction factor;

Here $\gamma_{R d}$ refers to the model uncertainty factor which is calculated using Equation 84. For the structural timber used in this study the model uncertainty variables of the mean $\mu_{\theta R}=1$ and standard deviation $\sigma=0.05$ prescribed in the JCSS probabilistic model code part 3 (2001) for the model uncertainty of timber are applied. The sensitivity factor $\alpha_{R}$ of 0.8 was used under the assumption that the condition described in Equation 66 is valid. In this study, two limit states were investigated, namely, the ultimate limit state (ULS) and serviceability limit state (SLS). A separate target reliability index $\beta$ is used for each of these limit states. For ULS conditions a target reliability of 3.0 is used as prescribed for reliability class RC2 in SANS 10160-1 (2011). Reliability class RC2 refers to residential, office and public buildings where the consequence 
of structure failure is deemed to be moderate with a moderate probability for loss of human life and social, economic and environmental consequences of failure. A target reliability of 1.5 is applied for SLS conditions in accordance to EN 1990 (2010) for the RC2 reliability class. These target reliability indexes are determined for a 50 year reference period. The inverse of the model uncertainty factor termed as the model uncertainty reduction factor $\varphi_{R d}$ shown in Equation 85 .

$$
\gamma_{R d}=\mu_{\theta R} \exp \left(-\alpha_{R} \beta V_{\theta R}\right)
$$

Where:

$\gamma_{R d} \quad$ is the model uncertainty factor;

$\mu_{\theta R} \quad$ is the mean of the model uncertainty variable;

$V_{\theta R} \quad$ is the coefficient of variation of the model uncertainty;

$\alpha_{R} \quad$ is the sensitivity factor.

$$
\varphi_{R d}=\frac{1}{\mu_{\theta R} \exp \left(-\alpha_{R} \beta V_{\theta R}\right)}
$$

Where:

$\varphi_{R d} \quad$ is the model uncertainty reduction factor;

$\mu_{\theta R}$ is the mean of the model uncertainty variable;

$V_{\theta R} \quad$ is the coefficient of variation of the model uncertainty;

$\alpha_{R} \quad$ is the sensitivity factor.

The material factor $\gamma_{m}$ accounts for the inherent variability of the material strength and statistical uncertainty of the strength results. The global formulation of the material factor is shown in Equation 86 where $R_{k}$ represents the characteristic value and $R_{d}$ represents the design value. This is then simplified for the case of a lognormal distribution (Holicky, 2009). The inverse of the material factor is shown by the material reduction factor $\varphi_{m}$ depicted in Equation 87.

$$
\gamma_{m}=\frac{R_{k}}{R_{d}}
$$

Where:

$\gamma_{m}$ is the material factor;

$R_{k} \quad$ is the characteristic resistance value;

$R_{d} \quad$ is the design resistance. 


$$
\varphi_{m}=\frac{1}{\gamma_{m}}=\frac{R_{d}}{R_{k}}
$$

Where:

$\varphi_{m} \quad$ is the material reduction factor;

$R_{k} \quad$ is the characteristic resistance value;

$R_{d} \quad$ is the design resistance.

For instances where the $5^{\text {th }}$ percentile is used as the characteristic value of the material property, Equation 87 is simplified to obtain Equation 88 which is used to calculate the material reduction factor (Sýkora et al, 2013). This is commonly used for ULS conditions and attracts a target reliability of 3.0 with the sensitivity factor of 0.8 (SANS 10160-1, 2011).

$$
\varphi_{m}=\frac{1}{\exp \left[\left(\alpha_{R} \beta-1.645\right) V_{m}\right]}
$$

Where:

$\varphi_{m} \quad$ is the material reduction factor;

$\beta \quad$ is the target reliability factor;

$V_{m} \quad$ is the coefficient of variation the material resistance;

$\alpha_{R} \quad$ is the sensitivity factor.

When the mean is used as the characteristic value for the material property, which is the case commonly used for SLS conditions, the simplified Equation 89 is used to determine the material factor. A target reliability of 1.5 is prescribed for SLS conditions (EN 1990, 2010).

$$
\varphi_{m}=\frac{1}{\exp \left(\alpha_{R} \beta V_{m}\right)}
$$

Where:

$\varphi_{m} \quad$ is the material reduction factor;

$\beta \quad$ is the target reliability factor;

$V_{m} \quad$ is the coefficient of variation the material resistance;

$\alpha_{R} \quad$ is the sensitivity factor.

In cases where the characteristic values for the material properties are determined using equivalent fractiles, the mean and standard deviation which make up the coefficient of variation would drive the values obtained for the partial factor. Therefore the set of material property strength results that have the lower coefficient of variation would result in a higher reduction factor. 


\section{Results and discussion}

\subsection{Physical properties}

\subsubsection{Surface defects}

The results recorded for checking defects are presented in Table 12 as measured in both the wet and dry states. A maximum allowable check width of 2 mm is listed in SANS 1707-1 (2010) and thus was used to determine the rejection rate of the samples. The laminated set experienced significantly less rejections with only 1 sample having check defects higher than the rejection limit in the wet state and 4 samples in the dry state when compared to the standard set which had 6 and 20 rejections in the wet and dry state respectively. The standard boards also had a larger increase in rejected samples after drying even though the average width of the checks remained the same with only the standard deviation increasing. The practical importance of these checking results should be investigated in a full truss arrangement instead of as a single board, as the checks could pose an issue when jointing individual boards into a truss structure using the nail-plated method or they could prove to be insignificant to the joint strength when in a full scale arrangement.

Table 12: Check defects recorded measured in wet and dry states

\begin{tabular}{|c|c|c|c|c|c|c|c|c|}
\hline \multirow{2}{*}{ Check } & \multicolumn{4}{|c|}{ Laminates } & \multicolumn{3}{c|}{ Standard boards } \\
\cline { 2 - 9 } & \multicolumn{2}{|c|}{ Wet } & \multicolumn{2}{c|}{ Dry } & \multicolumn{2}{c|}{ Wet } & \multicolumn{2}{c|}{ Dry } \\
\cline { 2 - 9 } & Length & Width & Length & Width & Length & Width & Length & Width \\
\hline Defect present (\%) & \multicolumn{2}{|c|}{33} & \multicolumn{2}{|c|}{38} & \multicolumn{2}{|c|}{53} & \multicolumn{2}{c|}{57} \\
\hline Average (mm) & 153.1 & 1.3 & 162.8 & 1.3 & 213.9 & 1.5 & 238.4 & 1.5 \\
\hline $\begin{array}{c}\text { Standard Deviation } \\
\text { (mm) }\end{array}$ & 109.3 & 0.6 & 87.0 & 0.8 & 119.1 & 0.7 & 115.0 & 0.9 \\
\hline Max (mm) & 485.0 & 2.5 & 375.0 & 4.0 & 589.0 & 4.0 & 618.0 & 4.0 \\
\hline Rejected (\%) & \multicolumn{2}{|c|}{1} & \multicolumn{2}{|c|}{4} & \multicolumn{2}{|c|}{6} & \multicolumn{2}{|c|}{20} \\
\hline
\end{tabular}

A limitation for maximum split length of up to $150 \mathrm{~mm}$ is prescribed in SANS 1707-1 (2010) where the split fissure extends completely through the thickness of the sample from one face to the opposing face. Due to this definition it was established that none of the laminated samples had end splits above these limitations as when a split was present it only extended through one of the two laminates and thus could not be classified as a true split defect. Thus the lamination 
process had restrained the split defects as for instances when there was an element of the defect present for a single half of the laminate in the wet state, it did not extend through the adhesive layer during drying.

Table 13 shows the results of end splits for the standard set in both the wet and dry states. Many of the samples had displayed an element of the defect but only to a small extent where the fissure commonly did not extend through the thickness of the board for a large length of the split even though the length of the surface fissure was marked and recorded. Thus 74 samples had displayed an element of the defect in the dry state with only 15 samples having end splits above the limitations in the dry state and 6 in the wet state (SANS 1707-1, 2010). The split defects did not appear to extend as greatly as expected during drying which was deemed to be as a result of the finger-joints, which are commonly positioned close to the end of the samples, restricting the growth of the split further along the length of the sample. These splits could also be further reduced by using nail plates as end caps, or anti-split screws to restrict the splitting in practice or a similar effect could be achieved by using facia boards fixed to the end of the boards when the roof trusses are assembled in the wet state.

Table 13: Split defects

\begin{tabular}{|c|c|c|c|c|}
\hline \multirow{2}{*}{ Split } & \multicolumn{3}{|c|}{ Standard boards } \\
\cline { 2 - 5 } & \multicolumn{2}{|c|}{ Wet } & \multicolumn{2}{c|}{ Dry } \\
\cline { 2 - 5 } & Length & Width & Length & Width \\
\hline Defect present (\%) & \multicolumn{2}{|c}{72} & \multicolumn{2}{c|}{74} \\
\hline Average (mm) & 86.7 & 1.9 & 115.1 & 1.9 \\
\hline Standard Deviation (mm) & 60.4 & 0.9 & 84.7 & 2.6 \\
\hline Max (mm) & 349.0 & 4.5 & 451.0 & 21.0 \\
\hline Rejected (\%) & \multicolumn{3}{|c|}{6} & \multicolumn{3}{c|}{15} \\
\hline
\end{tabular}

\subsubsection{Warp}

The results recorded for bow deformation of the two sets are displayed in Table 14 below. It is shown that 90 of the 100 face laminated samples displayed an element of bow with an average bow of $2.43 \mathrm{~mm}$ being recorded. For the standard boards, 92 had an element of bow deformation with an average of $2.49 \mathrm{~mm}$. None of the samples had exceeded the $20 \mathrm{~mm}$ limit of allowable bow deformation for a $2 \mathrm{~m}$ long sample which is set out in SANS 1707-1 (2010). Thus it is shown that even though the samples had dried under severe conditions, bow deformation did 
not pose any significant issue to the yield of the material. No significant variation was found between the two sets in terms of bow with only a slight improvement in mean being noted for the laminated samples. The distribution of bow results are depicted in Figure 26 for the two sets.

Table 14: Results for bow deformation of the laminated and standard sets

\begin{tabular}{|c|c|c|c|c|c|}
\hline Bow & $\begin{array}{c}\text { Defect present } \\
(\boldsymbol{\%})\end{array}$ & $\begin{array}{c}\text { Average } \\
(\mathbf{m m})\end{array}$ & $\begin{array}{c}\text { Std Dev } \\
(\mathbf{m m})\end{array}$ & $\begin{array}{c}\text { Max } \\
(\mathbf{m m})\end{array}$ & $\begin{array}{c}\text { Rejected } \\
(\boldsymbol{\%})\end{array}$ \\
\hline Laminates & 90 & 2.43 & 1.70 & 8 & 0 \\
\hline Standard Boards & 92 & 2.49 & 1.81 & 10 & 0 \\
\hline
\end{tabular}

\section{Bow}

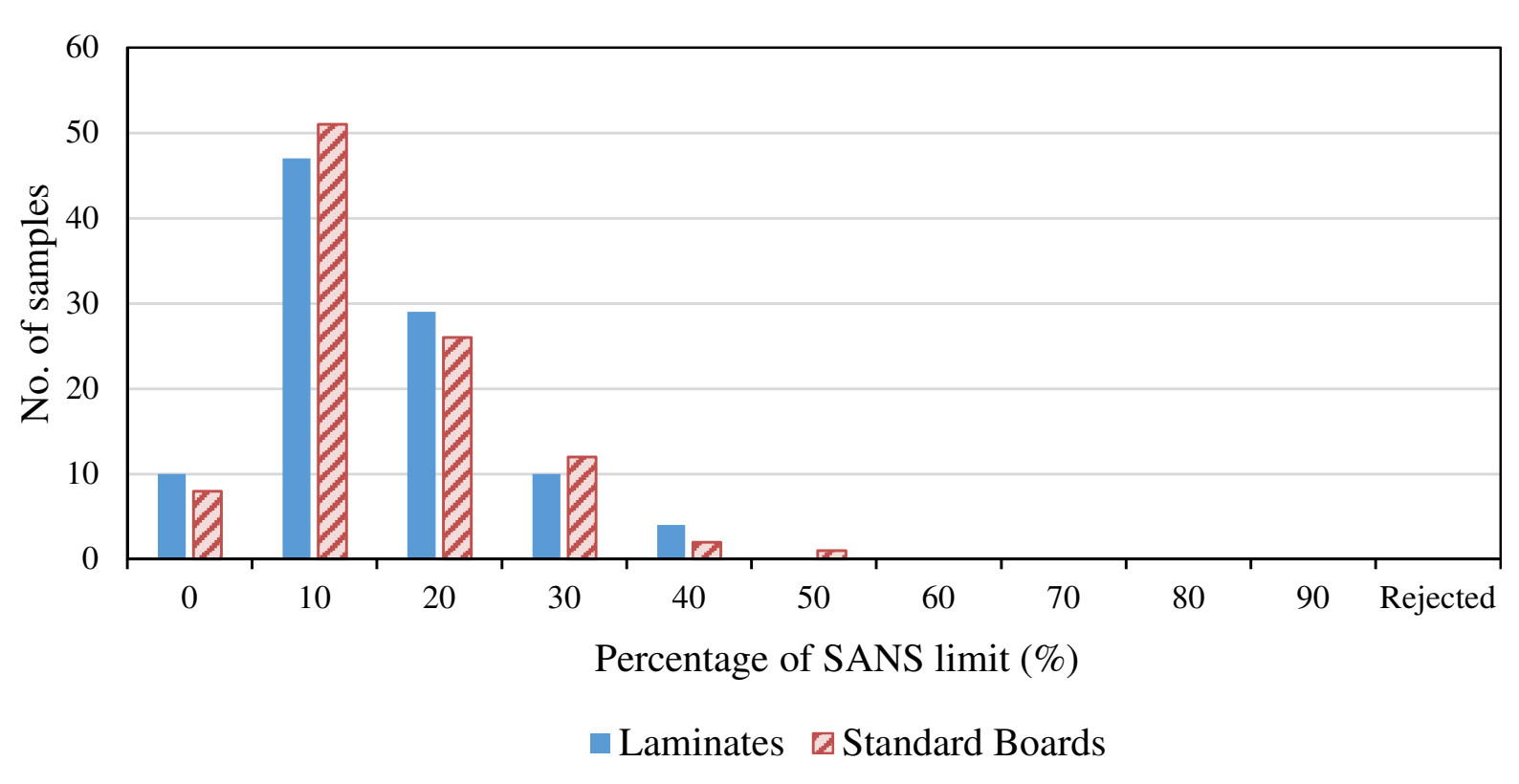

Figure 26: Distribution of bow results as a percentage of allowable bow

In Table 15 the levels of cup recorded for each set is depicted. Neither of the two sets had any samples which exceeded the limit of $3 \mathrm{~mm}$ of cup per $100 \mathrm{~mm}$ width of each sample (SANS 1707-1, 2010). The standard boards exhibited slightly more cup with a mean of $1.27 \mathrm{~mm}$ compared to the $0.98 \mathrm{~mm}$ of the face laminates. This was deemed to occur due to the end of the standard boards being free to deform as opposed to the laminates which were restricted by the corresponding laminate and the possibility of the finger-joint being close to the end of the board for at least one of the laminates which further restricts the deformation. The relatively short 
spans between finger joints are believed to decrease the cup which may form at the end of the boards resulting in a $100 \%$ yield of samples with respect to cup limitations. Figure 27 shows the distribution of cup results of the two sets as a percentage of the allowable cup.

Table 15: Results for cup deformation of the laminated and standard sets

\begin{tabular}{|c|c|c|c|c|c|}
\hline Cup & $\begin{array}{c}\text { Defect present } \\
(\boldsymbol{\%})\end{array}$ & $\begin{array}{c}\text { Average } \\
(\mathbf{m m})\end{array}$ & $\begin{array}{c}\text { Std Dev } \\
(\mathbf{m m})\end{array}$ & $\begin{array}{c}\text { Max } \\
(\mathbf{m m})\end{array}$ & $\begin{array}{c}\text { Rejected } \\
(\boldsymbol{\%})\end{array}$ \\
\hline Laminates & 49 & 0.98 & 0.36 & 2.00 & 0 \\
\hline $\begin{array}{c}\text { Standard } \\
\text { Boards }\end{array}$ & 86 & 1.27 & 0.46 & 2.50 & 0 \\
\hline
\end{tabular}

\section{Cup}

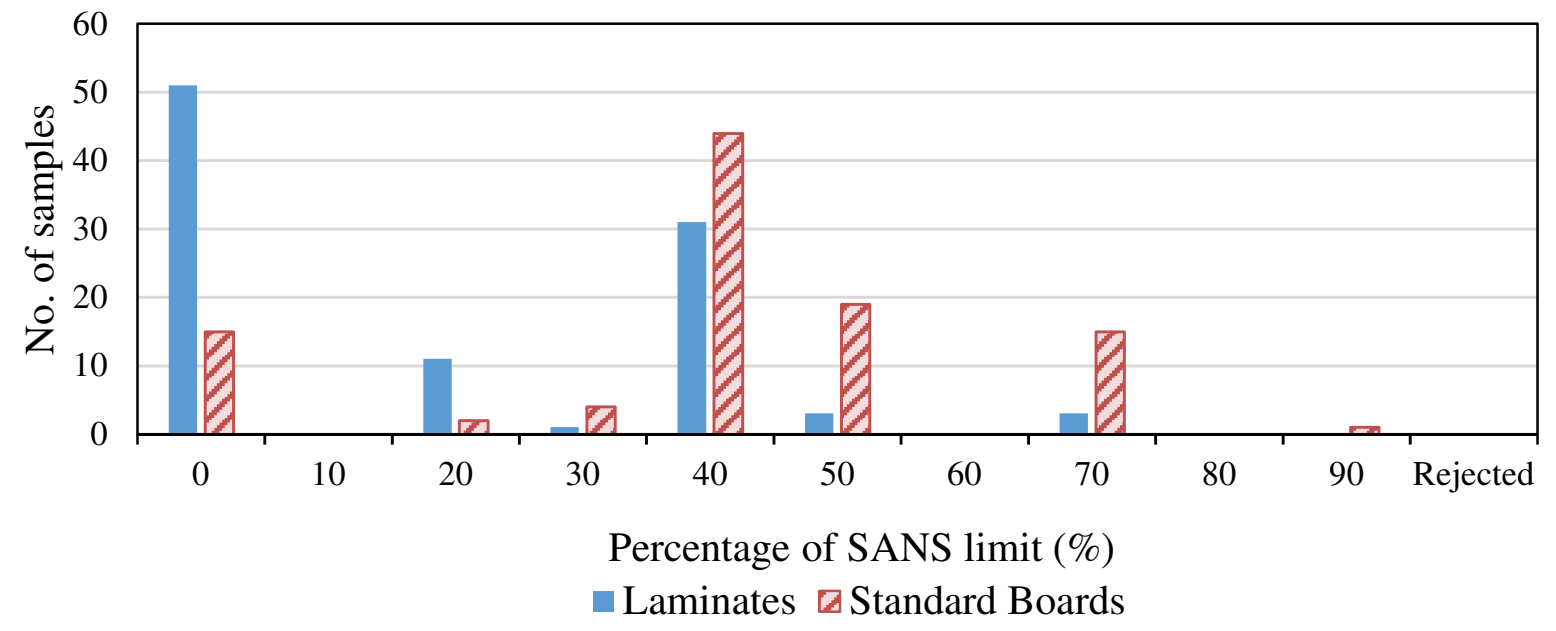

Figure 27: Distribution of cup results as a percentage of allowable cup

Twist was noted to be a possible critical defect for young Eucalyptus grandis boards in an investigation completed by Crafford (2013). In that study it was found that a total of $30 \%$ of the samples did not adhere to twist limitations of SANS 1707-1 (2010). Although the set of smaller dimensioned samples tested, namely the $48 \times 73 \mathrm{~mm}$ set, had the majority of twist rejections with $45 \%$ compared to the larger size of $36 \times 111 \mathrm{~mm}$ dimension boards only exhibiting a $14 \%$ rejection rate. This variation was deemed to be caused by the higher percentage of pith material being present in the smaller dimensioned samples as they had originated from younger trees. 
The results obtained for twist in this study are shown in Table 16 along with the distribution of results for each set which is depicted in Figure 28. It is shown here that the face laminated set had an average twist approximately 1 degree lower than that of the standard boards with 13 less samples showing any level of twist. This is also portrayed in Figure 28 where it is visible that the laminates showed a lower percentage of twist with respect to the limit of 4.667 degrees for a $2 \mathrm{~m}$ long sample as extrapolated from Table 2 of SANS 1707-1 (2010). Only 1 sample experienced twist above the limit for the laminated set compared to the 9 standard samples rejected for these samples with dimensions of $36 \times 102 \mathrm{~mm}$. This is similar to the results obtained by Crafford (2013) for the samples of 36 x $111 \mathrm{~mm}$ dimensions which confirms that samples containing less pith material would experience less twist deformation.

The results obtained for the laminated and standard sets are promising when compared to a study completed by Dowse (2010) on select mechanical properties of young Pinus patula sawn timber where $57 \%$ of the samples were rejected according to the twist limitations set out in the structural softwood timber code SANS 1783-2 (2012). It is evident that the face lamination can further ameliorate the twist deformation along with the finger-jointing as some sections in the finger-jointed boards twist in opposing directions and to varying extents which has the potential to lower the overall twist of the sample. The face laminat0dion is deemed to extend this averaging out of the defects as the laminates could twist in conflicting directions or if one would have the tendency to twist further than the other. Thus the laminates being bonded together lowers the overall twist as depicted here where the laminated set experienced a substantially lower rejection rate than the standard set.

Table 16: Results for twist deformation of the laminated and standard sets

\begin{tabular}{|c|c|c|c|c|c|}
\hline Twist & $\begin{array}{c}\text { Defect present } \\
(\boldsymbol{\%})\end{array}$ & $\begin{array}{c}\text { Average } \\
(\mathbf{d e g})\end{array}$ & $\begin{array}{c}\text { Std Dev } \\
(\mathbf{d e g})\end{array}$ & $\begin{array}{c}\text { Max } \\
(\mathbf{d e g})\end{array}$ & $\begin{array}{c}\text { Rejected } \\
(\boldsymbol{\%})\end{array}$ \\
\hline Laminates & 77 & 1.69 & 0.94 & 4.68 & 1 \\
\hline Standard Boards & 90 & 2.62 & 1.40 & 5.87 & 9 \\
\hline
\end{tabular}




\section{Twist}

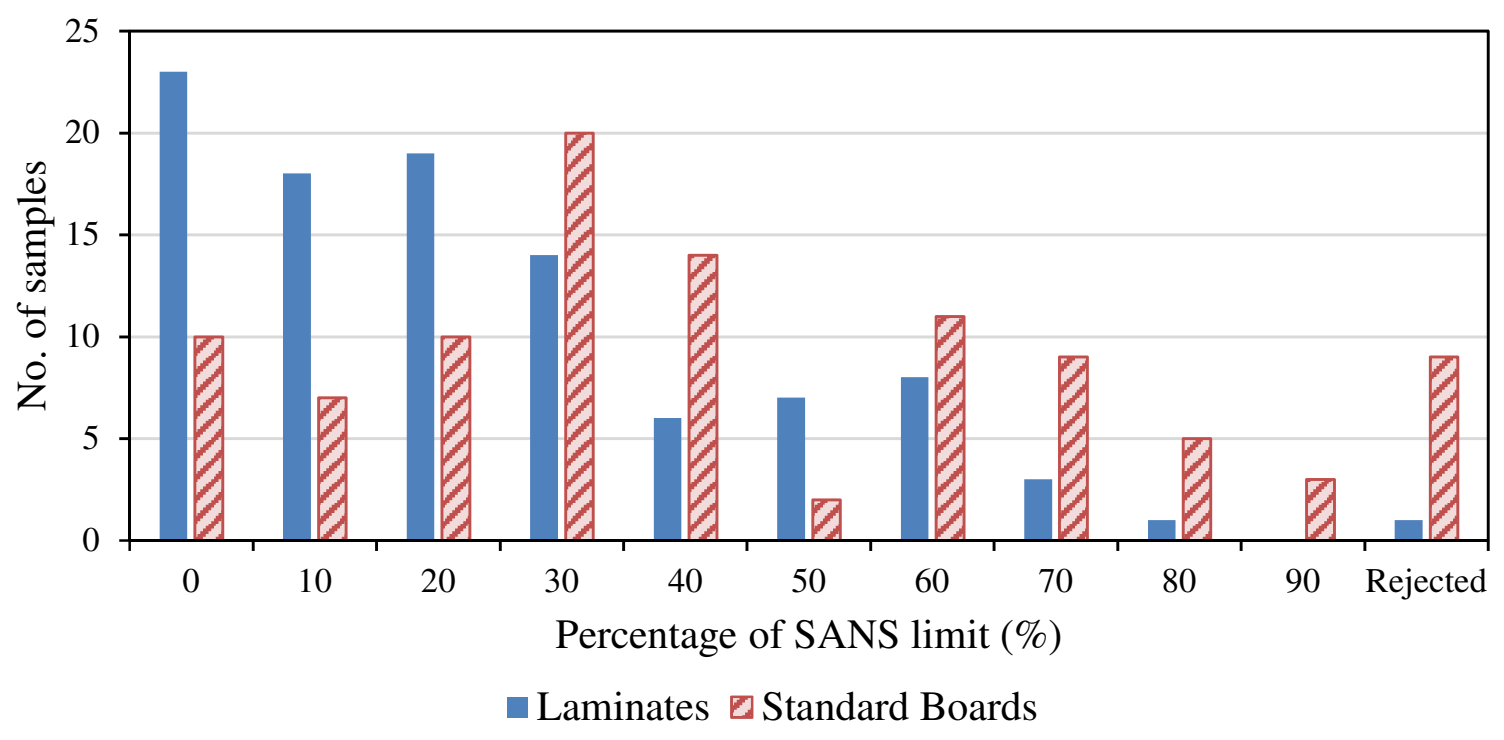

Figure 28: Distribution of twist results represented as a percentage of allowable twist.

\subsubsection{Density and moisture content}

The density results recorded for the samples are listed in Table 17 with the distribution of results for both sets being depicted in Figure 29. Both sets had density levels above the grade S7 requirements of $425 \mathrm{~kg} / \mathrm{m}^{3}$ listed in SANS 1783-2 (2012). Low standard deviations were noted showing that consistent density values were recorded with no significant outliers being found. No statistically significant difference was found between the means at the $95 \%$ confidence level.

Table 17: Density results recorded just prior to destructive testing

\begin{tabular}{|c|c|c|c|c|c|}
\hline Density & Mean $\left(\mathbf{K g} / \mathbf{m}^{\mathbf{3}}\right)$ & $\begin{array}{c}\text { Std Dev } \\
\left(\mathbf{K g} / \mathbf{m}^{\mathbf{3}}\right)\end{array}$ & $\begin{array}{c}\mathbf{C O V} \\
(\mathbf{\%})\end{array}$ & $\mathbf{M a x}\left(\mathbf{K g} / \mathbf{m}^{\mathbf{3}}\right)$ & $\begin{array}{c}\mathbf{M i n} \\
\left(\mathbf{K g} / \mathbf{m}^{\mathbf{3}}\right)\end{array}$ \\
\hline Laminates & 518.20 & 34.71 & 6.70 & 608.47 & 448.54 \\
\hline Standard Boards & 516.15 & 44.66 & 8.65 & 646.63 & 438.92 \\
\hline
\end{tabular}




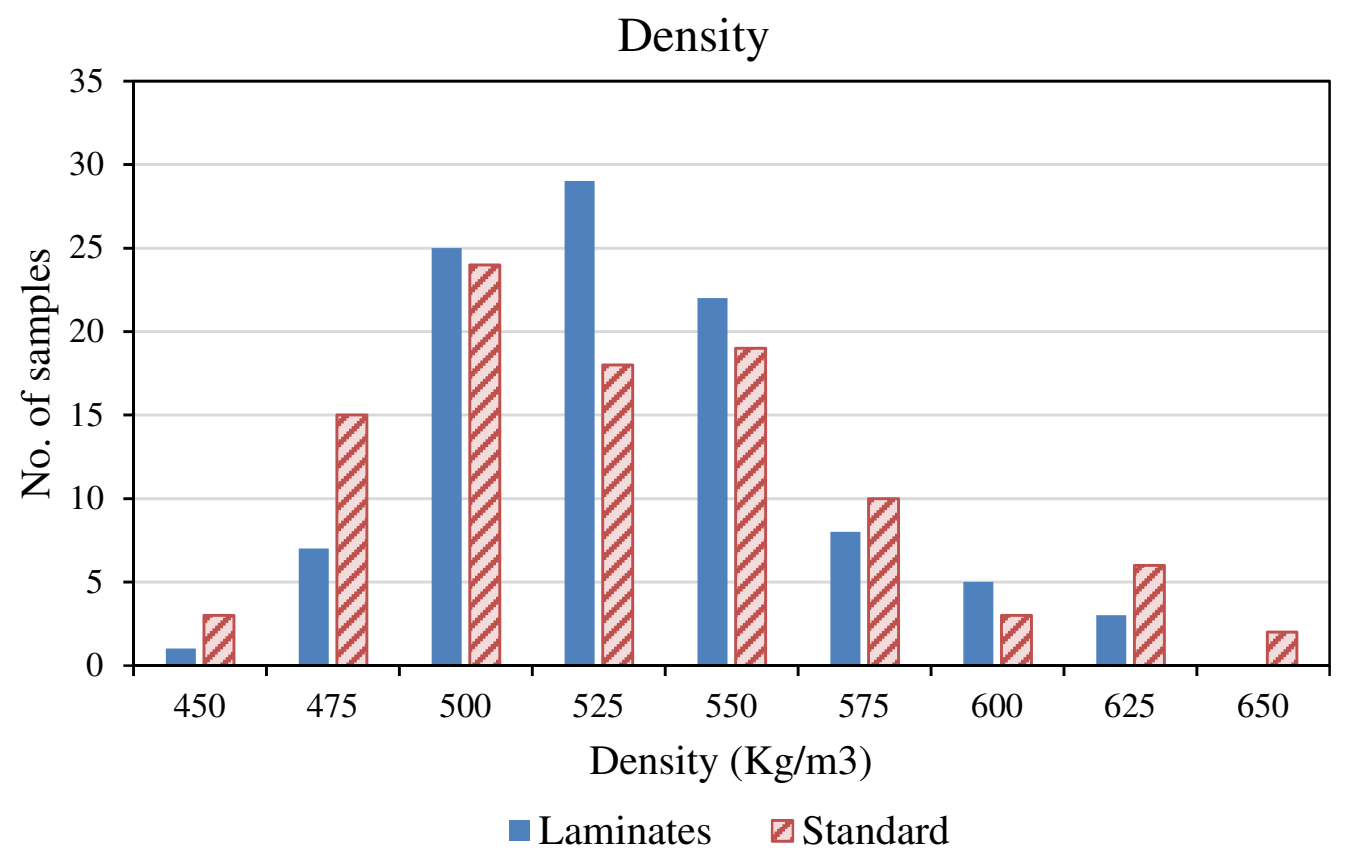

Figure 29: Distribution of density results recorded just prior to destructive testing

Table 18 shows that the standard set had shown a mean moisture content slightly higher than the laminated set with a mean of $13.31 \%$ as opposed to $12.84 \%$. This is also depicted in Figure 30 where the distribution of the standard set is shifted slightly to the right compared to the laminated set. Both sets exhibit low coefficient of variation values of approximately $6 \%$ which shows that consistent drying was achieved for both sets in the greenhouse. The use of fans blowing through the stacked samples is deemed to have assisted in achieving these consistent moisture content results by ensuring that the samples at the centre of the stack had enough air flowing over them to facilitate the drying.

Table 18: Moisture content results recorded just prior to destructive testing

\begin{tabular}{|c|c|c|c|c|c|}
\hline Moisture Content & $\begin{array}{c}\text { Mean } \\
(\boldsymbol{\%})\end{array}$ & $\begin{array}{c}\text { Std Dev } \\
(\boldsymbol{\%})\end{array}$ & $\begin{array}{c}\text { COV } \\
(\boldsymbol{\%})\end{array}$ & $\begin{array}{c}\text { Max } \\
(\boldsymbol{\%})\end{array}$ & $\begin{array}{c}\text { Min } \\
(\boldsymbol{\%})\end{array}$ \\
\hline Laminates & 12.84 & 0.76 & 5.92 & 15.05 & 10.60 \\
\hline Standard Boards & 13.31 & 0.81 & 6.12 & 15.40 & 10.70 \\
\hline
\end{tabular}




\section{Moisture Content}

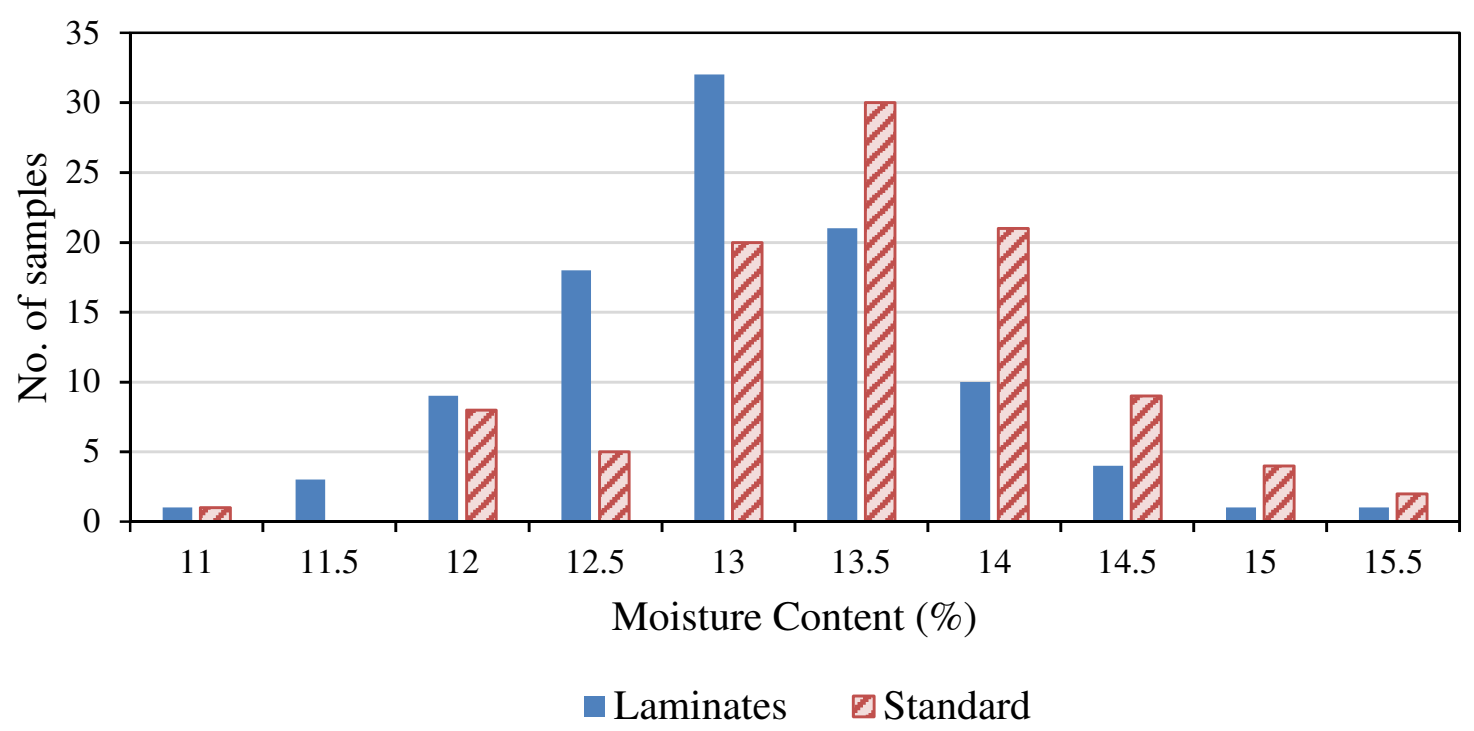

Figure 30: Distribution of moisture contents recorded just prior to destructive testing

\subsection{Destructive tests}

The common failure modes experienced by the samples upon completion of the four point bending tests are displayed in Figure 31 to Figure 34. Many samples exhibited brash tension failure (clean break) adjacent to the finger-joint as shown in Figure 31. Some samples experienced diagonal tension failure originating at the finger-joint as depicted in Figure 32 or originating at defects on the tension edge of the board represented in Figure 33. Localised cross grain tension failures were also noted as shown in Figure 34 (Bodig and Jayne, 1982). Thus there was no definitive failure mode found for the samples although most had brash failure next to the finger-joint. 


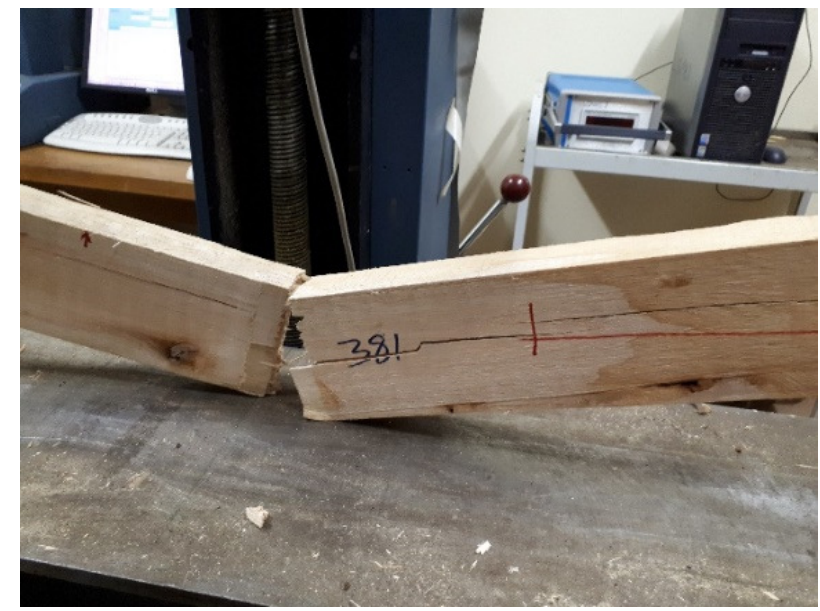

Figure 31: Bending test - brash tension failure adjacent to a finger-joint

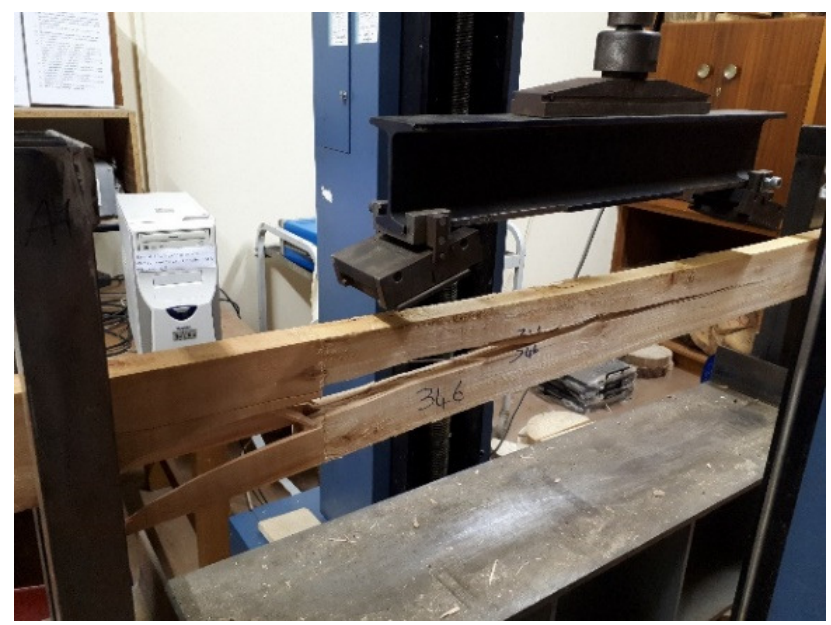

Figure 32: Bending test - diagonal tension failure originating at finger joint

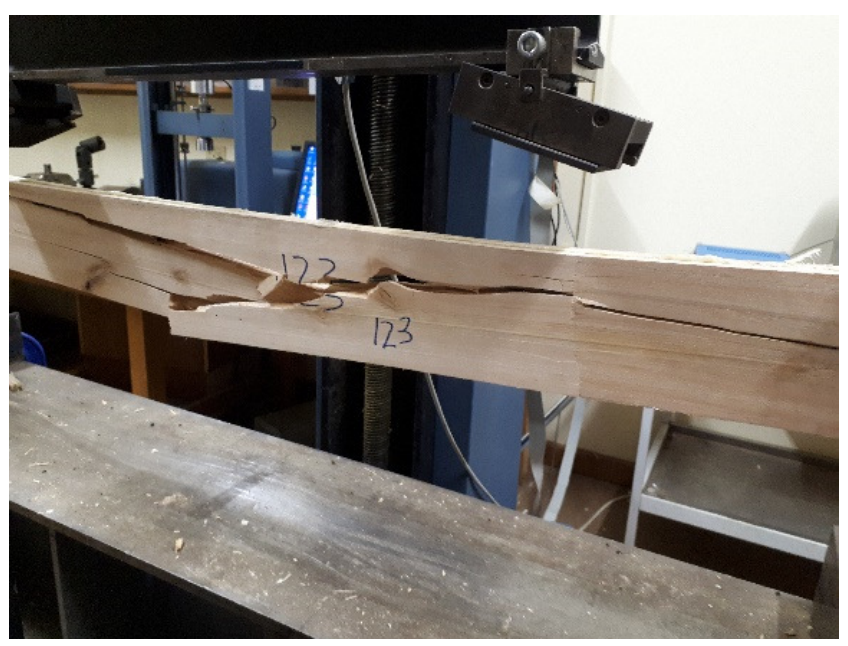

Figure 33: Bending test - diagonal tension failure originating at defect 


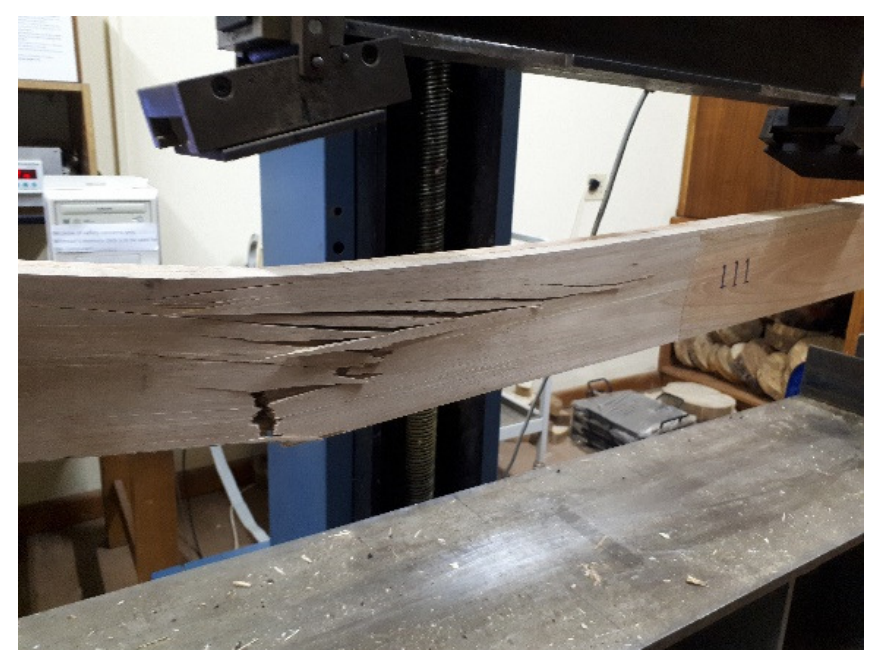

Figure 34: Bending test - localised cross grain tension failure

\subsubsection{Distributions}

The results of the chi-square goodness of fit tests are displayed in the figures below as obtained using Statistica for the MOE and MOR results of both sets.
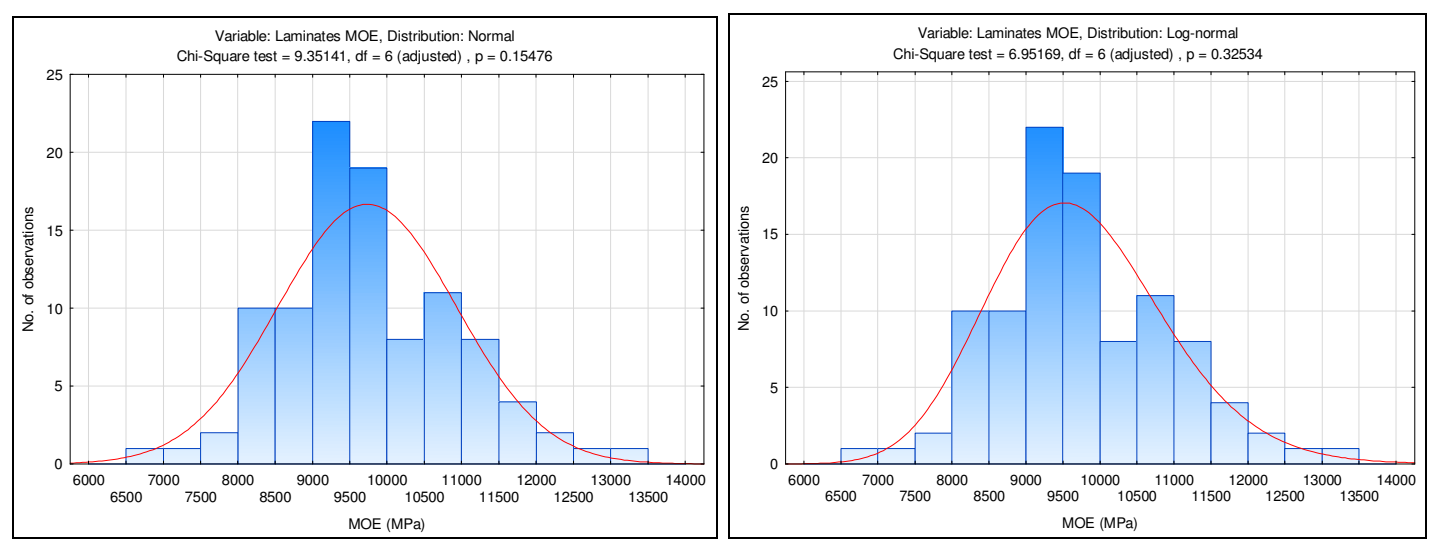

Figure 35: Laminates MOE normal and lognormal distribution fits 

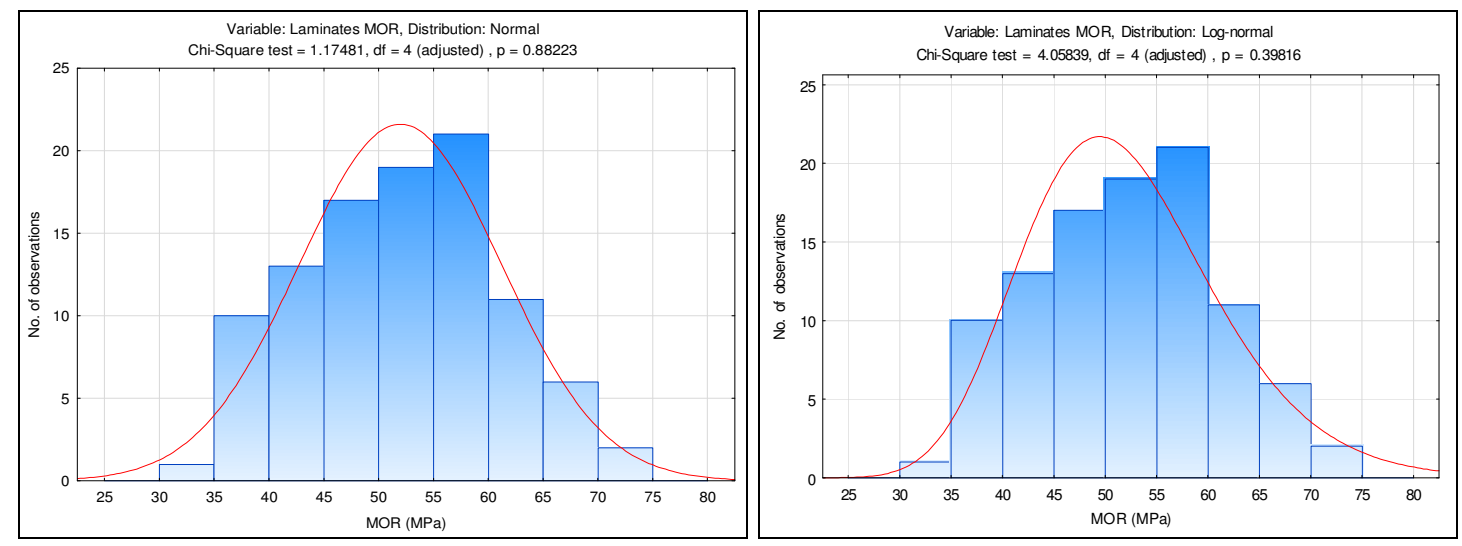

Figure 36: Laminates MOR normal and lognormal distribution fits
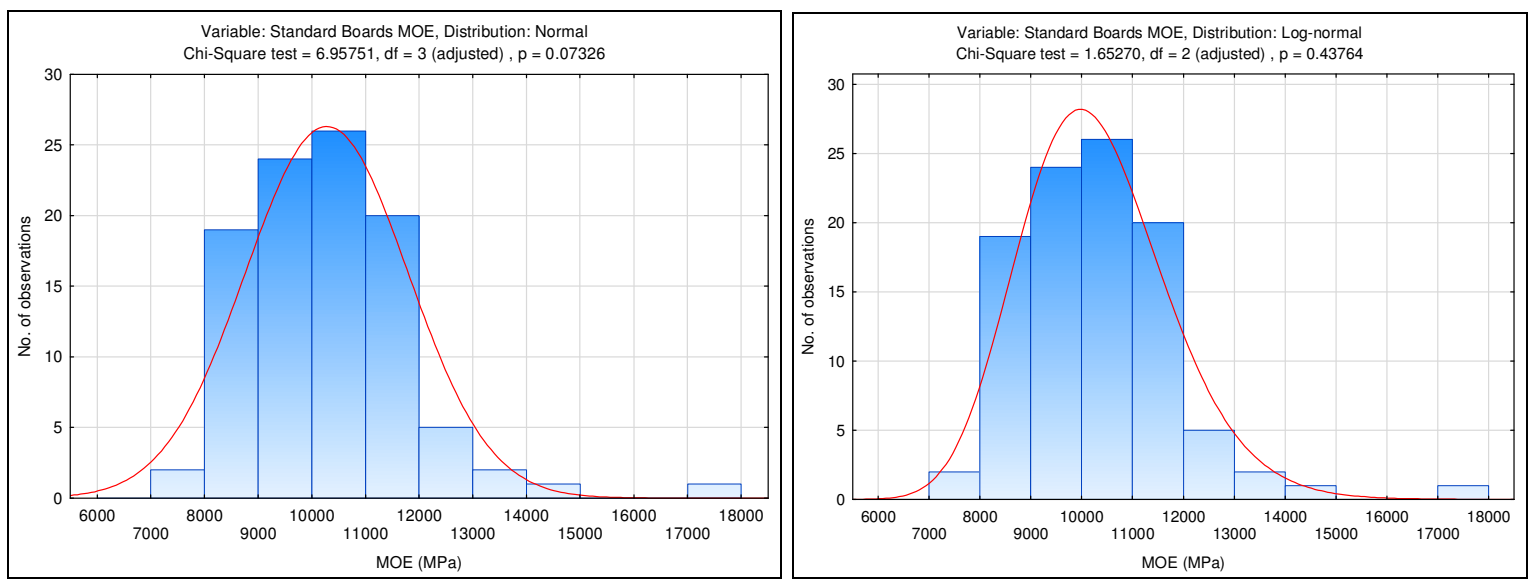

Figure 37: Standard boards MOE normal and lognormal distribution fits
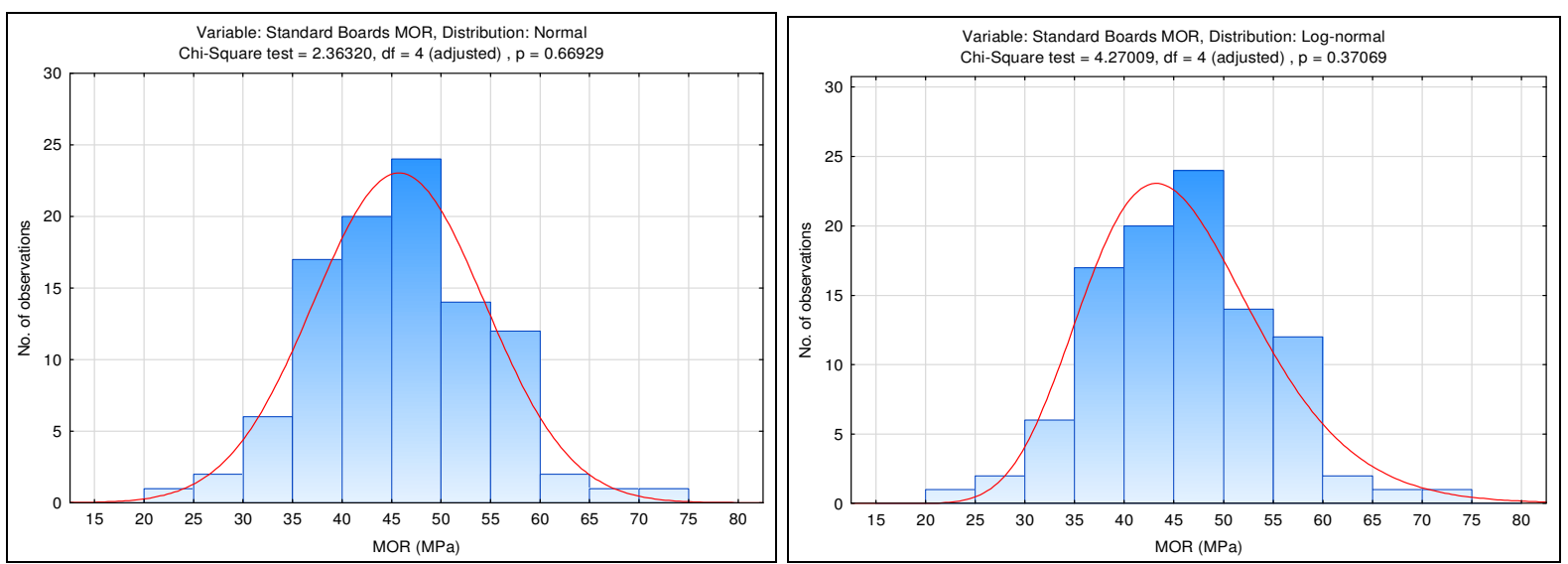

Figure 38: Standard boards MOR normal and lognormal distribution fits

The degree of significant difference between the sets increases as the p-value decreases, thus a higher $\mathrm{p}$-value indicates a more accurate fit to the expected distribution. It is shown here that 
all of the sets conform to an acceptable p-value (where $\mathrm{p}>0.05$ ) for both the normal and lognormal distribution fits. There is however only low agreement with the normal distribution for both of the MOE sets where a p-value of 0.15 and 0.07 was obtained for the laminated and standard sets respectively. These low p-values show an increased difference between the sample distributions and the expected normal distribution. The lognormal distribution is thus deemed to be acceptable to be used to represent the data as low difference is obtained between the sample distributions and expected distributions for all sets. This decision is also motivated as the lognormal distribution is prescribed to represent the MOR and MOE of structural timber in the JCSS probabilistic model code (2001).

\subsubsection{Modulus of rupture}

Table 19 displays the basic statistics of the recorded bending strength results of the two sets. Both sets displayed strength results which surpassed the SANS characteristic grade stress for grade S10 (23.3 MPa) with $5^{\text {th }}$ percentile values above $30 \mathrm{MPa}$ for both sets. No particularly weak boards were experienced with the minimum values for both sets being larger than the grade S7's $5^{\text {th }}$ percentile requirement of $15.8 \mathrm{MPa}$ while the lowest structural grade S5, having a requirement of 11.5 MPa is well exceeded (SANS10163-1, 2005). Although the laminated samples had achieved a characteristic stress of $5 \mathrm{MPa}$ greater than the standard boards, the confidence intervals calculated for these sets at the $95 \%$ confidence level overlapped each other which represents that the difference between these $5^{\text {th }}$ percentile values is not statistically significant. However, inspecting the data points around the $5^{\text {th }}$ percentile values of each set as shown in Figure 39 where the $5^{\text {th }}$ percentile value is marked by a bar, it appears from visual observation as if this "tail" section of each set is different. It is visible from the spread of the lowest $10 \%$ of values shown in Figure 39 that large gaps in the tail of results can cause a misrepresentation of the $5^{\text {th }}$ percentile which in this case could vary by $2 \mathrm{MPa}$ due to the spread of data. It might be that higher sample numbers will reveal statistically significant differences in $5^{\text {th }}$ percentile values of the different sets or that the statistical method used was not appropriate. Future studies could perhaps investigate the methods used to compare $5^{\text {th }}$ percentile values and specifically the appropriate sample numbers required for such comparisons. The coefficient of variation of the laminates was found to be approximately $1 \%$ less than that of the 
standard boards which would result in a marginally higher material resistance reduction factor due to the slightly lower variability in strength results.

Table 19: Basic statistics of MOR results of the laminated and standard sets

\begin{tabular}{|c|c|c|c|c|c|c|c|}
\hline MOR & $\begin{array}{c}\text { Mean } \\
(\mathbf{M P a})\end{array}$ & $\begin{array}{c}\text { Std Dev } \\
(\mathbf{M P a})\end{array}$ & $\begin{array}{c}\text { COV } \\
(\boldsymbol{\%})\end{array}$ & $\begin{array}{c}\text { 5th Perc } \\
(\mathbf{M P a})\end{array}$ & $\begin{array}{c}\text { Max } \\
(\mathbf{M P a})\end{array}$ & $\begin{array}{c}\text { Min } \\
(\mathbf{M P a})\end{array}$ & $\begin{array}{c}\text { Range } \\
(\mathbf{M P a})\end{array}$ \\
\hline Laminates & 52.0 & 9.2 & 17.7 & 36.6 & 75.0 & 30.2 & 44.8 \\
\hline Standard & 45.8 & 8.7 & 18.9 & 31.2 & 72.6 & 22.3 & 50.3 \\
\hline
\end{tabular}

\section{Ranked lowest $10 \%$ of MOR Values}

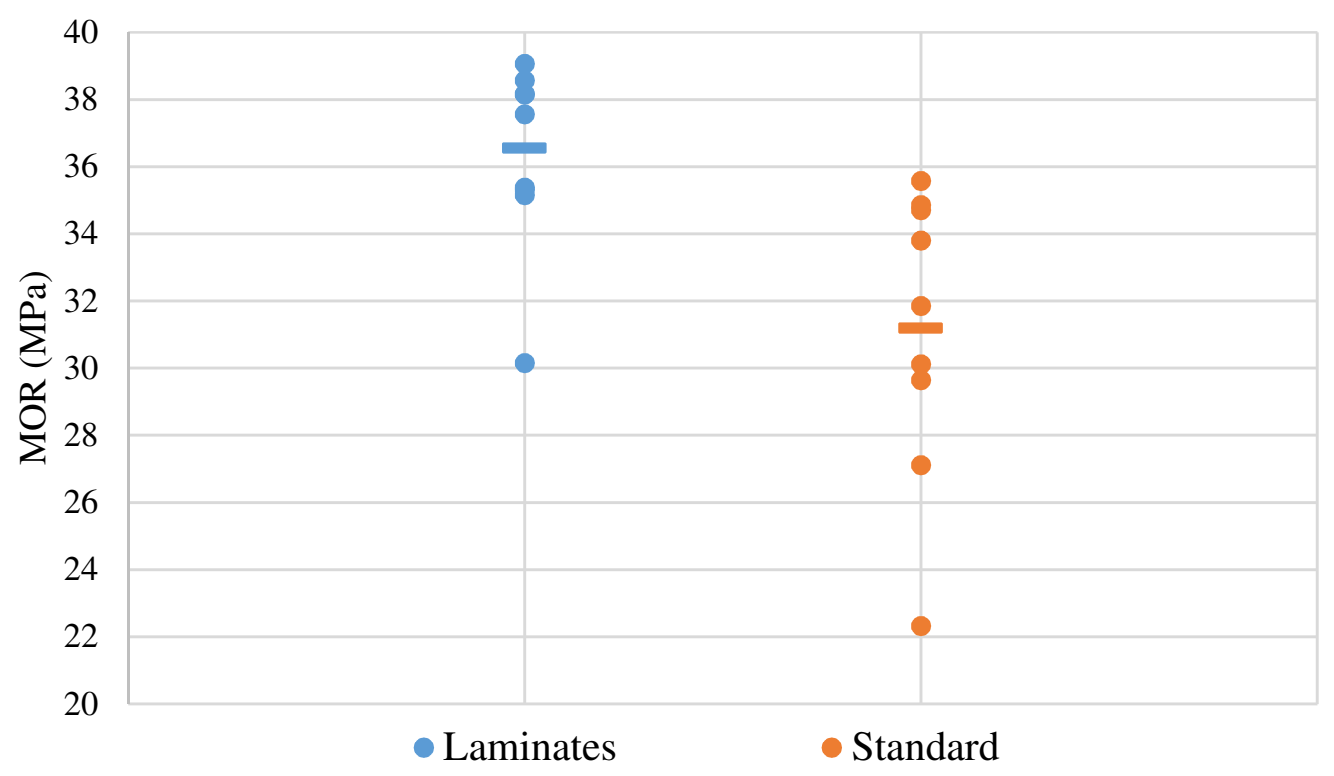

Figure 39: Distribution of lowest $10 \%$ of MOR values $\left(5^{\text {th }}\right.$ percentile marked with bar)

As shown by the bootstrapped ANOVA comparison in Figure 40 where the laminated and standard sets were also compared to results obtained by Crafford (2013) of wet and dry Biligom samples, a statistically significant difference was found between the means of the laminated and standard sets at the 0.05 significance level. The larger mean value obtained for the laminated set could be attributed to the lamination process decreasing the effect of defects present in a specimen. This reduction is caused by the random orientation of the laminates as the defect does not extend through the entire thickness of the sample. A statistically significant similarity was also recorded between the standard set and the dry Biligom set of Crafford (2013). Figure 41 displays the distributions of the sets, it can be seen that the 
distributions are very similar in shape with the laminated set having a greater percentage of samples with higher strength values.

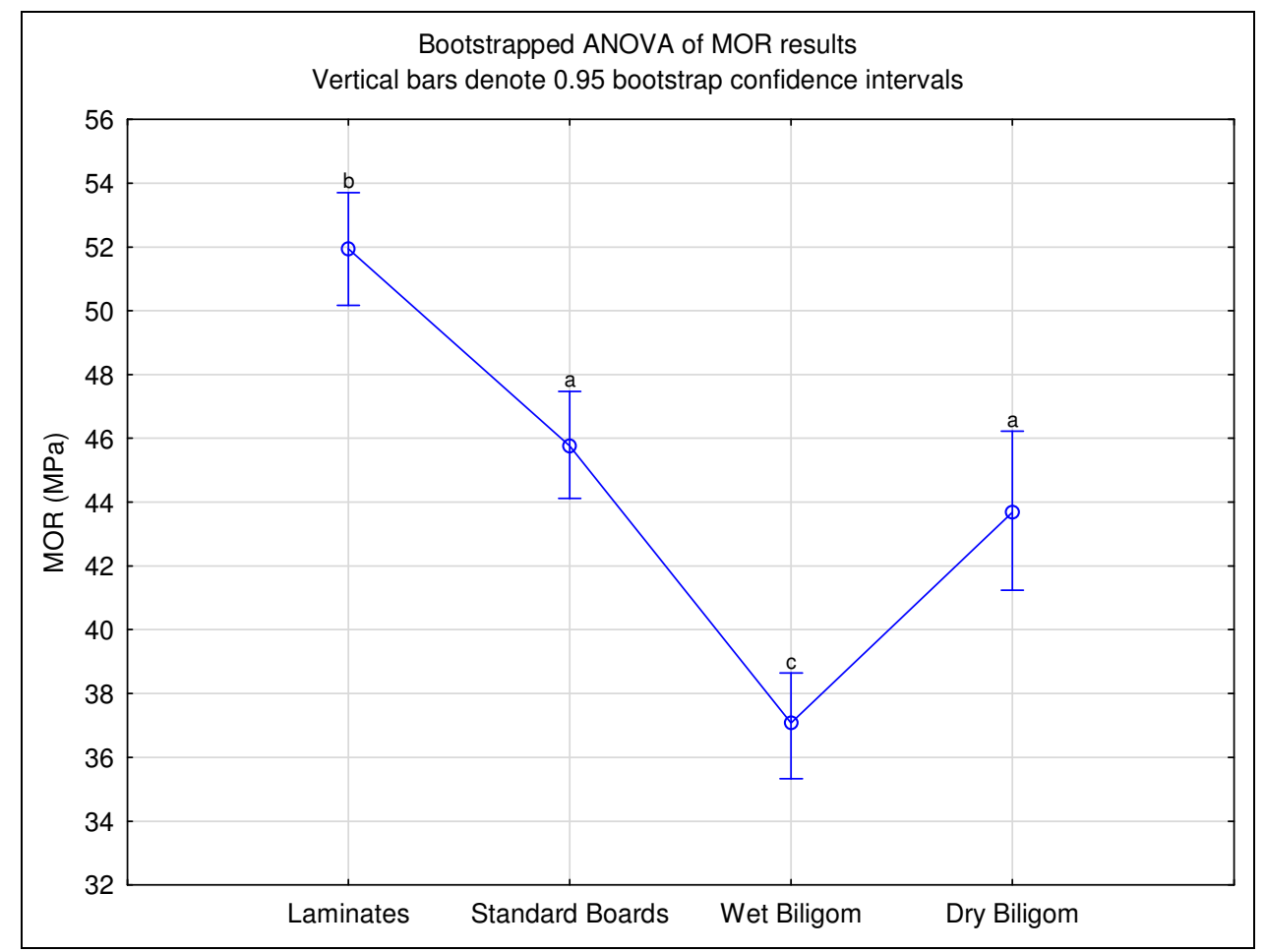

Figure 40: Bootstrapped ANOVA comparison of the MOR results

Distribution of MOR results

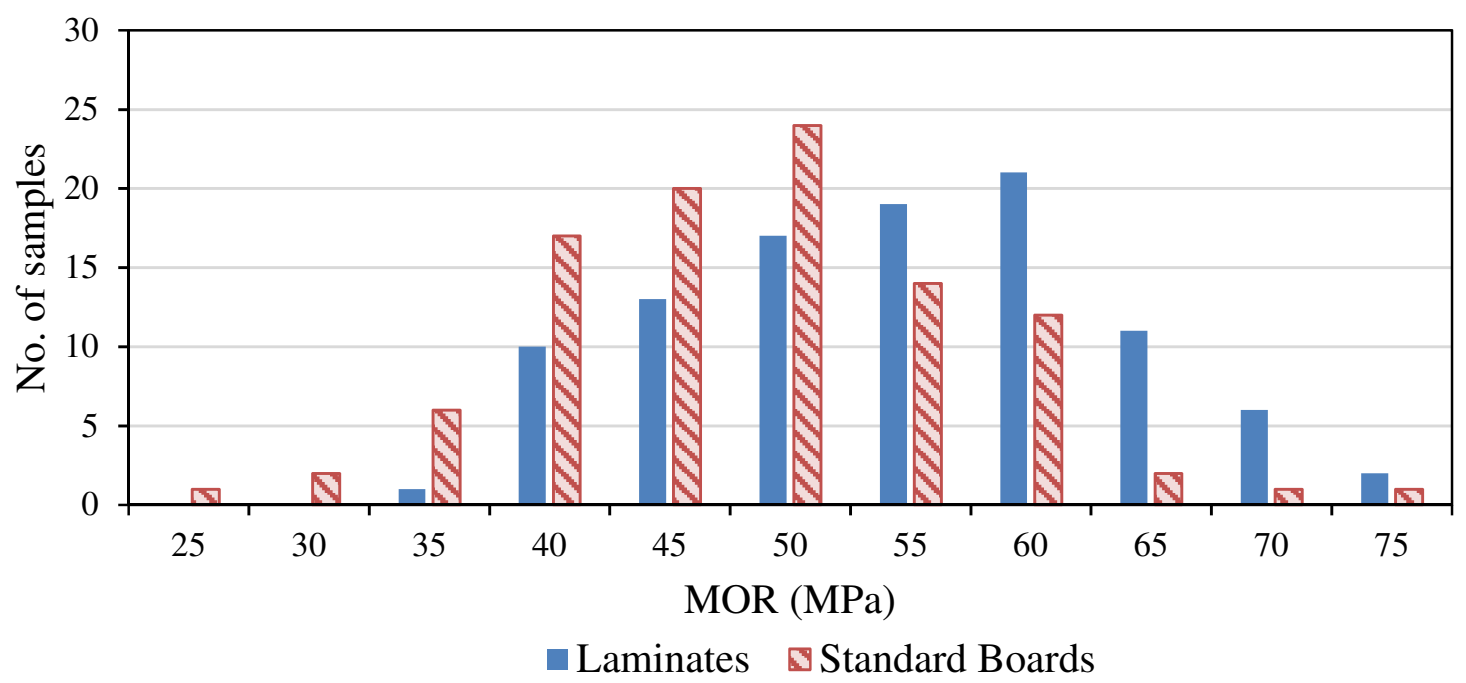

Figure 41: Distribution of MOR results of the laminated and standard boards 
It is evident from the high coefficient of variation values recorded in the study on SA pine as shown in Table 2 that the young finger-jointed Eucalyptus grandis has much less variability in the strength properties of the resource. The characteristic stress results for the SA pine was also much lower than that of the finger-jointed Eucalyptus grandis with sawmill 5 obtaining a characteristic value which would not even surpass requirements for grade S5 structural timber.

\subsubsection{Modulus of elasticity}

The stiffness results of the samples as measured on edge are listed in Table 20. Both sets had results higher than the grade $\mathrm{S} 7$ required mean value of $9600 \mathrm{MPa}$ and $5^{\text {th }}$ percentile value of $5700 \mathrm{MPa}$ which has been included in the draft version of SANS 10163-1 for use in design. The mean stiffness of the standard set was statistically significantly higher than that of the laminated set as shown in Figure 42 of the bootstrapped ANOVA test completed at the $95 \%$ confidence level. Even though the difference in means was statistically significant, less variation was found between the $5^{\text {th }}$ percentile values which was deemed to not be statistically significantly different at the $95 \%$ confidence level as the confidence intervals of the two sets overlapped. The spread in the lowest $10 \%$ of results for the laminated and standard sets are shown in Figure 43.

Table 20: Basic statistics of MOE results of the laminated and standard sets

\begin{tabular}{|c|c|c|c|c|c|c|c|}
\hline MOE & $\begin{array}{c}\text { Mean } \\
(\mathbf{M P a})\end{array}$ & $\begin{array}{c}\text { Std Dev } \\
(\mathbf{M P a})\end{array}$ & $\begin{array}{c}\text { COV } \\
(\boldsymbol{\%})\end{array}$ & $\begin{array}{c}\text { 5th Perc } \\
(\mathbf{M P a})\end{array}$ & $\begin{array}{c}\text { Max } \\
(\mathbf{M P a})\end{array}$ & $\begin{array}{c}\text { Min } \\
(\mathbf{M P a})\end{array}$ & $\begin{array}{c}\text { Range } \\
(\mathbf{M P a})\end{array}$ \\
\hline Laminates & 9729 & 1199 & 12.33 & 8031 & 13203 & 6880 & 6323 \\
\hline Standard & 10279 & 1516 & 14.75 & 8328 & 17019 & 7904 & 9114 \\
\hline
\end{tabular}




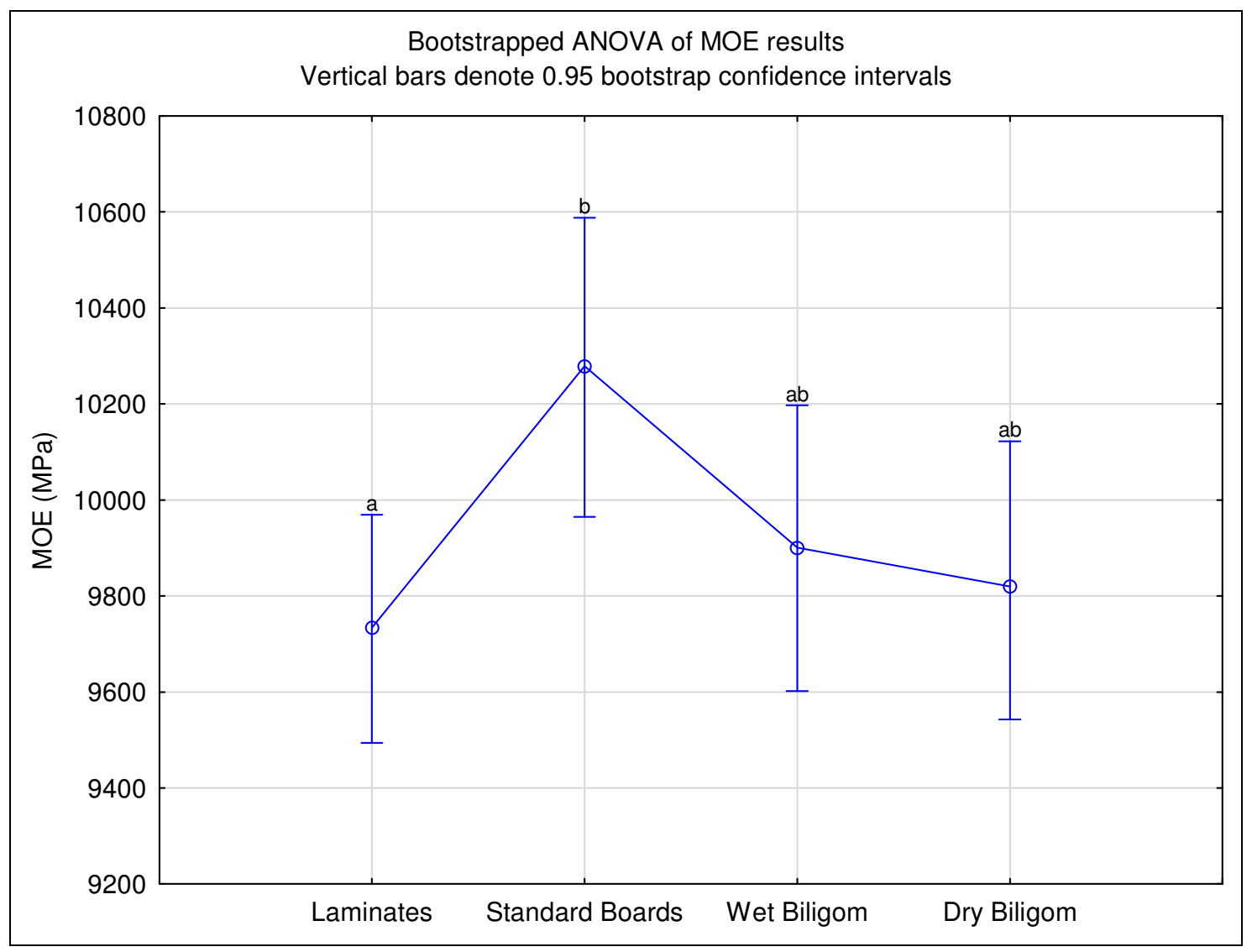

Figure 42: Bootstrapped ANOVA results of the MOE means

Ranked lowest $10 \%$ of MOE Values

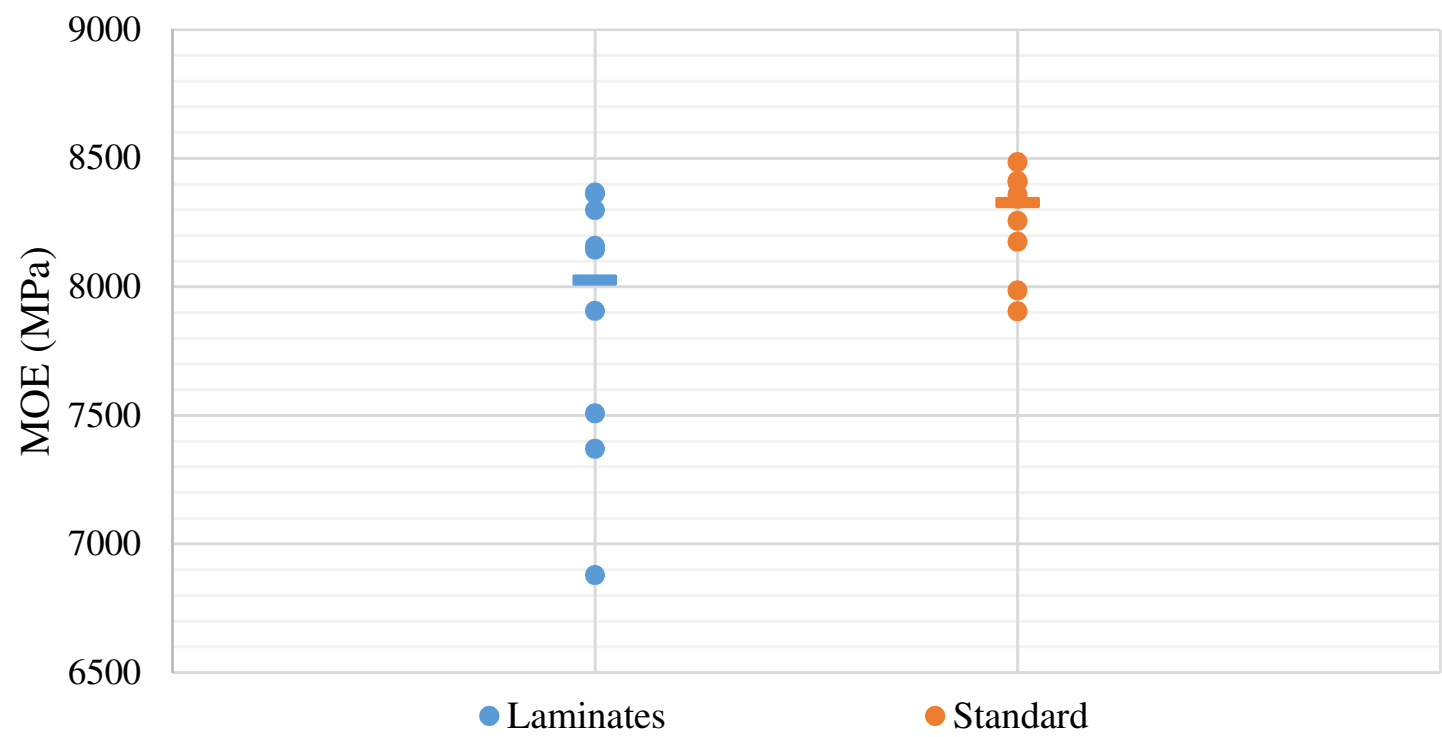

Figure 43: Distribution of lowest $10 \%$ of MOE values $\left(5^{\text {th }}\right.$ percentile marked with bar) 
Although the standard boards had a higher average stiffness, the face laminated samples had a $2.5 \%$ lower variation from the mean which is represented by the opposing coefficient of variation values. The more condensed distribution of results obtained for the laminated set is evident in the histogram provided in Figure 44. This also displays that one outlier was recorded for the standard set with a maximum value of 17018.67 MPa compared to the next highest value of $14364.16 \mathrm{MPa}$ which is in a similar region of the maximum value recorded for the laminated set. The sample which achieved this outlier result is shown in Figure 45. This high stiffness is possibly a result of the lack of defects present on the tension and compression edges of the sample as the failure occurred cleanly, directly adjacent to the finger-joint. This conclusion was made as the density, mass and moisture content of the sample were not outliers although this sample was 1 of the 9 samples which exhibited a level of twist above the SANS requirements. Thus the settlement of the specimen during the initial stages of applied load which is caused by the twist may have resulted in the higher MOE value being recorded.

\section{Distribution of MOE results}

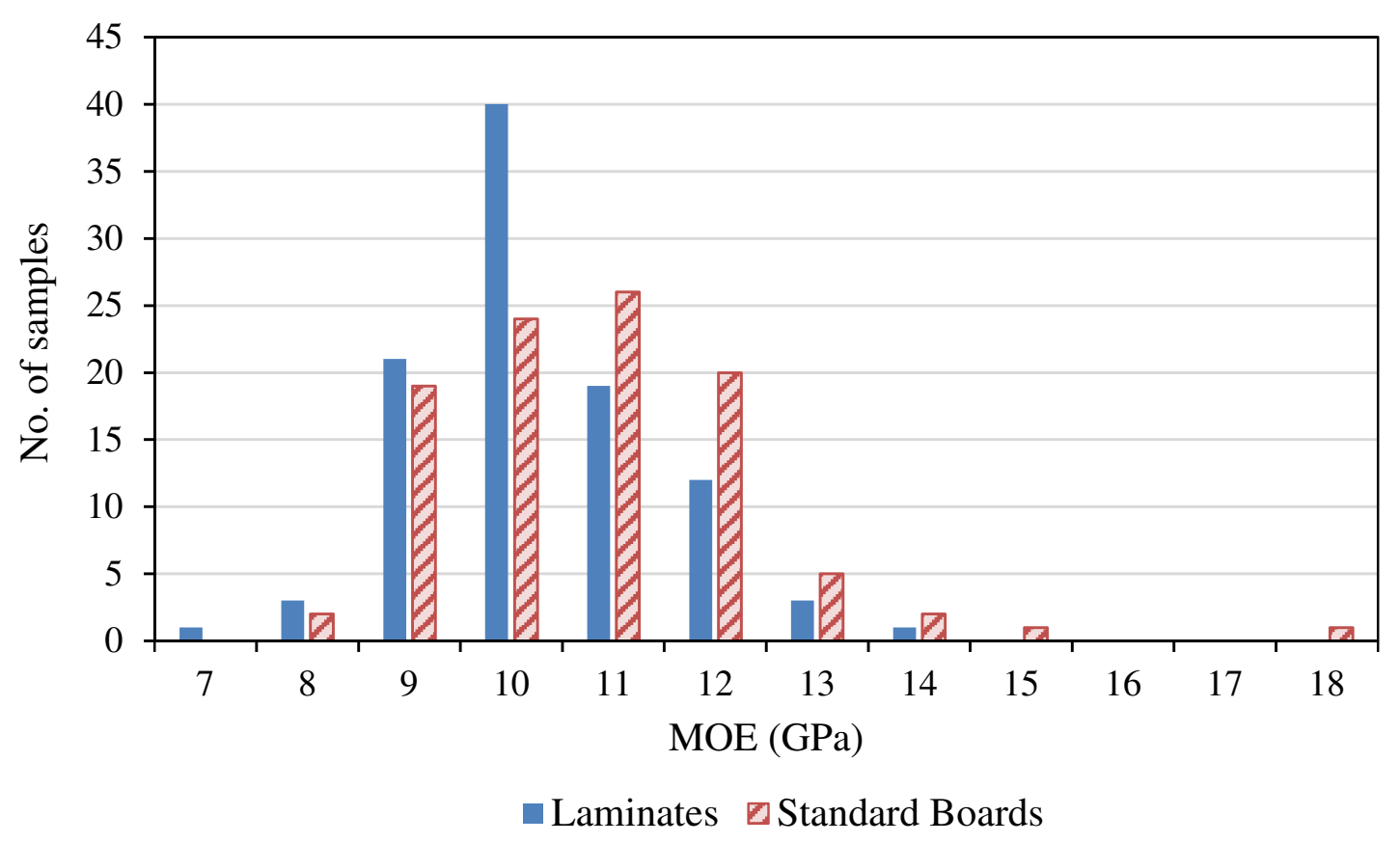

Figure 44: Distribution of MOE results for the laminated and standard sets 


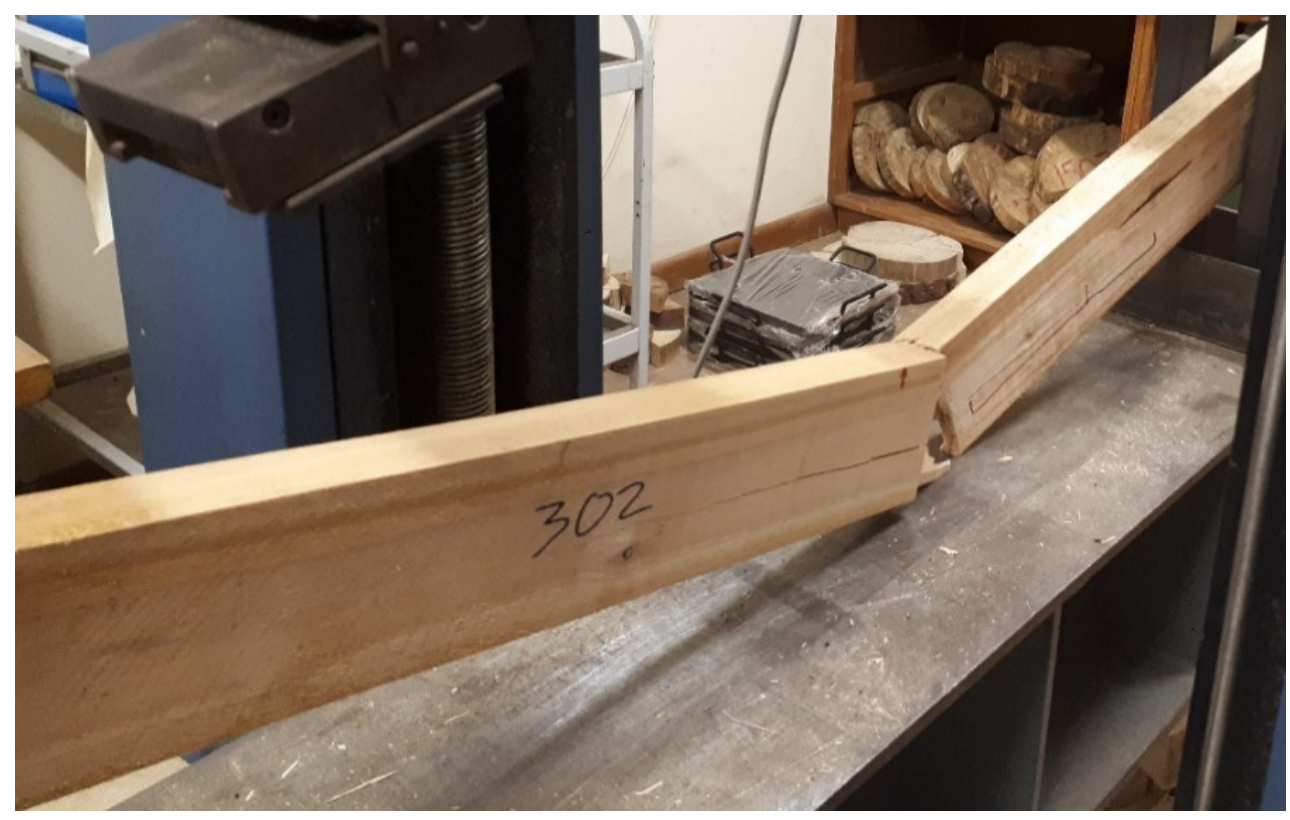

Figure 45: Sample which achieved the outlying MOE result

When compared to the MOE results of various SA pine resources depicted in Table 3 as obtained by Crafford and Wessels (2011) it is noted that higher mean results were recorded for the finger-jointed Eucalyptus grandis apart from the sawmill 1 which had mean of 9961.4 MPa. In Table 3 a large variation was found between the mean MOE results obtained from the different resources and much larger coefficient of variation values were recorded when compared to the young Eucalyptus grandis.

\subsubsection{Correlation between MOR and MOE}

The relationship between stiffness and bending strength is one of the most widely used relationships in the structural grading of timber. Figure 46 shows the correlation between the MOR and MOE results of the two sets. The correlation coefficients $\left(\mathrm{R}^{2}\right)$ were $18 \%$ and $23 \%$ for the laminates and standard boards respectively. This is considerably lower than commonly experienced for softwoods where correlations of $40 \%$ to $70 \%$ are experienced in most literature (Thelandersson and Larsen, 2003). These results are also lower than the $44 \%$ recorded by Nocetti et al. (2017) where tests were completed on older non-engineered Eucalyptus grandis of 20 to 25 years old. It is believed that the finger-jointing contributed to the lower correlations as the segment with the lowest MOE along the length of the sample affects the MOE strength of the entire specimen but does not affect the MOR strength to the same extent. 


\section{MOR vs MOE Relationship}

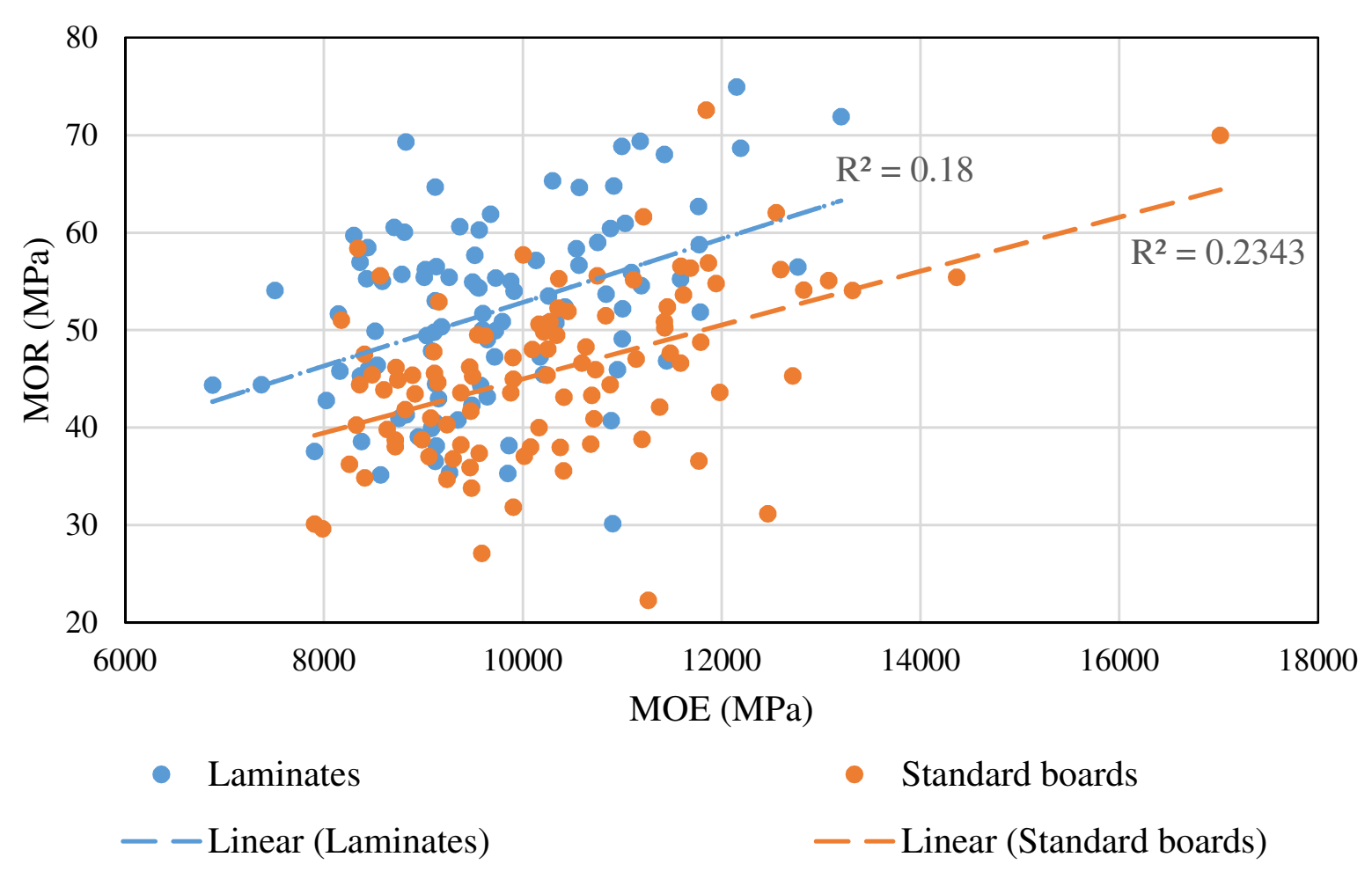

Figure 46: Correlation between MOR and MOE results for both sets

It was a surprising result that the laminates had a significantly higher mean MOR than the standard boards but a significantly lower mean MOE. There is generally a good relationship between MOE and MOR of timber and one would expect a consistent result for MOE and MOR means when comparing two sets of timber resources. It is not clear why the two different sets behaved differently. It was in fact expected that the both the MOE and MOR means of the laminated set of boards would be higher due to the better dispersal of defects through the volume of the specimen. In softwoods a large defect in a solid board such as a knot usually has a critical influence on the MOE, the location of failure, as well as the MOR. In laminates it is unlikely that two critical defects will be placed next to each other during the adhesion process and therefore a higher MOE and MOR values from laminates was expected. In this case the MOR was higher for laminates (as expected) but not the MOE. Relatively less information is available on hardwoods and specifically Eucalyptus stiffness and failure behaviour than softwoods (which is the predominant structural timber material). Future studies could address this in an attempt to better explain the mechanical behaviour of laminated Eucalyptus material. 


\subsection{Material resistance reduction factor}

In this study the formulation described in Equation 81 is used to calculate the material resistance reduction factors consisting of two components namely: the material reduction factor and the model uncertainty reduction factor.

\subsubsection{Model uncertainty factor}

The JCSS probabilistic model code (2001) suggests a model uncertainty variable having a mean of 1 and a coefficient of variation ranging from $0.05-0.1$ with a lognormal distribution for cases where the load duration uncertainty effects are taken into account in separate partial factors. A coefficient of variation of 0.1 is listed for cases where the load duration effects are not accounted for by a separate partial factor. Other uncertainties which can affect the material resistance such as load duration, load sharing, stressed volume, moisture content and pressure treatment attract their own partial factors in SANS 10163-1 (2003). Thus a coefficient of variation of 0.05 was initially selected for use in this study. Baravalle et al. (2017) had noted the use of a model uncertainty coefficient of variation of 0.07 for the material resistance of standard and laminated structural timber with reference to the range provided by JCSS (2001). A sensitivity analysis was completed to determine the extent of an effect the use of a higher coefficient of variation would have on the final material resistance reduction factor. This was completed for a target reliability of 3 (ULS) and 1.5 (SLS) using a fixed material reduction factor of 0.895 for the $\beta=3$ case and 0.838 for $\beta=1.5$. The resulting range of material resistance reduction factors are shown for the accompanying range of model uncertainty coefficient of variations in Table 21 with an accompanying graph in Figure 47.

Table 21: Variation of material resistance reduction factor for changing model uncertainty coefficient of variation.

\begin{tabular}{|c|c|c|c|c|c|c|}
\hline Model uncertainty COV (\%) & 5 & 5.5 & 6 & 6.5 & 7 & 7.5 \\
\hline $\boldsymbol{\varphi M ~ f o r ~ S L S ~ w i t h ~} \boldsymbol{\beta}=\mathbf{1 . 5}$ & 0.789 & 0.784 & 0.780 & 0.775 & 0.770 & 0.766 \\
\hline $\boldsymbol{\varphi M ~ f o r ~ U L S ~ w i t h ~} \boldsymbol{\beta}=\mathbf{3 . 0}$ & 0.794 & 0.784 & 0.775 & 0.765 & 0.756 & 0.747 \\
\hline
\end{tabular}




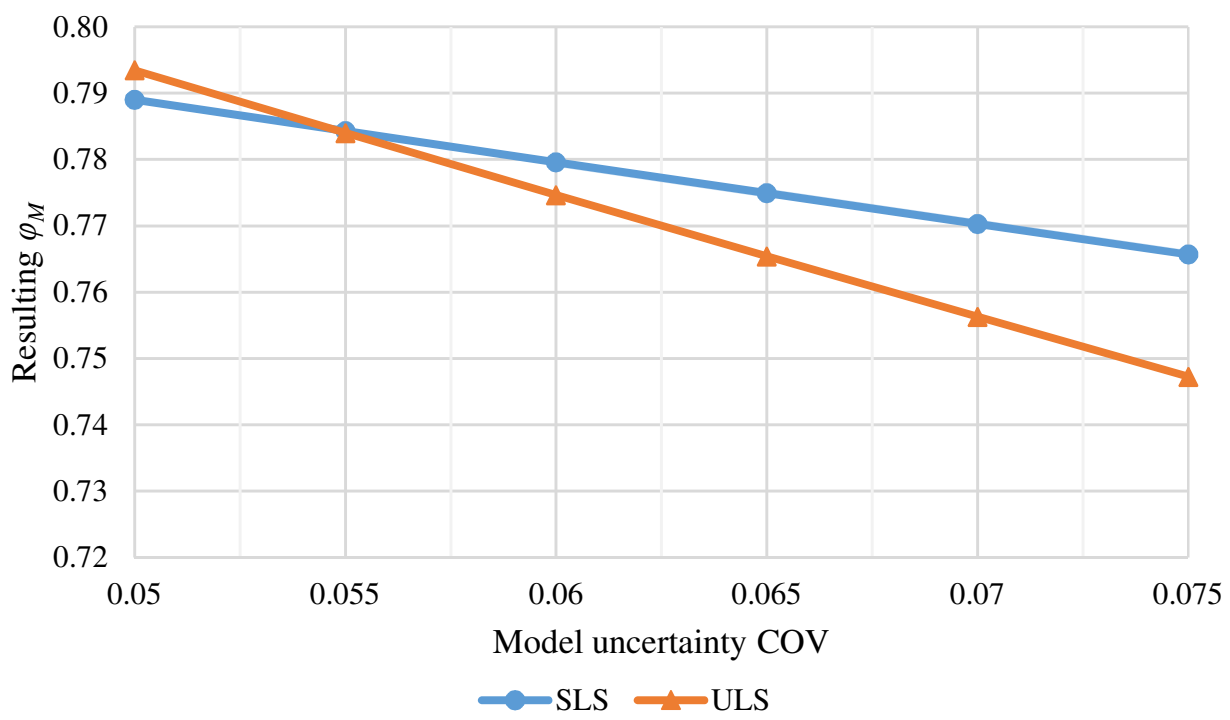

Figure 47: Change in material resistance reduction factor with respect to variation in model uncertainty coefficient of variation

Figure 47 shows a linear relationship between the decrease in material resistance partial factor and the increase of model uncertainty coefficient of variation. A small change is evident with the increase in coefficient of variation. It is deemed that the initially chosen coefficient of variation of 0.05 is to be maintained as the other factors which may cause uncertainty are already accounted for by other partial factors in SANS 10163-1 (2003). Thus the resulting model uncertainty factors are displayed in Table 22 as calculated for the two target reliability cases.

Table 22: Model uncertainty reduction factors $\varphi_{R d}$ relating to the two target reliability levels

\begin{tabular}{|c|c|c|}
\hline Target Reliability $\boldsymbol{-} \boldsymbol{\beta}$ & $\mathbf{1 . 5}$ & $\mathbf{3}$ \\
\hline Model Uncertainty $-\boldsymbol{\varphi}_{\boldsymbol{R} \boldsymbol{d}}$ & 0.942 & 0.89 \\
\hline
\end{tabular}

\subsubsection{Material factor}

The formulation of the material reduction factor described in Equation 84 and Equation 85 implies that under equivalent target reliability and sensitivity factor conditions, the coefficient of variation of the material resistance results distribution would drive the value obtained for the reduction factor. In other words, a lower variation in material resistance results cause a higher 
reduction factor while a higher coefficient of variation produces a lower and thus governing reduction factor (for this case where factors smaller than 1 are used). Therefore the coefficient of variation results from the destructive tests were first analysed to determine which of the material properties would produce the governing reduction factor. It was found that the MOR results had a variation on average $5 \%$ higher than that of the MOE. The reduction factors are calculated for both material properties to determine which would govern.

\subsubsection{Material factor from MOE results}

The material reduction factors $\varphi_{M}$ of the MOE results were calculated for three separate cases. The calculations in these cases are differentiated by the target reliability used and the method applied in SANS 10163-1 (2003) to select the characteristic value of material resistance. SLS conditions were used in case 1 where a target reliability of $\beta=1.5$ is applied and the mean is used as the characteristic value, employing Equations 83, 85 and 89. Case 2 and case 3 refers to ULS conditions where a target reliability of 3.0 is prescribed for both cases thus Equations 83,85 and 88 were used. A differentiation is included between the two cases as the method of selecting the characteristic value is different in the current SANS 10163-1 code when compared to the new draft version. The current method is applied in case 2 where the mean is used as the characteristic value $\left(\mathrm{E}_{\mathrm{M}}\right)$ for ULS conditions. This is contrary to the traditional method of the $5^{\text {th }}$ percentile value being used as the characteristic value $\left(\mathrm{E}_{0.05}\right)$ for ULS cases. The draft version of SANS 10163-1 applied the traditional method of selecting the characteristic value and is represented by case 3 .

The material factors, as calculated for the three cases, are displayed in Table 23, Table 24 and Table 25. Here the factors are calculated using results from the standard boards, laminated set and results obtained for tests on SA pine boards produced by the sawmill 1 which was the best performing sawmill in the study completed by Crafford \& Wessels (2011). The calculations for this SA pine is included to illustrate the potential advantage that the lower variation achieved by the Eucalyptus grandis presents. This inclusion also displays the issue of using the mean as the characteristic value for ULS condition as a factor far below the current 0.68 was achieved for SA pine in case 2. Factors were also determined using results obtained by Crafford (2013) for flexural testing completed on two different sizes of dry young, finger-jointed Eucalyptus grandis. This was included to show the possible variation in factors between the sizes of 
specimens due to the varying COV between the sizes. It is to be noted that the DB $36 \mathrm{x} 111 \mathrm{~mm}$ and DB 73 x $48 \mathrm{~mm}$ sets consisted of only 50 specimens which could affect the variations recorded and the validity of results due to lack of accuracy which may occur when determining the $5 \%$ fractile value.

Table 23: MOE material factors case 1 - SLS thus $\beta=1.5$ and mean as characteristic (EM)

\begin{tabular}{|c|c|c|c|c|c|}
\hline Reduction Factors & Laminates & Standard & Sawmill 1 & $\begin{array}{c}\text { DB 36 x } \\
\mathbf{1 1 1}\end{array}$ & DB 73 x 48 \\
\hline Model Uncertainty $-\boldsymbol{\varphi}_{\boldsymbol{R} \boldsymbol{d}}$ & 0.94 & 0.94 & 0.94 & 0.94 & 0.94 \\
\hline Material Factor $-\boldsymbol{\varphi}_{\boldsymbol{m}}$ & 0.86 & 0.84 & 0.80 & 0.88 & 0.82 \\
\hline Material Resistance $-\boldsymbol{\varphi}_{\mathbf{M}}$ & 0.81 & 0.79 & 0.75 & 0.83 & 0.77 \\
\hline
\end{tabular}

Table 24: MOE material factors case 2 - ULS thus $\beta=3.0$ and mean as characteristic (EM)

\begin{tabular}{|c|c|c|c|c|c|}
\hline Reduction Factors & Laminates & Standard & Sawmill 1 & DB 36 x 111 & DB 73 x 48 \\
\hline Model Uncertainty $-\boldsymbol{\varphi}_{\boldsymbol{R} \boldsymbol{d}}$ & 0.89 & 0.89 & 0.89 & 0.89 & 0.89 \\
\hline Material Factor $-\boldsymbol{\varphi}_{\boldsymbol{m}}$ & 0.74 & 0.70 & 0.64 & 0.78 & 0.67 \\
\hline Material Resistance $-\boldsymbol{\varphi}_{\mathbf{M}}$ & 0.66 & 0.62 & 0.57 & 0.69 & 0.60 \\
\hline
\end{tabular}

Table 25: MOE material factors case $3-\operatorname{ULS}$ thus $\beta=3.0$ and $5^{\text {th }}$ percentile as characteristic $\left(\mathbf{E}_{0.05}\right)$

\begin{tabular}{|c|c|c|c|c|c|}
\hline Reduction Factors & Laminates & Standard & Sawmill 1 & DB 36 x 111 & DB 73 x 48 \\
\hline Model Uncertainty $-\boldsymbol{\varphi}_{\boldsymbol{R} \boldsymbol{d}}$ & 0.89 & 0.89 & 0.89 & 0.89 & 0.89 \\
\hline Material Factor $\boldsymbol{-} \boldsymbol{\varphi}_{\boldsymbol{m}}$ & 0.91 & 0.90 & 0.87 & 0.93 & 0.88 \\
\hline Material Resistance $-\boldsymbol{\varphi}_{\mathbf{M}}$ & 0.81 & 0.79 & 0.77 & 0.82 & 0.78 \\
\hline
\end{tabular}

It is shown here that the resulting factors for case 1 and case 3 produce very similar results for both Eucalyptus grandis sets which are $11 \%$ higher for the standard boards and $13 \%$ higher for the laminates than the current resistance factor prescribed for structural timber of 0.68 . This result was expected due to the lower variation of results obtained for the Eucalyptus grandis sets when compared to similar SA pine. On the contrary, very low reduction factors were calculated for the current ULS conditions represented by case 2. Here, values below the current resistance factor were obtained for all sets, with the calculation for SA pine from sawmill 1 
producing a reduction factor $11 \%$ less than that prescribed in SANS 10163-1 (2003). This supports the notion of the traditional method of using the mean as characteristic value for SLS and $5^{\text {th }}$ percentile as characteristic for ULS conditions to be adopted for MOE in the updated version of SANS 10163-1 as the current method appears to not adhere to target reliability conditions. The factors obtained for the dry bending tests of Crafford (2013) correlate closely to the standard and laminated samples for MOE results with the larger specimens producing a slightly higher reduction factor due to a lower variability while the small sized specimens exhibited higher variability but to a lesser extent than for the MOR results.

\subsubsection{Material factors from MOR results}

The MOR is used for calculations under ULS conditions where the $5^{\text {th }}$ percentile is taken as the characteristic value and a target reliability of 3.0 is applied. The resulting material resistance reduction factors calculated for the laminated and standard sets are shown in Table 26 along with the factor obtained using the MOR results of SA pine from sawmill 1 providing a comparison to SA pine as calculated using Equations 83, 85 and 89.

Table 26: Material factors for MOR

\begin{tabular}{|c|c|c|c|c|c|}
\hline Reduction Factors & Laminates & Standard & Sawmill 1 & DB 36 x 111 & DB 73 x 48 \\
\hline Model Uncertainty $-\boldsymbol{\varphi}_{\boldsymbol{R} \boldsymbol{d}}$ & 0.89 & 0.89 & 0.89 & 0.89 & 0.89 \\
\hline Material Factor $-\boldsymbol{\varphi}_{\boldsymbol{m}}$ & 0.88 & 0.87 & 0.76 & 0.89 & 0.75 \\
\hline Material Resistance $-\boldsymbol{\varphi}_{\mathbf{M}}$ & 0.78 & 0.77 & 0.68 & 0.79 & 0.66 \\
\hline
\end{tabular}

Positive results were obtained for the laminated and standard sets with material resistance reduction factors of approximately 0.77 being obtained which is 0.09 higher than the current factor listed in the design code of 0.68. Coincidently the factor obtained for the SA pine from sawmill 1 correlates closely to the 0.68 resistance factor listed in the code this is concerning as sawmill 1 had achieved significantly less variation than the other sawmills which suggests that the required target reliability would not be achieved by the other sawmills for SA pine. It was surprising to note that the laminated set had achieved a reduction factor which was only 0.007 higher than that of the standard set. It was expected that the inclusion of face lamination would have decrease the variability in strength results to a further extent than what is already achieved by the standard finger-jointed boards. This assumption was made as any defect present in a 
single half of the laminate would not extend through the whole width of the lamination due to the random orientation of the second laminate causing a reduction in variability of results. Due to the small variation in partial factors it is deemed that the standard boards had performed to such a good extent in terms of variability due to the finger-jointing that the inclusion of face lamination does not result in lower variation as the inherent variability of timber materials limits the level of variability that can be achieved by any system. The low factor achieved by the small dimension specimens tested by Crafford (2013) raise a concern that the variation in strength results could increase as the size of the specimen decreases. This theory is supported by the high factor of 0.79 obtained for the larger specimens which is 0.02 higher than the factor of the standard specimens that are slightly smaller $(36 \times 102 \mathrm{~mm})$. These results however are not conclusive as the two sets of Crafford (2013) consisted of only 50 specimens per set which lowers the validity of results. It does show that consideration should be given about the specimen size affecting variation in MOR results before deciding on a final material factor.

\subsubsection{Governing material factor}

It is thus suggested that a material resistance reduction factor of 0.77 be used for both the laminated and standard Biligom products tested in this study. This factor is governing when compared to reduction factor results for MOE cases 1 and 3 in accordance to conditions in the draft version of SANS 10163-1. The factor obtained for MOE case 2 is deemed to not govern as unrealistically low factors were obtained due to the method of selecting the characteristic value. For added simplicity, the factor of 0.77 should be applied for ULS and SLS calculations for each of the material properties as currently done through the use of 0.68 prescribed in SANS 10163-1 (2003). It is to be noted that the effect that specimen size may have on the variability in strength results of young, engineered Eucalyptus grandis needs to be investigated further before conclusive factors can be included into design codes. For this study, equivalent sized specimens were tested to allow for comparable results to determine the value of including face lamination into the system, this does however not show the different variations which may be experienced by other specimen sizes. 


\section{Conclusions and recommendations}

\subsection{Conclusions}

The initial aims of this study was to determine if face laminating the young, finger-jointed Eucalyptus grandis could further reduce defects experienced in the material and to determine if lower variation in strength test results would be achieved for the laminated boards. Material resistance reduction factors for the laminated and standard finger-jointed Eucalyptus grandis were calculated as this material was shown to exhibit lower variation in strength test results when compared to equivalent SA pine in a previous study. Thus material tests were completed for the face laminated and standard sets allowing for characteristic strength results to be determined along with recording the extent of defects in the material. These results were used to determine the governing material resistance reduction factors for the material.

The two sets had performed well in terms of warping defects with none of the samples exhibiting defects above rejection limits for bow and cup. The twist of the laminated set appears to have been restrained by the lamination process with only $1 \%$ of laminates having twist above rejection limits as opposed to the $9 \%$ for the standard set. This is deemed to be a result of the random orientation of the laminates as the inherent twist of the layers could be in opposing directions which would decrease the overall level of twist.

Significantly less checking rejections were recorded for the laminated set with only $4 \%$ being rejected while $20 \%$ of the standard set had checks above the limits as recorded in the dry state. These checks are of arguable importance as they were deemed to not have negatively affected the strength of the samples as boards with excessive check did not exhibit outlying strength results. Thus if they do not affect the joint strength of the boards in a full scale truss configuration they are not of importance where the visual effect of the checks would be concealed in a roof truss structure.

A positive effect of the lamination process was found for split limitation of the samples where none of the laminated set experienced split defects above the limitations as prescribed in SANS 1707-1 (2010). This was due to the splits that occurred in one layer of the laminated board not extending entirely through the adhesive and accompanying second layer. A total of $15 \%$ of the 
standard set was rejected according to split limitations. These splits could be restrained by applying end nail plates or screws to the boards during processing to restrict the split formation. Although the splits could possibly be limited for the standard set, the lamination process had proved efficient at decreasing the split rejection rate by $15 \%$.

The laminated and standard sets had both displayed good flexural strength properties with structural grade S7 requirements being achieved for both the MOR and MOE. The grade S7 strength results achieved by the material is higher than the S5 that is being recorded for equivalent SA pine which makes the finger-jointed Eucalyptus grandis a more valuable product. These results are also obtained while having a shorter rotation age allowing for a higher production rate of the material. As expected, the mean MOR of the laminated boards was significantly higher than that of the standard boards. However, the mean MOE of the laminated boards was significantly lower than that of the standard boards, which was unexpected.

Somewhat surprising results were obtained in terms of the variation in strength results for the two sets. No statistically significant difference was found between the coefficients of variation of the laminated and standard boards for MOR and MOE. It was expected that the lamination process would lower the variation in flexural strength results further than what is already achieved by the finger-joints present in both sets. It is deemed that the standard set had achieved low variation in results to such a level that the inclusion of face lamination would not improve the variability much further as there shall always be an inherent variability in timber materials down to a molecular level as it is a grown resource. These results are however positive when compared to similar SA pine where the best performing saw-mill had only achieved a coefficient of variation of $35 \%$ for MOR compared to the Eucalyptus grandis tested here, with a coefficient of variation of approximately $18 \%$ (Crafford and Wessels, 2011). This supports the notion of determining a separate material resistance partial factor for this material.

The material resistance reduction factors were calculated for target reliabilities of 1.5 for SLS conditions and 3.0 for ULS conditions in accordance to various cases of determining the characteristic value of the material property. It was established, when determining the material resistance reduction factor for MOE under ULS conditions prescribed in the current SANS 10163-1 (2005) of using the mean as characteristic value for MOE (Case 2), that very low 
factors were obtained for the laminated and standard set. The factor calculated for the SA pine of sawmill 1 was only 0.57 which is far below the factor of 0.68 prescribed in SANS 10163-1 for structural timber. This motivates the change applied in the draft version of SANS 10163-1 where the mean is used as the characteristic value for SLS conditions (Case 1) and the $5^{\text {th }}$ percentile as characteristic value for ULS conditions (Case 3). These cases had produced essentially equivalent resulting partial factors with 0.81 for the laminated set and 0.79 for the standard boards.

The material resistance reduction factor calculated for MOR was deemed to govern for the young Eucalyptus grandis. A factor of 0.78 was obtained for the laminated set and 0.77 for the standard boards which is 0.09 higher than the current factor of 0.68 prescribed for structural timber. This difference in reduction factor between the face laminated set and standard set is lower than expected which is explained by the small difference in coefficient of variation of the material resistance results. The factor of 0.77 is the governing factor for the material tested in this study as it was the lowest recorded factor.

The factor calculated for the results of the SA pine from sawmill 1 was 0.68 which matches the current resistance factor. This causes concern as sawmill 1 was the best performing sawmill by some margin. Thus SA pine timber produced by the remaining sawmills are not be adhering to required reliability levels according to results obtained by Crafford and Wessels (2011). Further research into the current performance of SA pine producing sawmills should be completed along with the implementation of quality control techniques to ensure that reliability levels are adhered to.

Although the lamination process did not reduce the variation in strength results to a significant extent, significantly lower defects were recorded for the laminated set. This would result in a higher yield of material with a better visual appeal which could allow for it to be a more valuable product. For both sets, the 0.09 gain in reduction factor may not seem to be a large advantage, but when coupled with the higher structural grade being achieved and the shorter rotation age than SA pine, the young, engineered Eucalyptus grandis is a promising option for structural timber use in a country as timber scarce as South Africa. 


\subsection{Recommendations}

- Additional testing should be completed on the green finger-jointed and face laminated samples, also measuring additional failure modes and material properties (i.e knots, grain deviation) of this processing method for the young Eucalyptus grandis. Together with analytical modelling of the stiffness and strength behaviour of the material it will hopefully lead to a better understanding of the strength and stiffness behaviour of laminated Eucalyptus grandis timber.

- Larger test sets that include samples of various standard dimensions should provide a more accurate representation of characteristic strengths and variability in strength results as it will be used in practice. The increased number of samples will possibly also reveal differences in $5^{\text {th }}$ percentiles between the treatments to a greater extent.

- The variability in strength results achieved by specimens of different standard dimensions should be investigated along with the resulting effect on the material resistance reduction factor.

- The lamination process could be optimised by using a functioning hand adhesive applicator device with an adhesive spread rate controllable pump and also quality clamping devices. A more consistent process has potential to reduce some variability in the results.

- The inclusion of additional layers within the laminates has the potential to further improve results obtained by the laminated set. This would also allow for smaller or younger trees to be used to produce larger sizes of dimensional timber.

- An economic study should be completed to determine whether face lamination and the consequent reduction in defects is a cost effective processing step.

- Further research into effect of longitudinal shrinkage of young, green Eucalyptus grandis trusses fixed into place in the wet state should be completed. 


\section{References}

AS/NZS 4063-1 (2010) Australian and New Zealand Standard. Characterization of structural timber. Part 1: Test Methods.

Baravalle, M. et al. (2017) 'Calibration of simplified safety formats for structural timber design’, Construction and Building Materials, 152, pp. 1051-1058.

Bergman, R. (2010) 'Chapter 13: Drying and Control of Moisture Content and Dimensional Changes', in Forest Service and Forest Products Laboratory (eds) Wood handbook - Wood as an engineering material. U.S. Dept. of Agriculture, pp. 1-20.

Bodig, J. and Jayne, B. (1982) Mechanics of wood and wood composites. New York: Van Nostrand Reinhold.

Braml, T. (2010) 'Zur Beurteilung der Zuverlässigkeit von Massivbrücken auf der Grundlage der Ergebnisse von Überprüfungen am Bauwerk'.

Bucher, C. (2011) 'Methods of Reliability Analysis in the context of RDO', in. Weimar Optimization and Stochastic Days 8.0, pp. 1-21.

Chamberlain, D. et al. (2005) Part I: The contribution, costs and development opportunities of the Forestry, Timber, Pulp and Paper industries in South Africa. South Africa.

Crafford, P. L. (2013) An investigation of selected mechanical and physical properties of young, unseasoned and finger-jointed Eucalyptus grandis timber. Stellenbosch University. Available at: http://scholar.sun.ac.za/handle/10019.1/80072.

Crafford, P. L. and Wessels, C. B. (2011) 'The flexural properties and structural grading of SA Pine', Stellenbosch University.

Crespell, P. and Gagnon, S. (2010) Cross Laminated Timber: a Primer, FPInnovations, Quebec, Canada. Vancouver: FPInnovations.

Crickmay and Associates (2004) Supply and demand study of softwood sawlog and sawn timber in South Africa. South Africa.

Crickmay and Associates (2014) South African lumber index: May 2014. Pietermaritzburg.

DAFF (2012) Department of Agriculture, Forestry and Fisheries, Republic of South Africa. Integrated Growth and Development Plan.

DAFF (2015) Department of Agriculture, Forestry and Fisheries, Republic of South Africa. Strategic Plan. doi: ISBN: 978-0-621-42474-4. 
Dinwoodie, J. M. (2000) Timber: Its nature and behavior. 2nd Editio. London and New York: E \& FN Spon.

Dowse, G. P. (2010) Selected mechanical properties and the structural grading of young Pinus patula sawn timber. Stellenbosch University.

DWAF (2009) Department of Water Affairs and Forestry, Republic of South Africa. Forestry 2030 Roadmap: Forestry Strategy 2009-2030. Available at: http://extwprlegs1.fao.org/docs/pdf/saf149602.pdf.

EN 1990 (2010) EN 1990:2002 Eurocode - Basis of structural design. Berlin: DIN Deutsches Institut für Normung e.V.

Faber, M. (2007) Risk and safety in civil engineering, Course notes, Lecture Notes. Swiss Federal Institute of Technology, .... ETH Zurich. doi: 10.3929/ethz-a-004230964.

Gardner, D. J. et al. (2014) Adhesion Theories in Wood Adhesive Bonding: A Critical Review. USA.

Hasofer, A. and Lind, M. (1974) 'Exact and Invariant Second Moment Code Format', Journal of Engineering Mechanics, 100(1), pp. 111-121.

Hesp, T. and Watson, R. (1964) 'The effects of water-borne preservatives applied byvacuum pressure methods on the strength properties of wood.', Wood, 29(6), pp. 50-53.

Holicky, M. (2009) Reliability analysis for structural design. first. Stellenbosch: Sun Media. doi: 10.18820/9781920689346.

Hollander, M. and Wolfe, D. (1999) Nonparametric Statistical Methods. 2nd editio. Wiley.

Implementation of Eurocodes. (2005) Handbook 2: Reliability of Backgrounds, Guide to the basis of structural reliability and risk engineering related to Eurocodes, supplemented by practical examples, Leonardo da Vinci pilot project.

JCSS (2001) Joint Committee on Structural Safety. Probabilistic Model Code. Zurich.

Kamke, F. a. and Lee, J. N. (2007) 'Adhesive penetration in wood: a review', Wood and Fiber Science, 39(2), pp. 205-220.

Lehringer, C. and Gabriel, J. (2014) 'Review of Recent Research Activities on One-Component PUR-Adhesives for Engineered Wood Products', in Aicher, S., Reinhardt, H., and Garrecht, H. (eds) Materials and Joints in Timber Structures. RILEM Bookseries. Dordecht: Springer, pp. 405-406. doi: 10.1007/978-94-007-7811-5.

Lenner, R. (2014) Safety Concept and Partial Factors for Military Assessment of Existing Concrete Bridges. Bundeswehr University Munich.

Madsen, B. (1992) Structural behavior of timber. North Vancouver: Timber Engineering Ltd. 
Nocetti, M. et al. (2017) 'Investigating the potential of strength grading green Eucalyptus grandis lumber using multi-sensor technology', BioResources, 12(4), pp. 9273-9286. doi: 10.15376/biores.12.4.9273-9286.

Panshin, A. ., De Zeeuw, C. and Brown, H. . (1964) Textbook of wood technology, Volume 1. 2nd editio. New York: McGraw-Hill.

Prion, G. L. (2004) 'Structural Timber Course', in. University of Stellenbosch.

Pröller, M. (2017) An investigation into the edge gluing of green Eucalyptus grandis lumber using a one-component polyurethane adhesive. Stellenbosch University.

SANS 10160-1 (2011) South African national standard. Basis of structural design and actions for buildings and industrial structures. Part 1: Basis of structural design. Pretoria.

SANS 10163-1 (2003) South African national standard. The structural use of timber Part 1: Limit-states design. 2.3, Construction. 2.3. Pretoria: Standards South Africa.

SANS 1707-1 (2010) South African national standard. Sawn eucalyptus timber Part 1 : Proofgraded structural timber.

SANS 1783-2 (2012) South African national standard. Sawn softwood timber Part 2: Stressgraded structural timber and timber for frame wall construction.

SANS 6122 (2008) South African national standard. Qualification testing of solid structural timber and laminated structural timber (glulam) for verifying timber grading systems in accordance to a given standard.

Shmulsky, R. and Jones, P. D. (2011) Forest products and wood science: An introduction. 6th Editio. United Kingdom: Wiley-Blackwell.

Smith, D. (1954) 'Maximum moisture content method for determining specific gravity of small wood samples’, (2).

Sterley, M. (2004) Green gluing of wood. KTH-Royal Institute of Technology.

Sýkora, M., Holický, M. and Marková, J. (2013) 'Verification of existing reinforced concrete bridges using the semi-probabilistic approach', Elsevier, Engineerin(56).

Thelandersson, S. and Larsen, H. J. (2003) Timber Engineering. John Wiley and Sons Ltd.

Walker, J. C. F. et al. (1993) Primary wood processing: principles and practice. London: Chapman \& Hall Ltd.

Walpole, R. E. et al. (2012) Probability and Statistics for Engineers and Scientists. Ninth edit, Power. Ninth edit. Harlow: Pearson Education Limited. doi: 10.1017/CBO9781107415324.004. 
Wand, E. K. E. C. (1990) Timbers of commercial value.

Wessels, C. B. (2016) Timber as a structural material. Department of Forest and Wood Science, Stellenbosch University.

Wessels, C. B. and Petersen, N. O. (2015) 'Strength and stiffness capacity utilisation of timber members in roof truss structures', Southern Forests, 77(4), pp. 305-307. doi: 10.2989/20702620.2015.1063033.

$\mathrm{Xu}, \mathrm{L}$. W. et al. (2013) 'A parametric bootstrap approach for two-way ANOVA in presence of possible interactions with unequal variances', Journal of Multivariate Analysis. Elsevier Inc., 115, pp. 172-180. doi: 10.1016/j.jmva.2012.10.008. 